\title{
EFFECT OF PULSED HIGH INTENSITY FOCUSED ULTRASOUND ON THE NERVE COMPOUND ACTION POTENTIAL AMPLITUDE AND CONDUCTION VELOCITY
}

\author{
By \\ Steve Tran \\ B.Sc. Engineering, Guelph University, 2007, Guelph, Canada
}

\author{
A Thesis \\ presented to Ryerson University \\ in partial fulfillment of the \\ requirements for the degree of \\ Master of Science \\ In the Program of \\ Biomedical Physics
}

Toronto, Ontario, Canada, 2013

(C) Steve Tran, 2013 


\section{AUTHOR'S DECLARATION}

I hereby declare that I am the sole author of this thesis. This is a true copy of the thesis, including any required final revisions, as accepted by my examiners.

I authorize Ryerson University to lend this thesis to other institutions or individuals for the purpose of scholarly research.

I further authorize Ryerson University to reproduce this thesis by photocopying or by other means, in total or in part, at the request of other institutions or individuals for the purpose of scholarly research.

I understand that my thesis may be made electronically available to the public. 


\title{
Effect of Pulsed High Intensity Focused Ultrasound On the Nerve Compound Action Potential Amplitude and Conduction Velocity
}

\author{
Master of Science, 2013 \\ Steve Tran \\ Biomedical Physics \\ Ryerson University
}

\begin{abstract}
Therapeutic HIFU has been used as a non-invasive energy modality to compromise nerve function since the 1950s. Several contributions have been made in recent years to characterize these effects on nerve function.

In this study, short repeated bursts of HIFU, termed as pulsed high intensity focused ultrasound (pHIFU), was directed at nerve tissue. The pHIFU transducer operated at a central frequency of $1.95 \mathrm{MHz}$ and had a focal length of approximately $12 \mathrm{~cm}$. The ventral nerve cord from the American Lobster (Homarus americanus), $n=15$, was sonicated cumulatively at 3 exposure times: $1 \mathrm{~s}, 6 \mathrm{~s}$, and $16 \mathrm{~s}$, at an intensity of $1010 \mathrm{~W} / \mathrm{cm}^{2}$, or focal pressure of $5.51 \mathrm{MPa}$. The compound action potential (CAP) and conduction velocity (CV) were seen to decrease as sonication exposure time to the nerve increased. The experiments performed demonstrate the feasibility to modulate nerve CAP and nerve CV using non-thermal mechanisms of ultrasound.
\end{abstract}




\section{ACKNOWLEDGEMENTS}

This dissertation would not have been possible without the guidance and the help of several individuals who in one way or another contributed and extended their valuable assistance in the preparation and completion of this study.

Firstly, I would like to give my sincere thanks to my supervisor, Dr. Jahan Tavakkoli. His expertise and guidance has been instrumental throughout my thesis work. The wisdom he has imparted will no doubt have a lasting influence on me beyond the scope of this thesis.

Dr. Jay Triano, Dean of Graduate Programs and Research at the Canadian Memorial Chiropractic College and Associate Professor within the Rehabilitation Sciences department at McMaster University, who provided the inspiration for me to continue my education at the graduate level. His passion for research and willingness to accommodate my school schedule has been significant in shaping my personal and professional growth.

Mosa Alhamami, MSc candidate in the department of Physics at Ryerson University, whose help in the lab, especially in the early stages of my thesis work, is greatly appreciated.

Arthur Worthington, Research Engineer in the department of Physics at Ryerson University, for his valued assistance with the lab equipment.

Last but not the least, my parents and brother, for their continued moral support and reassurance that I was on the right path despite times when the combined load from the graduate school and work became nearly over whelming. 


\section{Table of Contents}

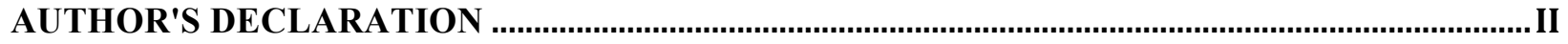

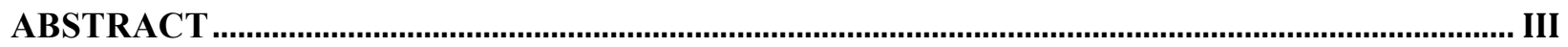

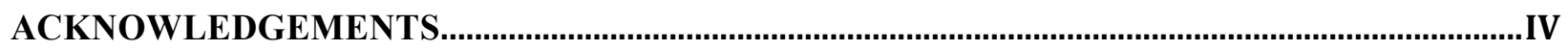

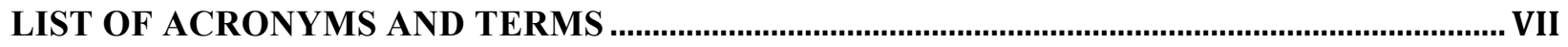

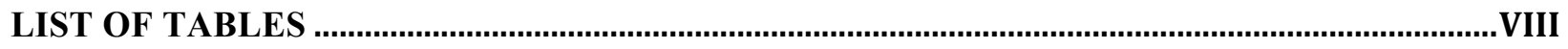

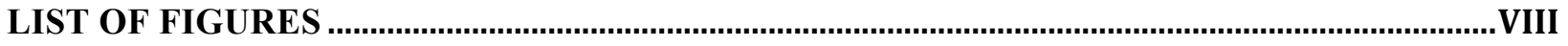

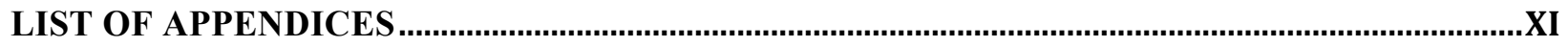

CHAPTER 1 : BACKGROUND AND INTRODUCTION.............................................................. 1

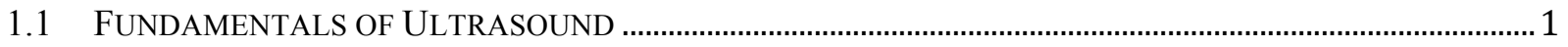

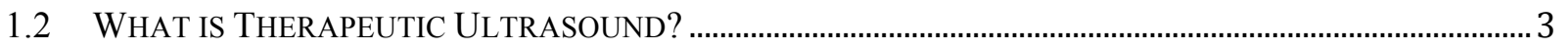

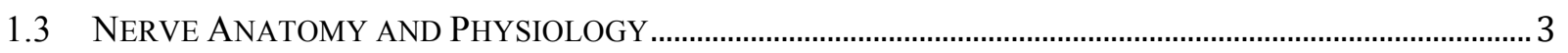

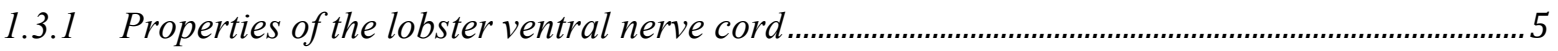

1.4 NERVE ELECTROPHYSIOLOGY - CONDUCTION OF AN ACTION POTENTIAL .......................................... 7

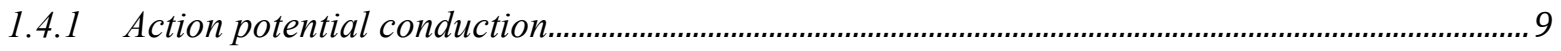

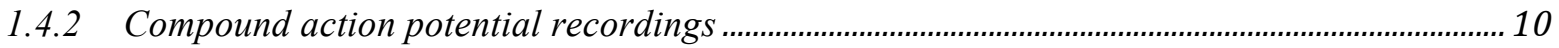

1.5 PAST STUDIES USING THERAPEUTIC ULTRASOUND ON NERVES ........................................................... 12

1.6 THESIS HYPOTHESIS AND CONTRIBUTION ....................................................................................... 35

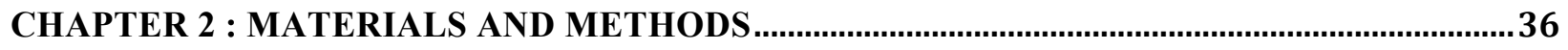

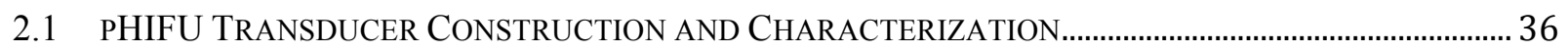

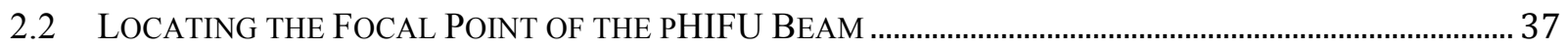

2.3 EFFECT OF THE NOSE PIECE ON THE PHIFU BEAM.......................................................................... 40

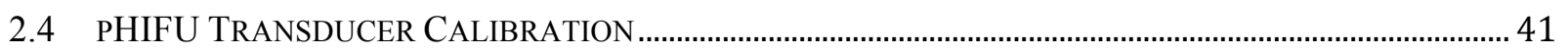

2.4.1 Theory of measuring ultrasound power using a radiation force method ...................................... 43

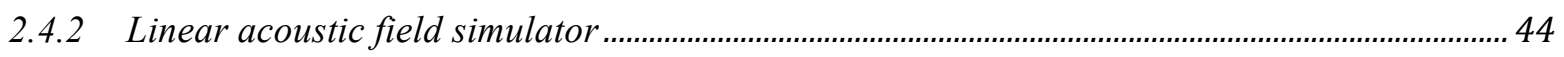

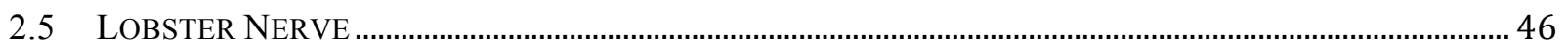

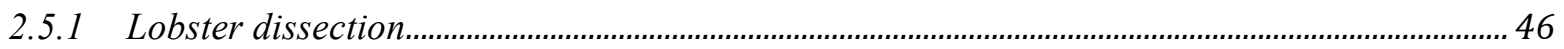

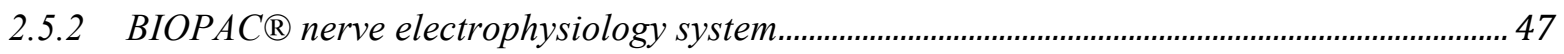

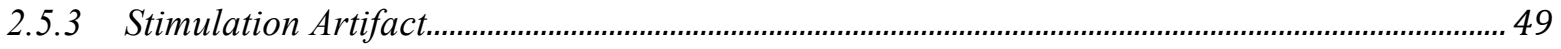

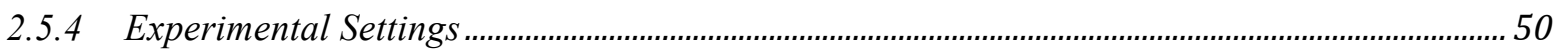

2.5.5 Temperature Rise in Nerve Caused by Ultrasound..................................................................5 54

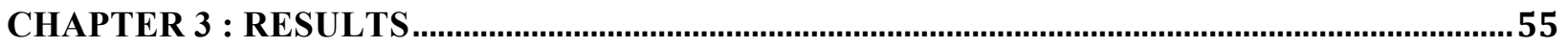

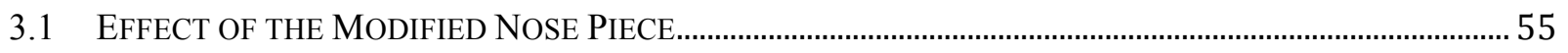

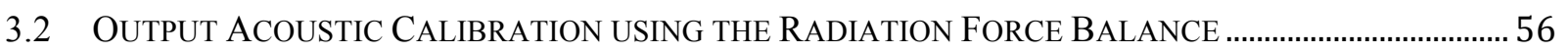




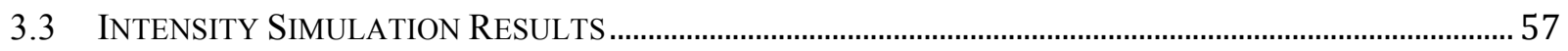

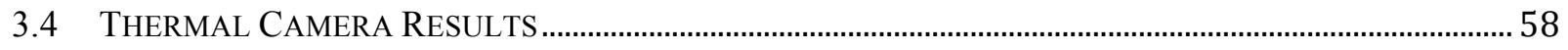

3.5 LOBSTER NERVE COMPOUND ACTION POTENTIAL................................................................................. 59

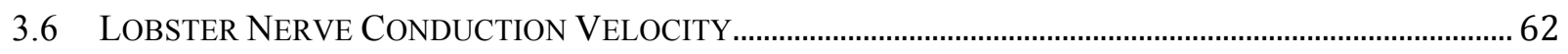

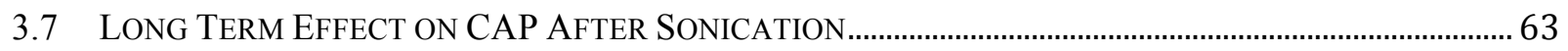

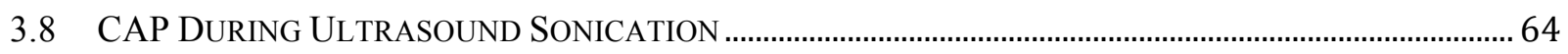

CHAPTER 4 ： DISCUSSION

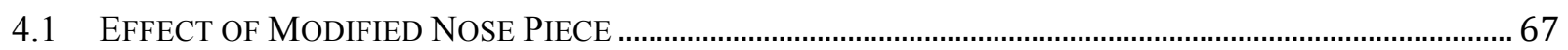

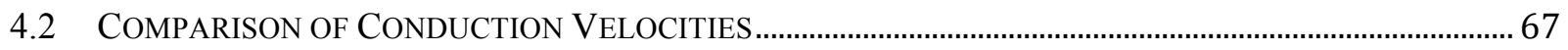

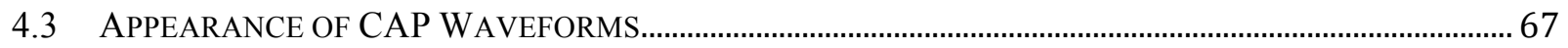

4.4 EFFECT OF NERVE CAP AMPLITUdE DURING PHIFU SONICATION AND THE LONG TERM EFFECTS

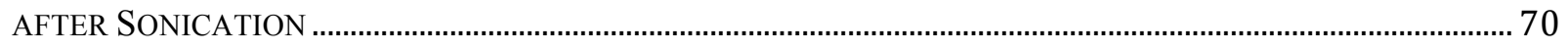

4.5 COMPARISON OF THE INTENSITY USED BY MIHRAN (1990)…........................................................ 71

4.6 EFFECT OF ULTRASOUND ON LOBSTER NERVE CAP AND CV …....................................................... 71

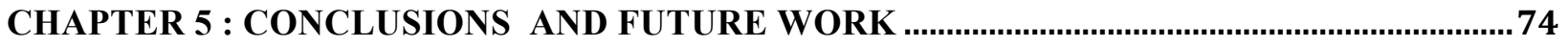

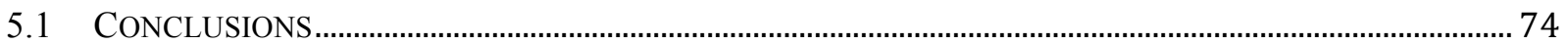

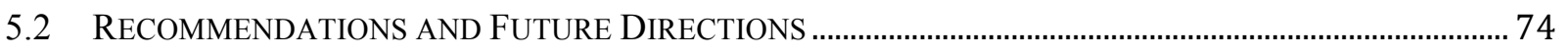

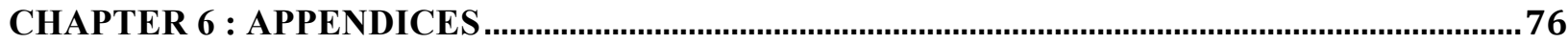

A1: TECHNICAL SPECIFICATIONS FOR THE ONDA RFB-2000 POWER METER ….......................................... 76

A2: INGREDIENTS FOR THE LOBSTER RINGERS SOLUTION …………....................................................... 76

A3: LIST OF EQUIPMENT USED IN THE STUDY ………............................................................................ 77

A4: HYdROPHONE RESUlTS TO COMPARE THE EFFECT OF THE NOSE PIECE ................................................. 77

A5: ONDA ACOUSTIC POWER CALIBRATION RESULTS................................................................................... 78

A6: SAMPLE CALCULATIONS For LOCATING ACTUAL FoCAL SPOT OF PHIFU TRANSDUCER................. 79

A7: TeChniCAL SPECIFICATIONS OF THE THERMoVision A40 THERMAL CAMERA ............................................ 79

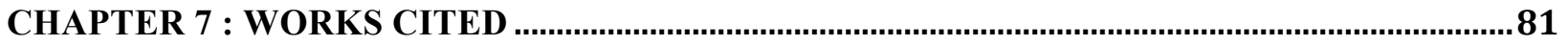




\section{List of Acronyms and Terms}

AP Action potential

$\mathrm{B}_{10}$ classification of a nerve CAP that recovers $\leq 10 \%$ of its initial baseline

$\mathrm{B}_{10-90}$ classification of a nerve CAP that recovers to $10-90 \%$ of its initial baseline

$\mathrm{B}_{90}$ classification of a nerve CAP that recovers $\geq 90 \%$ of its initial baseline

CAP Compound action potential

CMAP Compound muscle action potential

CNS Central nervous system

CV Conduction velocity

HIFU High intensity focused ultrasound

IFUS Intensive focused ultrasound

pHIFU Pulsed High intensity focused ultrasound

PNS Peripheral nervous system

RFB Radiation force balance

TAP Total acoustic power 


\section{List of Tables}

Table 1.1: Properties of ultrasound......................................................................................................

Table 1.2: Properties of nerves from different parts of lobster anatomy (Wright et al. 1958) .........6

Table 1.3: Field survey of ultrasound-induced effects on nervous tissue......................................... 30

Table 2.1: Parameters used in calculation of intensity field................................................................ 45

Table 2.2: Equipment setting for lobster experiments................................................................... 52

Table 3.1: Summary of normalized CAP nerve results after 1, 6, and 16 seconds of pHIFU

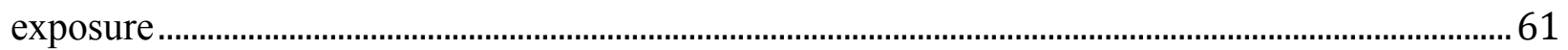

Table 3.2: Summary of normalized CV nerve results after 1,6 , and 16 seconds of pHIFU

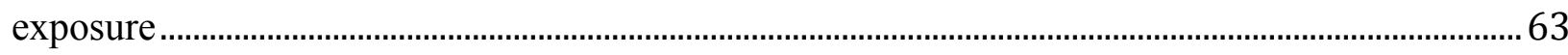

\section{List of Figures}

Figure 1.1: A visual description of the properties of sound waves (Lawrence 2007)................1

Figure 1.2: Types of Nerves (Marieb 2006) …………...............................................................

Figure 1.3: Anatomy of an American Lobster (Herrick, 1909) ..........................................................

Figure 1.4: Time course of an action potential in a neuron (Widmair 2006)...............................

Figure 1.5: Conduction of an action potential down a nerve axon (Widmair 2006) ................10

Figure 1.6: Placement of stim and recording terminals in a typical CAP setup (BIOPAC

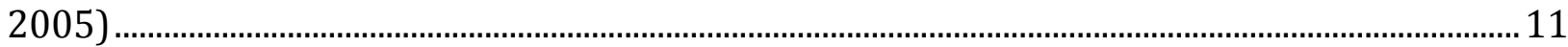

Figure 1.7: Snapshots of a CAP trace during action potential propagation (BIOPAC 2005).11

Figure 1.8: A) Drawing of the multi-beam ultrasound transducer; B) picture of the experimental setup. Ringers solution has not yet been inserted (Bernard et al. 1958)........13

Figure 1.9: Experimental Arrangement (Tsui et al. 2005)......................................................... 14

Figure 1.10: Variations in conduction velocity (CV) and compound action potential (CAP)

amplitude following ultrasonic stimulations (Tsui et al. 2005) ………………………………...... 14

Figure 1.11: a) CAPs time dependent peak to peak values of a single nerve; b) dynamic process of recurrence rate of CAPs; c) Dynamic process of determinism of CAPs; d) Dynamic process of entropy of CAPs (Yu et al. 2004) ................................................................15

Figure 1.12: Relative CMAP of rat sciatic after 5 second exposures of 390, 2255, 3310, and $7890 \mathrm{~W} / \mathrm{cm} 2$ at 0,2 , and 4 hours (short term) and 7(A) and 28(B) days (long term) (Foley et al. 2008)

Figure 1.13: Experimental set. a) Schematic vertical cross section of the sonication setup; b) Photograph of the nerve chamber, from above, showing the nerve mounted on the stimulating and recording electrodes in the lateral pools (Colucci et al. 2009) 18 
Figure 1.14: Action potential as a function of nerve temperature for the sonicated and water bath heated nerves (on nerve each) (Colucci et al. 2009) .................................................. 19

Figure 1.15: Block diagram of the experimental setup (Jabbary 2011).......................................2 20

Figure 1.16: Picture of the experimental setup (Jabbary 2011) ................................................... 20

Figure 1.17: Baseline CAP measurement showing the CAP amplitude before the HIFU

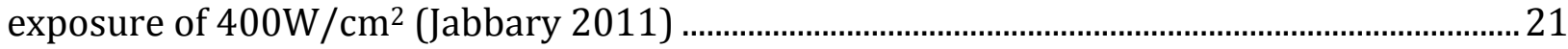

Figure 1.18: CAP measurement showing the CAP amplitude after the HIFU exposure of $400 \mathrm{~W} / \mathrm{cm}^{2}$ (Jabbary 2011)

Figure 1.19: Normalized compound action potential (CAP) vs. focal intensity of a 10-s HIFU exposure (Jabbary 2011)

Figure 1.20: Schematic representation of experimental setup (Mihran et al. 1990a; 1990b; 1996)

Figure 1.21: Ultrasound pulse intensity-duration plots at 2, 4, and $7 \mathrm{MHz}$; each point represents the pulse duration and ultrasound frequency needed to reduce normalized CAP amplitude by $20 \%$ of baseline value (Mihran et al. 1990a)

Figure 1.22: CAP amplitude response to pulsed ultrasound of a frog sciatic at $0.5 \mathrm{~ms}, 400$ $\mathrm{W} / \mathrm{cm} 2$; a) typical suppressive response b) typical excitatory response (Mihran et al. 1990a).

Figure 1.23: CAP amplitude response to pulsed ultrasound of a mouse sciatic (Mihran et al. 1996)

Figure 1.24: a) Experimental setup of worm experiment b) Electrical system used to stimulate and record CAP (Wahab 2012) 27

Figure 1.25: CAP response from pulsed ultrasound on a worm nerve (Wahab et al. 2012) 28 Figure 1.26: Conduction velocity response from pulsed ultrasound on a worm nerve

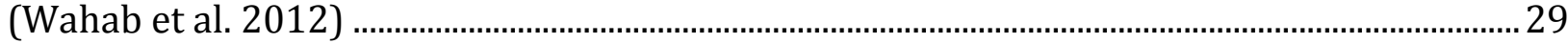

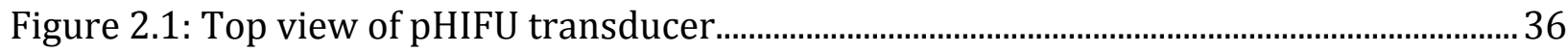

Figure 2.2: pHIFU transducer with plexiglass attachment. Dimensions are in $\mathrm{cm}$...................37

Figure 2.3: Picture showing the pHIFU ultrasound transducer and the hydrophone to determine the focal point of the transducer 38

Figure 2.4: Snapshot of oscilloscope showing time of flight of ultrasound beam to hydrophone 39

Figure 2.5: Comparison of the 2 conditions used to determine the effect of water jacket.... 41 Figure 2.6: Setup of the ONDA RFB-2000 system for TAP measurement.................................. 42 Figure 2.7: The pHIFU transducer (F\# 2.4) being calibrated by the ONDA RFB-2000

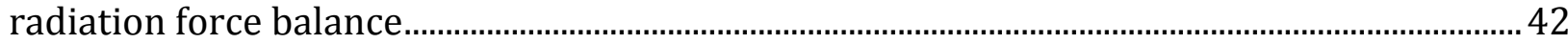

Figure 2.8: representation of variable used in equation 1.7 (Butt 2011) ..................................45

Figure 2.9: Dorsal view of an exposed lobster ventral nerve cord.............................................. 46 
Figure 2.10: Drawing showing the placement of the pHIFU transducer and nerve chamber

Figure 2.11: Close-up of the nerve chamber showing the pin out configuration 48

Figure 2.12: Typical stimulation artifact produced by putting a wetting string in the BIOPAC

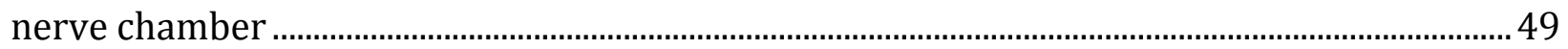

Figure 2.13: Block diagram of the experimental setup ............................................................. 51

Figure 2.14: Timing sequence diagram for pHIFU exposure showing method used to

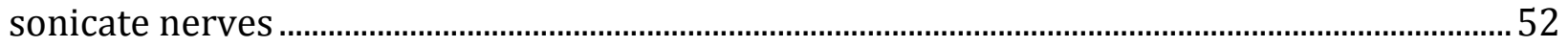

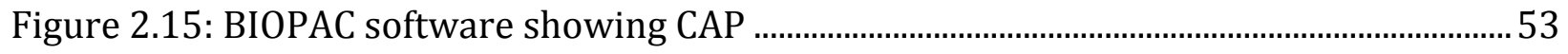

Figure 2.16: Temperature map of a lobster nerve using the thermal camer.............................. 54

Figure 3.1: Effect of the nose piece on the acoustic output of the pHIFU transducer.............. 55

Figure 3.2: Input voltage to the ultrasound system vs. output acoustic power measured

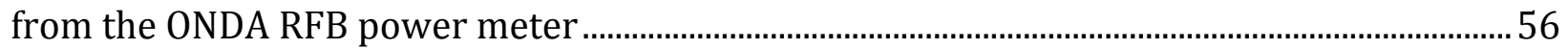

Figure 3.3: Simulated intensity profiles of the pHIFU beam .....................................................5

Figure 3.4: Output focal pressure vs input electrical power to the ultrasound system...........58 Figure 3.5: Temperature change of a typical nerve using the thermal camera during the

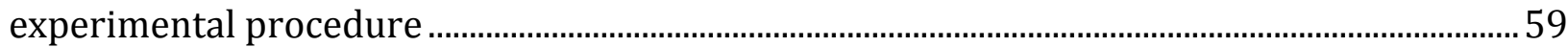

Figure 3.6: Categorization of nerve CAP results following sonication ........................................ 60 Figure 3.7: Average normalized CAP values following sonication of a nerve for 1 second $(n=11), 6$ seconds $(n=15)$, and 16 seconds $(n=10)$ 61

Figure 3.8: Average normalized $\mathrm{CV}$ values following sonication of a nerve for 1 second $(n=11), 5$ seconds $(n=15)$, and 10 seconds ( $n=10)$ 62

Figure 3.9: Normalized nerve conduction velocity vs. normalized nerve compound action potential at 3 sonication times. 63

Figure 3.10: Changes in nerve CAP amplitude 3.5 minutes following sonication ...................... 64

Figure 3.11: Nerve CAP amplitude during 1 second of pHIFU exposure.....................................65

Figure 3.12: Nerve CAP amplitude during 5 seconds of pHIFU exposure....................................65

Figure 3.13: Nerve CAP amplitude during 10 seconds of pHIFU exposure.................................66

Figure 4.1: Typical nerve CAP waveform measured in this thesis...............................................68

Figure 4.2: Typical nerve CAP waveform measured by Jabbary 2011 .......................................68

Figure 4.3: Typical nerve CAP waveform measured by Wahab et al. 2012 _...............................69

Figure 4.4: Typical nerve CAP waveform measured by Tsui et al. 2005 ................................69 


\section{List of Appendices}

A1: Technical Specifications for the ONDA RFB-2000 Power Meter......................................76

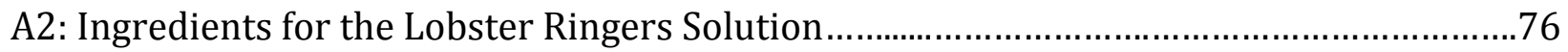

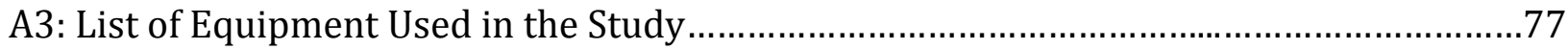

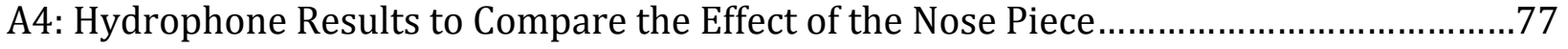

A5: ONDA Acoustic Power Calibration Results ............................................................78

A6: Sample Calculations for Locating Actual Focal Spot of pHIFU Transducer....................79

A7: Technical Specifications of the ThermoVision A40 Thermal Camera.............................79 


\section{Chapter 1 : Background and Introduction}

\subsection{Fundamentals of Ultrasound}

Ultrasound is a form of sound waves with frequencies higher than the audible range for humans (higher than $\sim 20 \mathrm{kHz}$ ). Sound waves are mechanical impulses of kinetic energy or vibrations propagating through a medium alternating between compression and rarefaction (see figure 1.1). Sound can be described in terms 1) frequency, number of cycles per second, 2) wavelength, the spatial distance of one complete cycle, 3) amplitude, the magnitude of the wave at a particular point in time, and 4) phase, denotes the particular point in the cycle of a sound waveform. Additionally, there are several derived properties of sound waves. These properties include: speed, intensity, pressure, and power (Lawrence 2007).

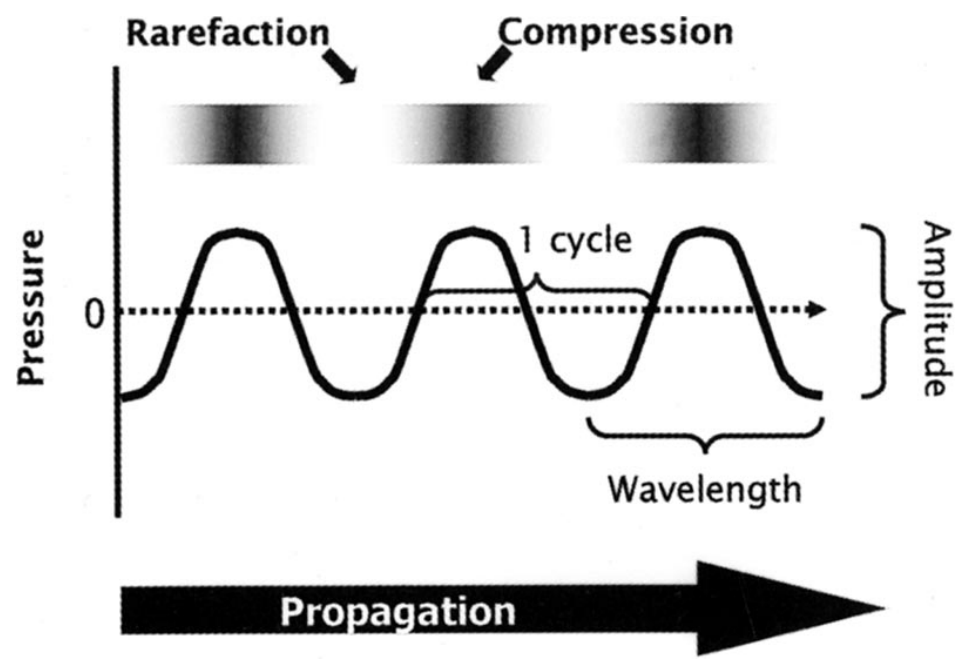

Figure 1.1: A visual description of the properties of sound waves (Lawrence 2007)

The speed at which a wave propagates through a medium is dependent on the density and compressibility of the medium it travels through. The intensity of a sound wave describes the amount of power hitting a cross sectional area per second. Pressure is the force per unit cross sectional area and has the unit of pascals. The power of a sound wave is a measure of the summed total energy of the sound source per second and has the unit of watts. Attenuation is the process whereby sound energy is reduced as it travels through a medium. This is a result of the 


\section{Chapter 1: Background and Introduction}

scattering of sound energy or the transformation of the energy into another form; at very high powers and in the dissipating medium; this is often detected as heat. Table 1.1 provides a summary of sound properties. (Wu et al. 2006; Cobbold 2007)

Table 1.1: Properties of ultrasound

\begin{tabular}{lccc}
\hline Property & Symbol & $\begin{array}{c}\text { SI } \\
\text { Units }\end{array}$ & Mathematical Relationship \\
\hline wavelength & $\lambda$ & $\mathrm{m}$ & $\lambda=\frac{c}{f}$ \\
frequency & $f$ & $\mathrm{~Hz}$ & cycles / second \\
speed & $v$ & $\mathrm{~m} / \mathrm{s}$ & $c=\frac{d}{t}=\frac{1}{\sqrt{\kappa \rho}}$ \\
attenuation factor & $\mu$ & $/ \mathrm{m}$ & $\mu=-\frac{1}{z} \ln \frac{p(z)}{p 0}$ \\
intensity & & &
\end{tabular}

\begin{tabular}{lccc}
\multicolumn{1}{l}{ instantaneous } & $i(t)$ & $\mathrm{W} / \mathrm{m}^{2}$ & $i(t)=\frac{p(t)^{2}}{\rho c}$ \\
\multicolumn{1}{c}{ time averaged } & $I$ & $\mathrm{~W} / \mathrm{m}^{2}$ & $I=\frac{p_{0}{ }^{2}}{2 \rho c}$ \\
pressure & $p$ & $\mathrm{~Pa}$ & $p=\sqrt{I \rho c}=\frac{F}{A}$ \\
power & $P$ & $\mathrm{~W}$ & $P=I A$ \\
dosage & $D$ & $\mathrm{~J}$ & $D=P t$
\end{tabular}

* For table 1: $c=$ speed of sound in the medium $(\mathrm{m} / \mathrm{s}) ; d=$ distance travelled $(\mathrm{m}) ; t=$ time $(\mathrm{s}) ; \kappa$ $=$ compressibility $\left(\mathrm{N} / \mathrm{m}^{2}\right) ; \rho=$ density of medium $\left(\mathrm{kg} / \mathrm{m}^{3}\right) ; p(\mathrm{z})=$ pressure at distance $\mathrm{z}(\mathrm{Pa}) ; p 0=$ pressure at surface of source $(\mathrm{Pa}) ; p_{0}=$ peak pressure amplitude $(\mathrm{Pa}) ; F=$ force applied $(\mathrm{N}) ; A=$ cross-sectional area $\left(\mathrm{m}^{2}\right)$. 


\section{Chapter 1: Background and Introduction}

\subsection{What is Therapeutic Ultrasound?}

Simply put, therapeutic ultrasound describes ultrasound being used to induce any type of bioeffect (ter Haar 2000). One of the major differences between therapeutic ultrasound and the more commonly known diagnostic ultrasound is the intensity at which they operate. Diagnostic ultrasound utilizes intensities of $0.5-50 \mathrm{~mW} / \mathrm{cm}^{2}$ whereas therapeutic applications use higher intensities of $0.2-10,000 \mathrm{~W} / \mathrm{cm}^{2}$ (Foley et al. 2006). Higher still are the intensities of focused therapeutic ultrasound.

High intensity focused ultrasound (HIFU) systems can produce acoustic intensities greater than $1000 \mathrm{~W} / \mathrm{cm}^{2}$ at the focus, and operate at frequencies typically in the range of $0.5-10 \mathrm{MHz}$. The great clinical advantage of HIFU is the ability to focus energy to a small region $(1 \mathrm{x} 10 \mathrm{~mm}$ ellipsoid) inside the body without damaging intervening tissue (Foley et al. 2006). The mechanism by which therapeutic ultrasound induces bio-effects are through production of heat energy and mechanical forces (ter Haar 2007).

\subsection{Nerve Anatomy and Physiology}

Nerves provide a pathway for signals to travel throughout the body by receiving and conducting electrochemical impulses. The classification of nerves is divided into: 1) the central nervous system (CNS), consisting of the brain and spinal cord, and 2) the peripheral nervous system (PNS), which is defined as everything but the CNS (Kardong 2006).

A nerve is composed of a collection of nerve cells also called neurons that come together and form a band to connect the nervous system with other organs. Neurons are the basic structural and functional units of the nervous system. They are specialized to respond to physical and 


\section{Chapter 1: Background and Introduction}

chemical stimuli, conduct electrochemical impulses, and release chemical regulators (Widmaier 2006). In addition, supporting cells make up the other half of the principal cell type. Supporting cells aid the functions of neurons and are about five times more abundant than neurons (Widmaier 2006). Although there are many types of supporting cells (ganglionic gliocytes, oligodendrocytes, microglia, astrocytes, ependymal cells), the 2 that are of greater relevance to this study are the schwann cells found in the peripheral nervous system and the oligodendrocytes in the central nervous system. Schawann cells and oligodendrocytes are responsible for the formation of an insulating covering around the nerve; called the myelin sheath. The myelin sheath protects the nerve from physical damage and well as provides electrical insulation from the surrounding nerve environment; it prevents inadvertent charges and stimuli from activating the nerve from outside the nervous system. Myelinated nerves also conduct impulses faster than un-myelinated nerves (Kardong 2006).

Nerves can be classified into 3 types based on their function (figure 1.2). Their classification is based on the direction in which the impulse travels and its innervating target. Sensory, also called afferent nerves, carry impulse signals from sensory receptors into the central nervous system. Nerves that conduct impulses out of the CNS to effector organs such as muscles and glands are called motor or efferent nerves. The third classification, association or interneurons, describes the communication of nerves to other nerves.

Further still, motor nerves can be sub-divided into: somatic, autonomic-sympathetic, parasympathetic (Kardong 2006) this classification is based on the nerve's physiological role in the living system, its innervating system, and the organ the nerve is affecting. The experiments described in this thesis refer to nerves that have been excised from its living system; as a result, the relationship of these nerves to other parts of the living system no longer exists and the 


\section{Chapter 1: Background and Introduction}

significance of somatic, autonomic, sympathetic, and parasympathetic nerves is not relevant in thesis.

Anatomically, nerves are made up of: 1) cell bodies, 2) dendrites, and 3) axons. Cell bodies produce the nutritional macromolecules used by the neurons to sustain life. Dendrites appear as branch-like structures and provide an area where chemical neurotransmitters can attach to and launch from. Axons provide a pathway for a nerve impulse to travel through. Although a nerve can comprise of many dendrites, each nerve has only one axon. Conduction of a nerve impulse is achieved through action potentials. (Widmaier et al. 2006; Marieb 2006)

The 3 main types of Neurons

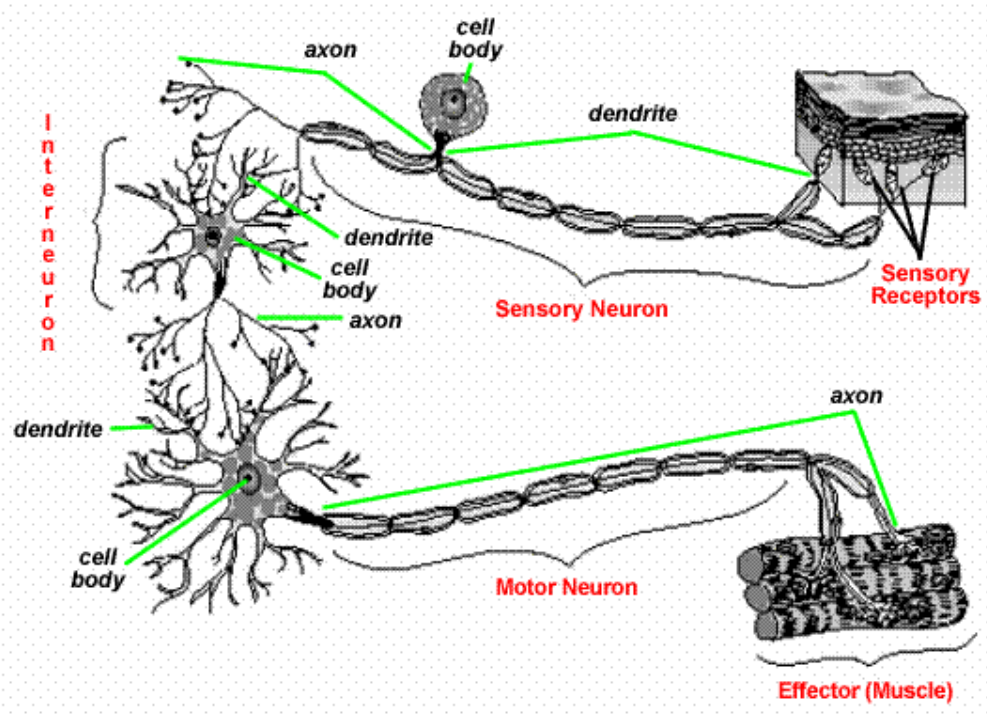

Figure 1.2: Types of Nerves (Marieb 2006)

\subsubsection{Properties of the lobster ventral nerve cord}

Lobsters have been used as the nerve model in past studies (Mihran et al. 1990; Jabbarry 2011). The lobster's ventral nerve cord is a convenient specimen because of its relatively large size 


\section{Chapter 1: Background and Introduction}

making them easier work with and their abundance in North America make them convenient to obtain. In medium sized lobster fibres $(10-20 \mu \mathrm{m})$, the schwann cells are thin $(0.1 \mu \mathrm{m})$; as a result, lobster nerves do not have a myelin sheath (Schmitt et al. 1956; Dowling 2001). Lobster nerves have slower nerve-pulse conduction speed and less protection against current leak and physical trauma that myelinated nerves benefit from (Schmitt et al. 1956).

It should be noted, nerves taken from different parts of a lobster have varying conduction properties. Table 1.2 presents work done by Wright et al. (1958), that illustrates the variability in nerve conduction. The ventral nerve cord is used in the experiments in this study (figure 1.3). The physical properties of the ventral nerve cord, also referred to as the giant cord, are shown bolded in table 1.2. The $k$-value is the excitability rate constant; it represents the probability per second for cell to go from a closed to open/excited state. The excitability threshold of the nerves was observed to decrease after electrical stimulation was applied to the nerve but only lasted for a few milliseconds. This increase in nerve excitability was recorded and termed the supernormal phase duration.

Table 1.2: Properties of nerves from different parts of lobster anatomy (Wright et al. 1958)

\begin{tabular}{rccccc}
\hline & $\begin{array}{c}\text { Giant } \\
\text { Cord }\end{array}$ & $\begin{array}{c}\text { Chela Fast } \\
\text { Closer }\end{array}$ & Opener & $\begin{array}{c}\text { Leg Fast } \\
\text { Closer }\end{array}$ & Open \\
\hline Diameter $(\mu \mathrm{m})$ & $\mathbf{9 0 - 1 8 0}$ & $80-125$ & $70-90$ & $70-100$ & $40-80$ \\
Velocity $(\mathrm{m} / \mathrm{s})$ & $\mathbf{1 8 - 2 0}$ & $18-20$ & $14-18$ & $12-18$ & $7-13$ \\
$\mathrm{k}$ value $\left(\times 10^{3} / \mathrm{sec}\right)$ & $\mathbf{1 . 0 - 2 . 0}$ & $1.0-1.7$ & $0.75-1.0$ & $0.75-1.5$ & $0.35-0.75$ \\
$\begin{array}{r}\text { Supernormal Phase } \\
\text { Duration }(\mathrm{ms})\end{array}$ & $\mathbf{0 - 2}$ & $0-2$ & $2-8$ & $0-5$ & $05-10$
\end{tabular}




\section{Chapter 1: Background and Introduction}

The ambient temperature of a lobster at sea ranges from around -2 to $29{ }^{\circ} \mathrm{C}$, (Reynolds et al. 1979). Since the experiments in our study were done at room temperature $\left(\sim 22{ }^{\circ} \mathrm{C}\right)$, this is in the range of normal lobster living so it is assumed operating temperature did not play a significant role in any observed changes in nerve function.

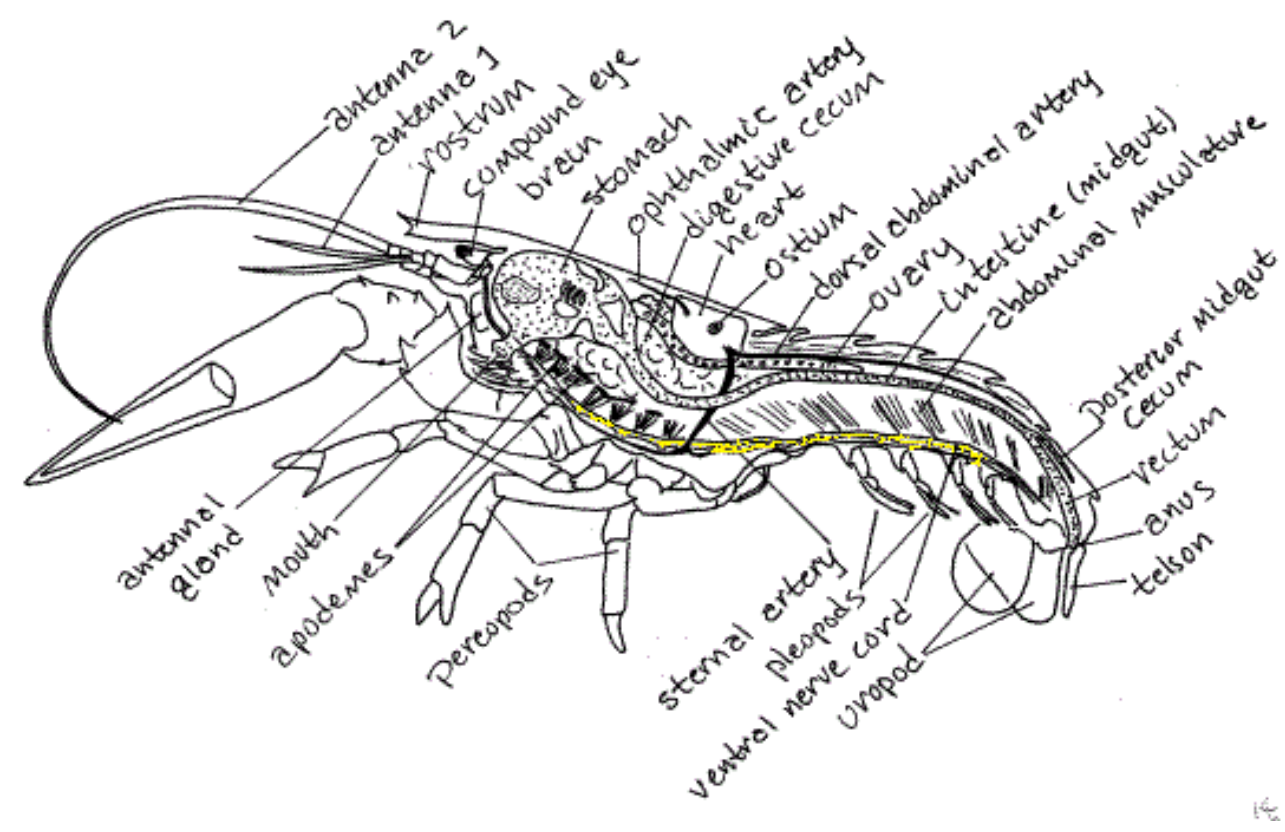

Figure 1.3: Anatomy of an American Lobster (Herrick, 1909)

\subsection{Nerve Electrophysiology - Conduction of an Action Potential}

The current understanding of nerve conduction at the molecular level can be traced back to Nobel laureates Hodgkin and Huxley's (1952) pioneering work in modeling the kinetics behind the action potential in squid axons. They demonstrated that conduction of a nerve impulse was achieved through a coordinated effort of several ion-channels located on the nerve membrane. 


\section{Chapter 1: Background and Introduction}

Action potentials are the means by which nerves transmit impulses. Nerve action potentials are short lasting events in which the electrical potential (difference in voltage: inside versus outside) of the nerve cell membrane rises and/or falls (Hille 2001). An action potential (AP) can be initiated by several ways: 1) chemically through neurotransmitters such as acetylcholine 2) mechanically as in the case in some sensory nerves 3) and electrically if the electric stimulus is large enough in amplitude and long enough in duration.

Action potentials are formed by the exchange of charges of ion particles through the cell membrane. Although the type of ions involved in APs vary among species and even differ in organs within the same species, sodium $\left(\mathrm{Na}^{+}\right)$and potassium $\left(\mathrm{K}^{+}\right)$have been found to be the primary ions involved in most organisms including lobsters (Homarus Americanus - aka American Lobster).

The time course of a nerve cell action potential follows a specific sequence of events and is shown in figure 1.4. The membrane potential of a nerve is measured as the inside voltage potential minus the outside membrane potential. Once a stimulus raises the membrane potential above its threshold, $\mathrm{Na}+$ channels on the membrane open up. Because the concentration of $\mathrm{Na}^{+}$ is much greater outside of the nerve cell, $\mathrm{Na}+$ rushes into the cell and the AP deflects upward rapidly; this is called the depolarizing stage. Very soon after, $\mathrm{Na}+$ channels deactivate and $\mathrm{K}+$ channels open, initiating the next stage. In the repolarizing stage, $\mathrm{K}+$ follows the concentration gradient and rushes out of the cell making the inside of the cell less positive and drives the membrane potential back down to its resting membrane potential. The displaced $\mathrm{Na}+$ is pumped back out of the cell and $\mathrm{K}+$ is pumped back in through active transport ion channels. 


\section{Chapter 1: Background and Introduction}

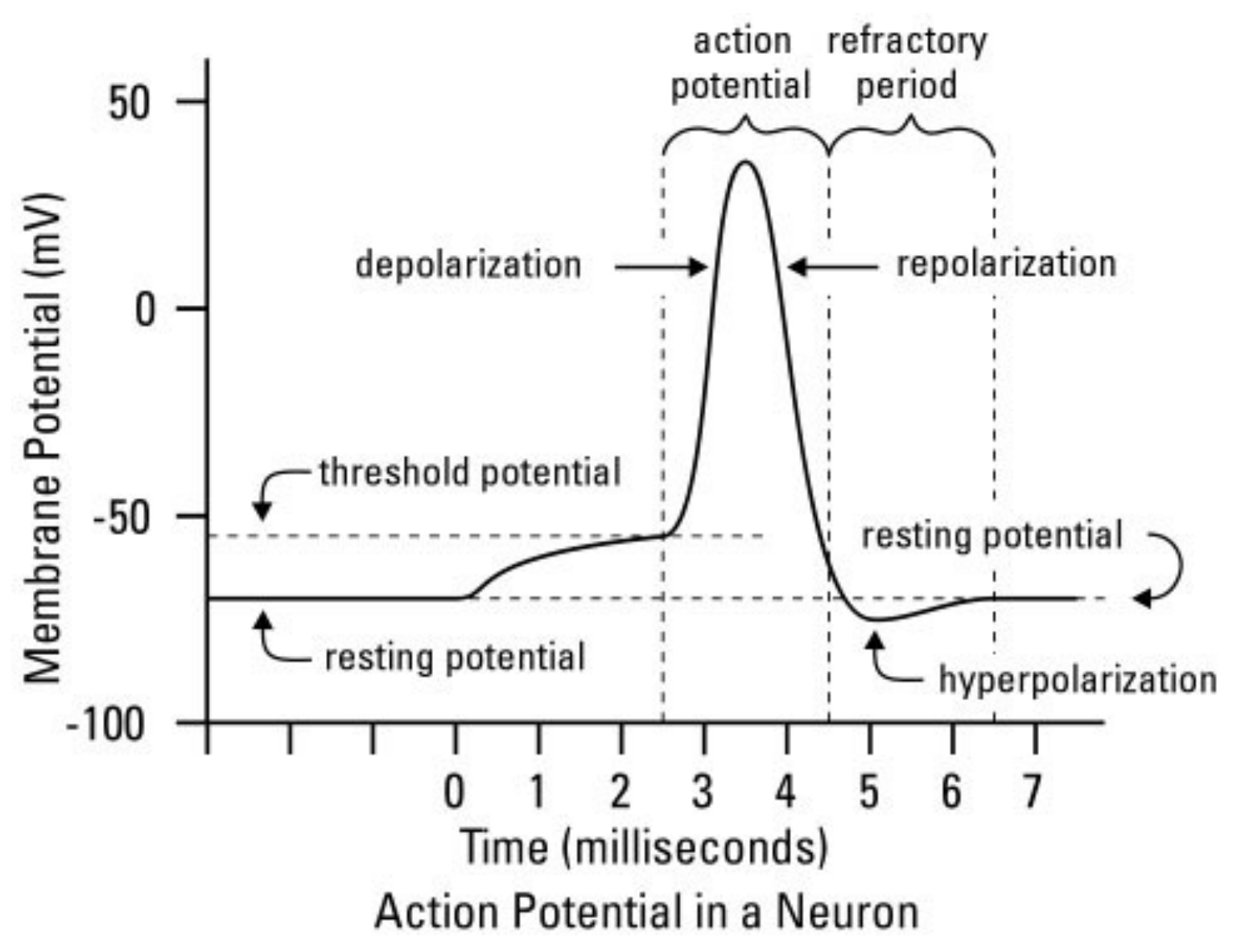

Figure 1.4: Time course of an action potential in a neuron (Widmair 2006)

\subsubsection{Action potential conduction}

The action potential described in the previous section depolarizes only a small, localized area of the nerve. Transmission of a nerve impulse is achieved through a series of regenerations of APs along the nerve axon. Figure 1.5 illustrates the successive stages of propagation of an AP. Each action potential injects positive charges that spread to adjacent regions. The action potential produced at the first location by an initial stimulus in the axon membrane serves as the depolarization stimulus for the next region of the second membrane, which can then produce the action potential. The action potential in this second region, in turn, serves as a depolarization 


\section{Chapter 1: Background and Introduction}

stimulus for the production of the AP in a third region, and so on. This cascading effect is responsible for conduction of an AP down the nerve axon.

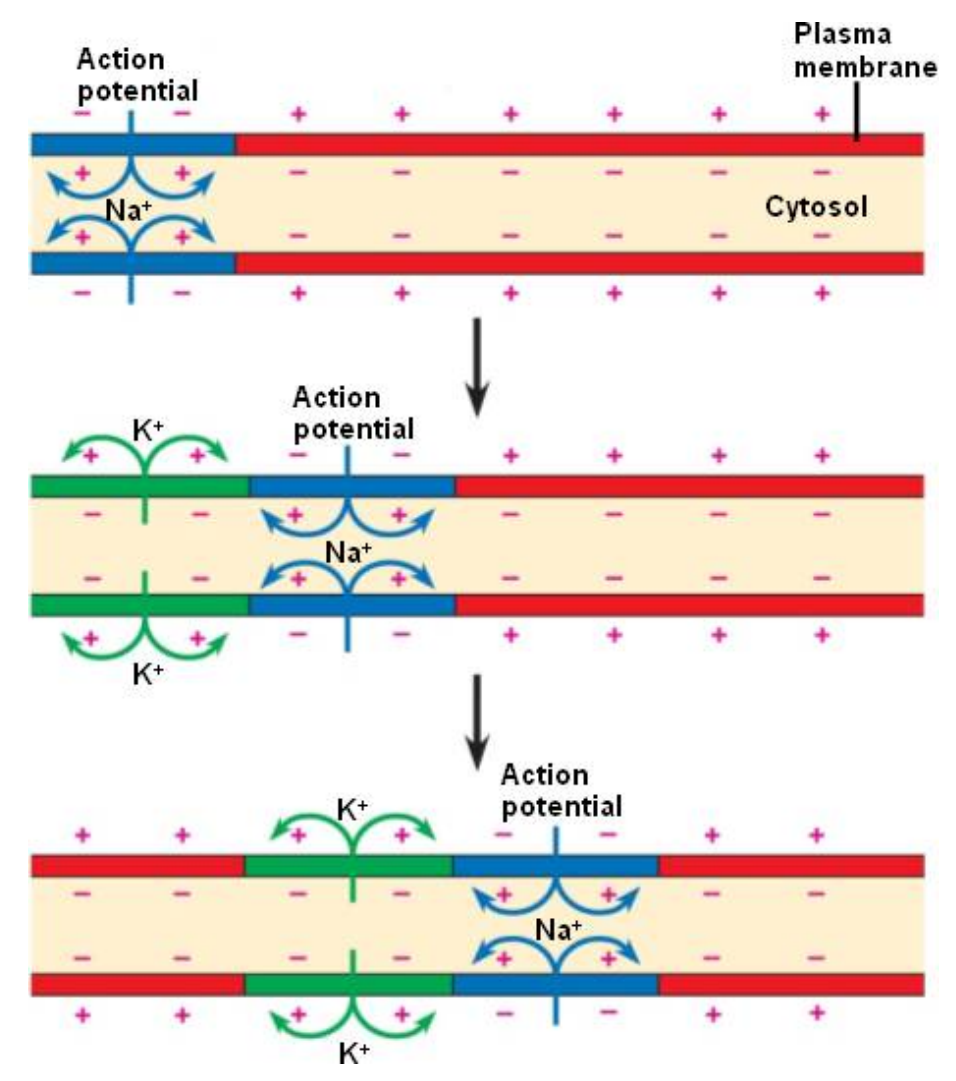

Figure 1.5: Conduction of an action potential down a nerve axon (Widmair 2006)

\subsubsection{Compound action potential recordings}

A compound action potential (CAP) measures the summation voltage potential of a bundle of nerve fibres. It is a measure of the outside membrane potential at one point versus the outside membrane potential at another point along the nerve. Measurements are performed using a pair of recording electrodes along a nerve. Figure 1.6 displays a schematic of a CAP recording setup. An action potential stimulus is first initiated at one end of the nerve. This can be done $e x$ vivo by a pair of stimulating electrodes that elicit a higher than threshold voltage. The action potential will be seen by recording electrode proximal to the stimulus first as it propagates along 


\section{Chapter 1: Background and Introduction}

the nerve. The CAP trace will deflect upward when it crosses the negative terminal and downward when it crosses the positive terminal. Maximum CAP amplitudes represent the voltage value of the peak of the CAP response. Conduction speed can be calculated using the distance between the recording electrodes.

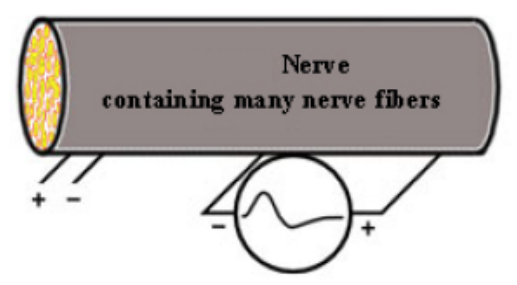

Figure 1.6: Placement of stim and recording terminals in a typical CAP setup (BIOPAC 2005)

Figure 1.7 shows the successive stages of a CAP recording as the action potential crosses each recording electrode. Nerve fibers are shown in yellow. Stimulated areas are shown in blue.

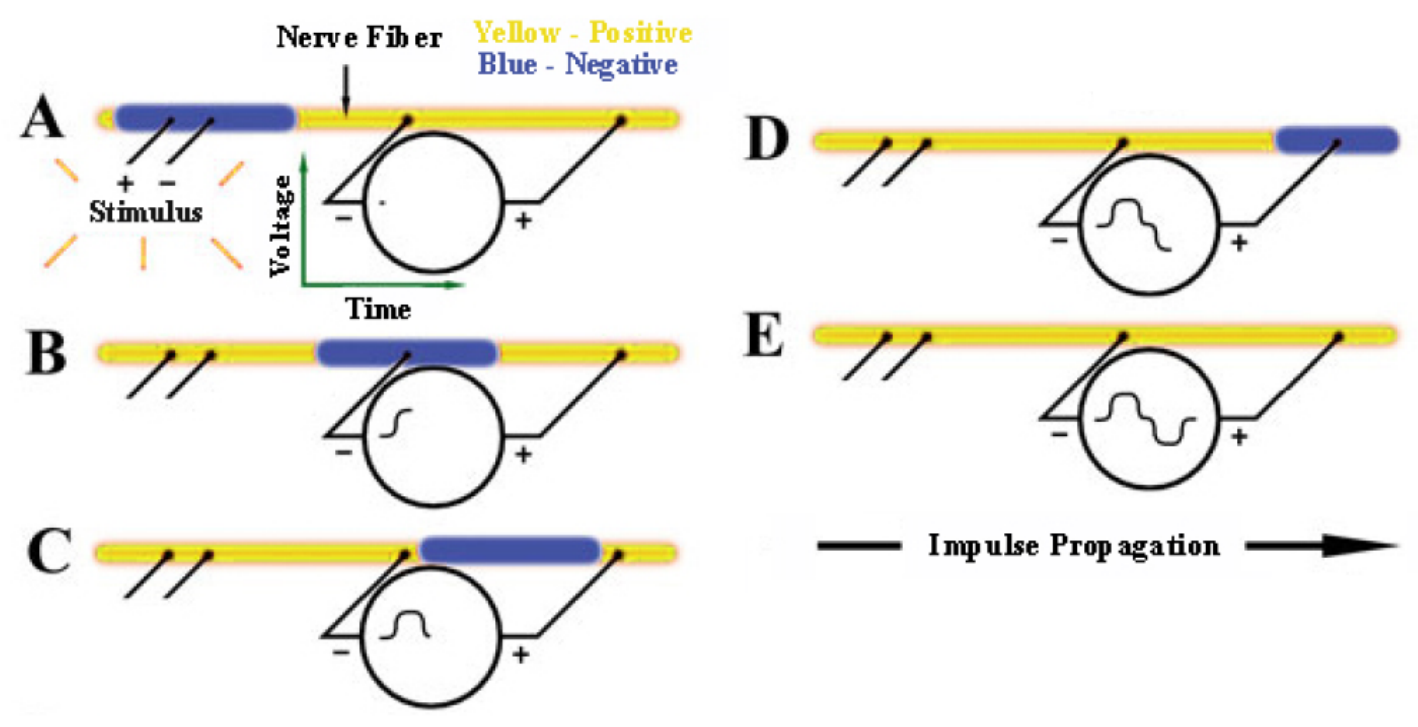

Figure 1.7: Snapshots of a CAP trace during action potential propagation (BIOPAC 2005)

When an external stimulus that exceeds a certain threshold level is applied, an action 


\section{Chapter 1: Background and Introduction}

potential will occur, creating the nerve impulse shown in blue. Since the voltmeter's "-" and "+" terminals at this instant are at the same voltage potential, it records 0 Volts. (B) The nerve impulse will propagate along the nerve with a constant amplitude and velocity until it eventually passes through the voltmeter's "-" terminal, causing it to record a positive (upward) voltage reading. (C) Propagation will continue and a point may be reached where the nerve impulse is between the voltmeter's "-" and"+" terminals, causing it to record 0 Volts. (D) Propagation will continue and eventually pass the voltmeter's "+" terminal, causing it to record a negative (downward) voltage reading. (E) At some point, the impulse propagation will be complete; with the entire nerve fibre returned to its resting state and the voltmeter recording 0 volts. The Voltage vs. Time recording will then be complete.

\subsection{Past Studies Using Therapeutic Ultrasound on Nerves}

As early as 1955, Bernard et al. used focused ultrasound on the CNS. Lesions were formed in the cortex and internal capsule of 104 anaesthetized cats using the setup shown in figure 1.8. The multi-beam acoustic transducer consisted of four separate focusing elements. The focused beams from all the elements intersected at a common region. The animal subjects were mounted in a head holder with the pan tied to scalp. The pan was filled with Ringer fluid to provide a coupling medium for the ultrasound. Each cat was sonicated at pressure amplitudes between 2.22 - 4.8 MPa for duration of $1-7$ seconds. All reported cats showed lesions in a subsequent histological analysis. The survival times after sonication ranged from 2 hours to 32 days. 


\section{Chapter 1: Background and Introduction}
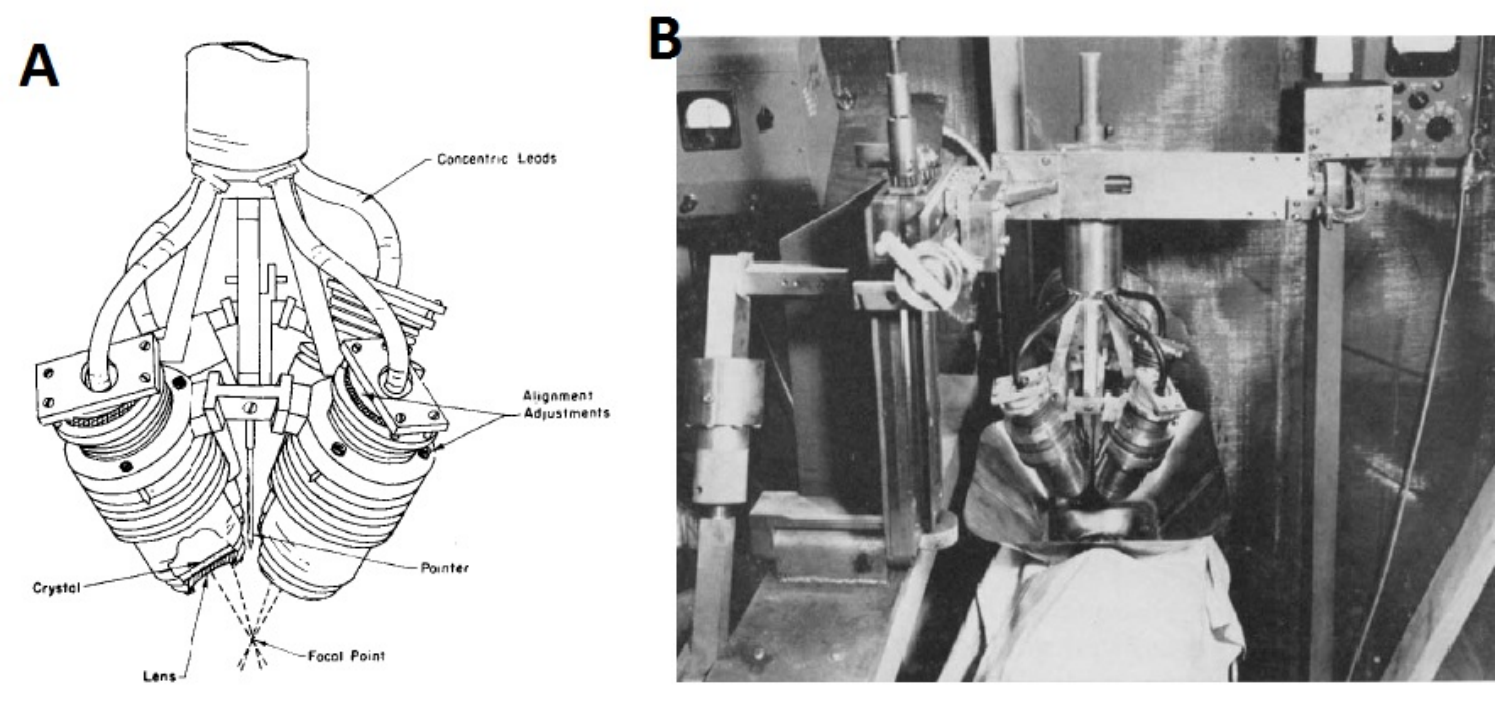

Figure 1.8: A) Drawing of the multi-beam ultrasound transducer; B) picture of the experimental setup. Ringers solution has not yet been inserted (Bernard et al. 1958)

From 1978 to 1996, Gavrilov and colleagues successfully used focused ultrasound extracorporally to simulate neural structures and induced tactile sensations (heat, pain) and auditory function. Focused ultrasound at frequencies from $0.48 \mathrm{MHz}$ to $2.67 \mathrm{MHz}$ and varying focus dimensions were directed at points on the hand and the labyrinth of the ear; these targeted areas were marked on the skin enabling the same points to be stimulated on subsequent occasions. Tactile thresholds (touch, warmth, cold, pain) were recorded and mapped.

In 2005, Tsui and colleagues observed changes in nerve conduction velocities as a result of ultrasound exposures. An excised sciatic nerve from a bullfrog was placed in a nerve chamber containing ringer's solution (figure 1.9). Paraffin oil was sprinkled over the entire nerve to prevent drying. The nerve was exposed to continuous wave ultrasound (centre frequency of 3.5 $\mathrm{MHz}$ and focal length of $9.53 \mathrm{~cm}$ and focal beam width of $4.8 \mathrm{~mm}$ ) at acoustic powers of 1,2 , $3 \mathrm{~W}$ for 5 min.; CAP signal was collected once per second. This study found that both 


\section{Chapter 1: Background and Introduction}

conduction velocity and CAP amplitude of nerves increased at $1 \mathrm{~W}$ sonication whereas conduction velocity increased but CAP amplitude decreased at 2 and $3 \mathrm{~W}$ (figure 1.10).

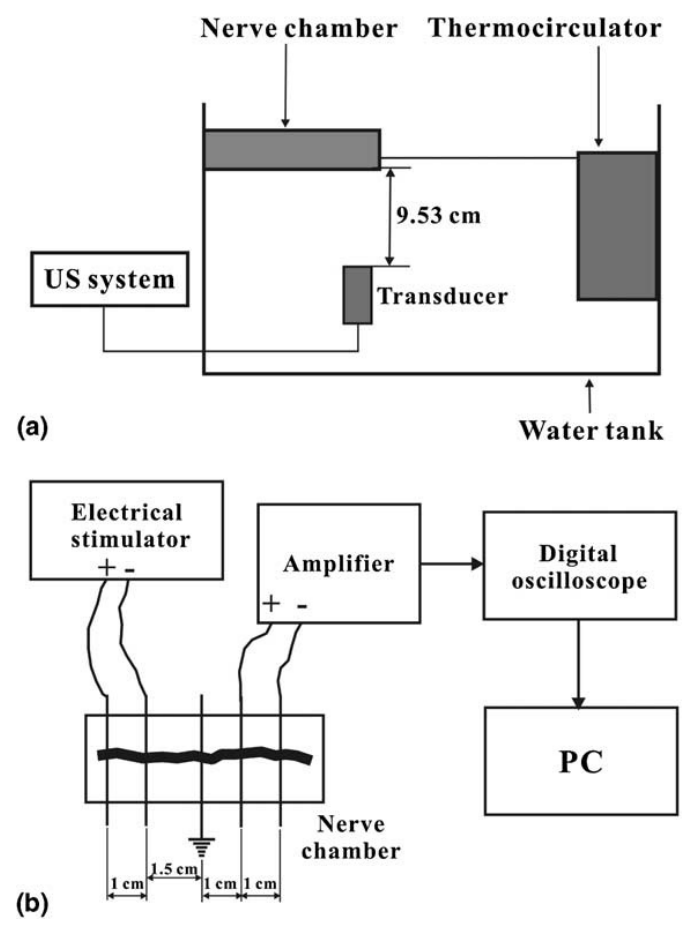

Figure 1.9: Experimental Arrangement (Tsui et al. 2005)
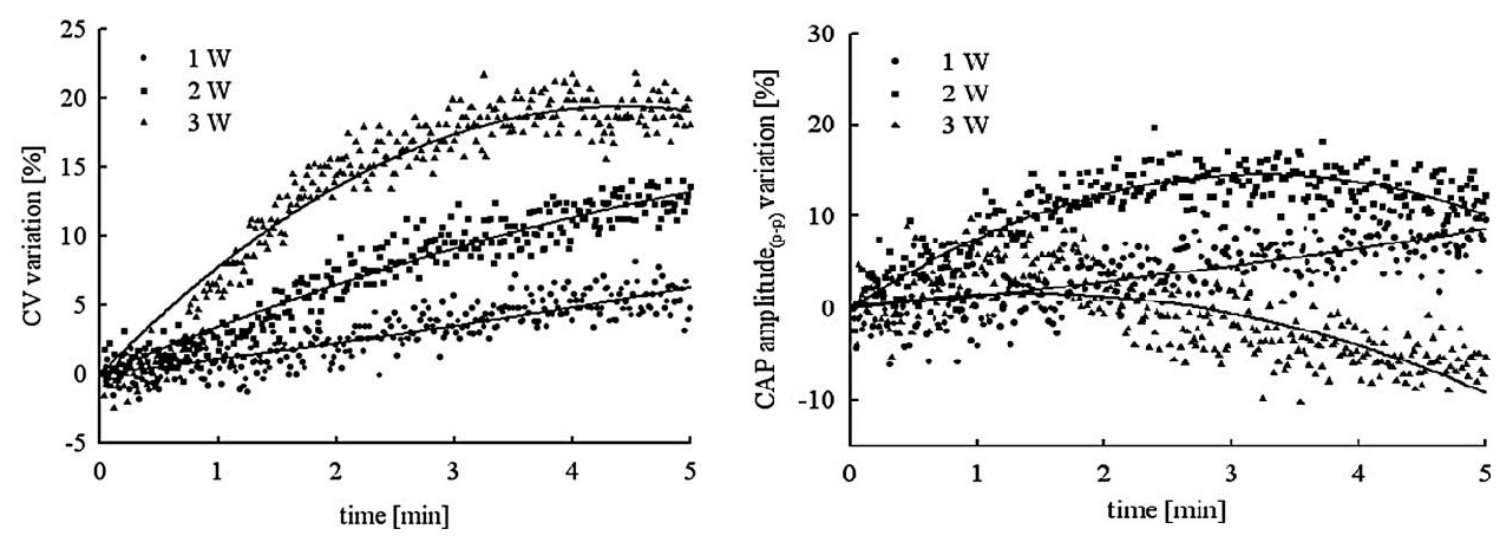

Figure 1.10: Variations in conduction velocity (CV) and compound action potential (CAP) amplitude following ultrasonic stimulations (Tsui et al. 2005) 


\section{Chapter 1: Background and Introduction}

In 2008, Yu and colleagues investigated the time dependent effects focused ultrasound had on the CAP amplitudes of toad sciatic nerves. Their results showed that significant and rapid decrease in CAP occurred after 26 seconds of ultrasound exposure. It was also noted that recoverability in CAP was possible if sonication ceased prior to nerve death. This study also introduced a method of recurrence plots to quantify the dynamic effects on nerve function induced by focused ultrasound (figure 1.11).

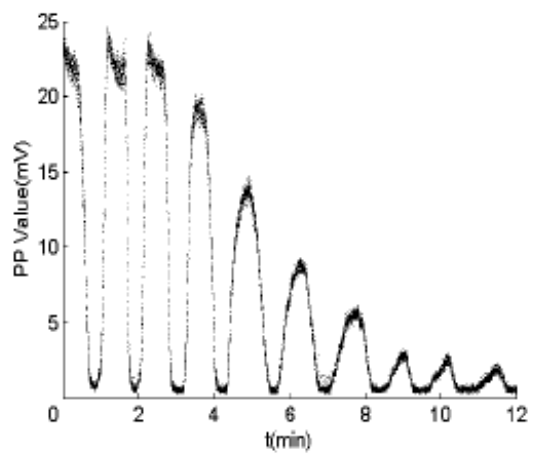

(a)

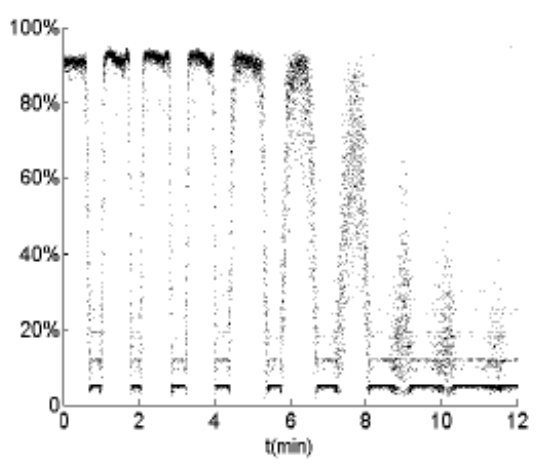

(c)

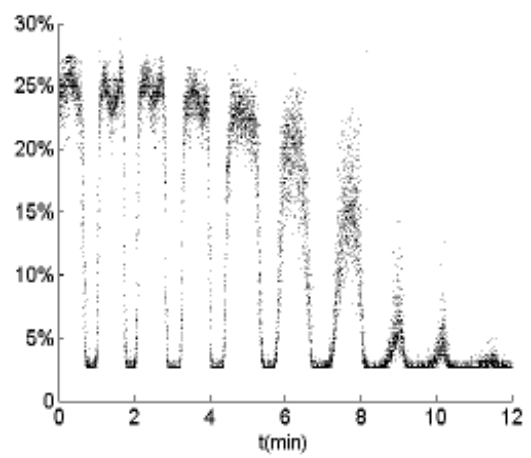

(b)

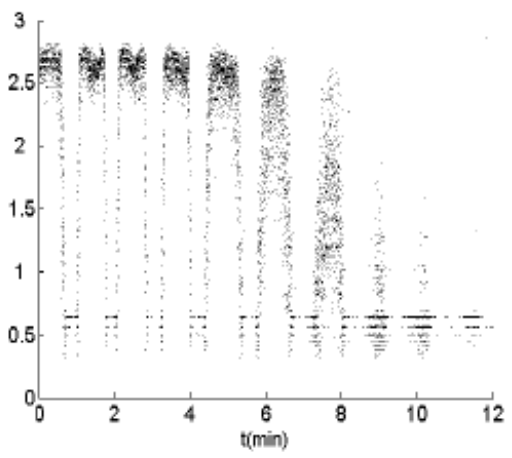

(d)

Figure 1.11: a) CAPs time dependent peak to peak values of a single nerve; b) dynamic process of recurrence rate of CAPs; c) Dynamic process of determinism of CAPs; d) Dynamic process of entropy of CAPs (Yu et al. 2004)

The use of recurrence quantification analysis has been usefully applied in physiology and are especially suitable for the detection of short non-stationary data such as electromyography and 


\section{Chapter 1: Background and Introduction}

electrocardiograms (Marwan 2002). The dynamic process of recurrence rate shown figure $1.11 \mathrm{~b}$ describes the percentage of recurrent states in the system. The dynamic process of determinism seen in figure $1.11 \mathrm{c}$ relates to the embeddibility of the system. The dynamic process of entropy shown in figure $1.11 \mathrm{~d}$ describes the complexity of the dynamical system. The recurrence plots produced similar curves to the CAP values seen in figure 1.11a and it was concluded by $\mathrm{Yu}$ et al. that recurrence quantification analysis could become another methodology for studying the effects of focused ultrasound on nerve CAP.

In 2008, Foley and colleagues investigated the short and long term exposure-dependent effects of HIFU on nerve function. This group had already shown permanent nerve CAP suppression at $1930 \mathrm{~W} / \mathrm{cm}^{2}$ (Foley et al. 2006) in rabbit sciatic nerves. The in-vivo study was conducted on the sciatic nerve in rats. To measure nerve function, electromyography was used to obtain the compound muscle action potential (CMAP) of the leg muscle innervated by the sciatic nerve. Any impairment of the sciatic nerve function was assumed to reveal itself as a decrease in CMAP. A custom HIFU device was applied to the middle of the exposed nerve of an anesthetized rat by direct contact. The location of the nerve middle was determined by visualization, without the aid of any imaging technique. The nerve was treated with a $5.7 \mathrm{MHz}$ HIFU beam for $5 \mathrm{~s}$ at intensities of 390, 2255, 3310, and $7890 \mathrm{~W} / \mathrm{cm}^{2}$. Measures of CMAP were taken immediately after sonication and at intervals of 2 and 4 hours for the short-term study and 7 and 28 days for the long-term study. In addition, a histo-pathalogy study was done on nerves and histological differences between the HIFU treated and control nerves were observed. 


\section{Chapter 1: Background and Introduction}
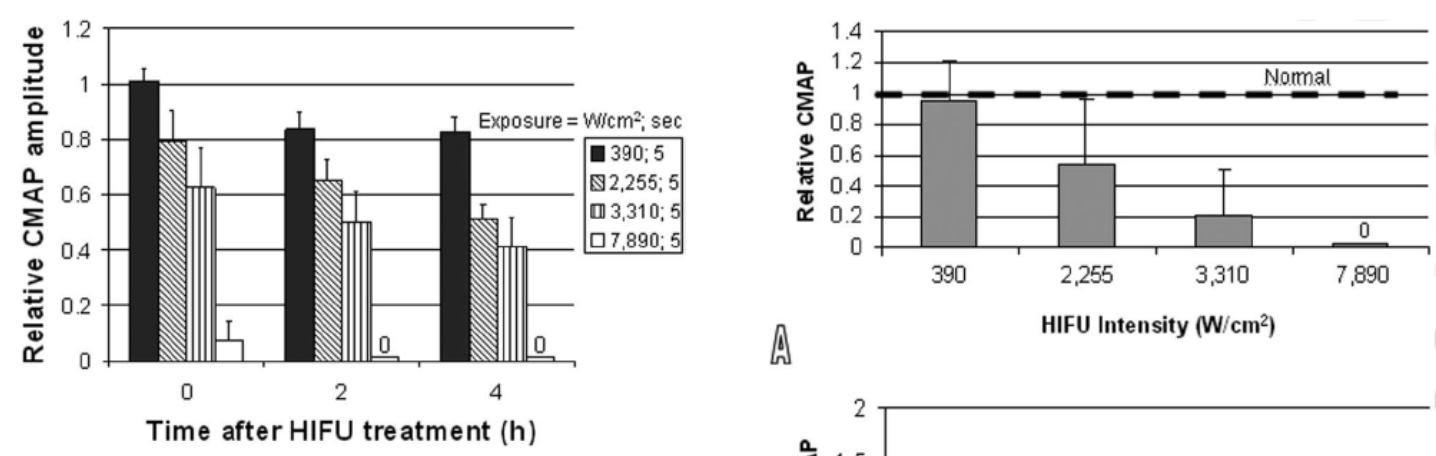

A

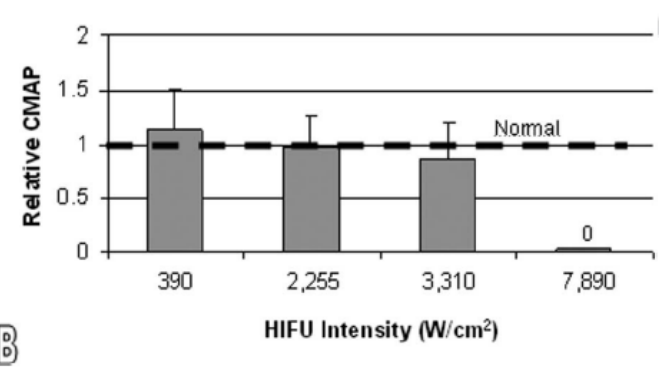

Figure 1.12: Relative CMAP of rat sciatic after 5 second exposures of 390, 2255, 3310, and $7890 \mathrm{~W} / \mathrm{cm} 2$ at 0,2 , and 4 hours (short term) and 7(A) and 28(B) days (long term) (Foley et al. 2008)

The short-term study, top left graph of figure 1.12, found that relative CMAP amplitude decreased with increased HIFU exposures. Histology showed, nerves treated with the highest exposure, $7890 \mathrm{~W} / \mathrm{cm}^{2}$, showed axon swelling, broken myelin accumulation, disorganized fibre structure, and signs indicating cell death. The long-term study, graph A and B in figure 1.12, found that mean relative CMAP decreased with increasing HIFU exposure at 7 days. At the 7 and 28 day follow up there was no measurable CMAP at the $7890 \mathrm{~W} / \mathrm{cm}^{2}$ exposure. At the 3 lower intensities CMAP amplitudes returned to approximately baseline values after 28 days. Foley's study had demonstrated the ability of HIFU to impair nerve function as a function of intensity, albeit with physical damage to the nerve. 


\section{Chapter 1: Background and Introduction}

In 2009, Colucci and colleagues showed results that supported the hypotheses: 1) nerve block can be induced by ultrasound exposures with frequencies that can travel through the skull $(0.5$ $\mathrm{MHz}-0.8 \mathrm{MHz}), 2)$ nerve block can be induced by longer sonification times (10 - 30s) that gradually increase temperature or where high intensity bursts needed; prior studies used sonication times of $5 \mathrm{~s}$ or less, and 3) heating the surrounding tissue around the nerve is enough to induce a nerve block. Figure 1.13 shows a picture of the nerve chamber used in the study. The nerve chamber was divided into three compartments. The end compartments housed the stimulating and recording electrodes. The nerve ran through all three compartments. The middle compartment was filled with ringer's solution while the end compartments were filled with mineral water to assure electrical isolation. A heated coil and thermocouple was inserted into the middle compartment to control and record ringer solution temp. Colucci also noted that there is a difference in action-potential of the nerve when comparing its decreased CAP amplitude due to HIFU vs. temperature increase alone (figure 1.14). This infers that although loss in CAP, is for the most part due to rise in temperature, there is another component in HIFU that also contributes to decrease nerve CAP. In other words, there must also be a non-thermal mechanism for in vitro nerve inhibition.
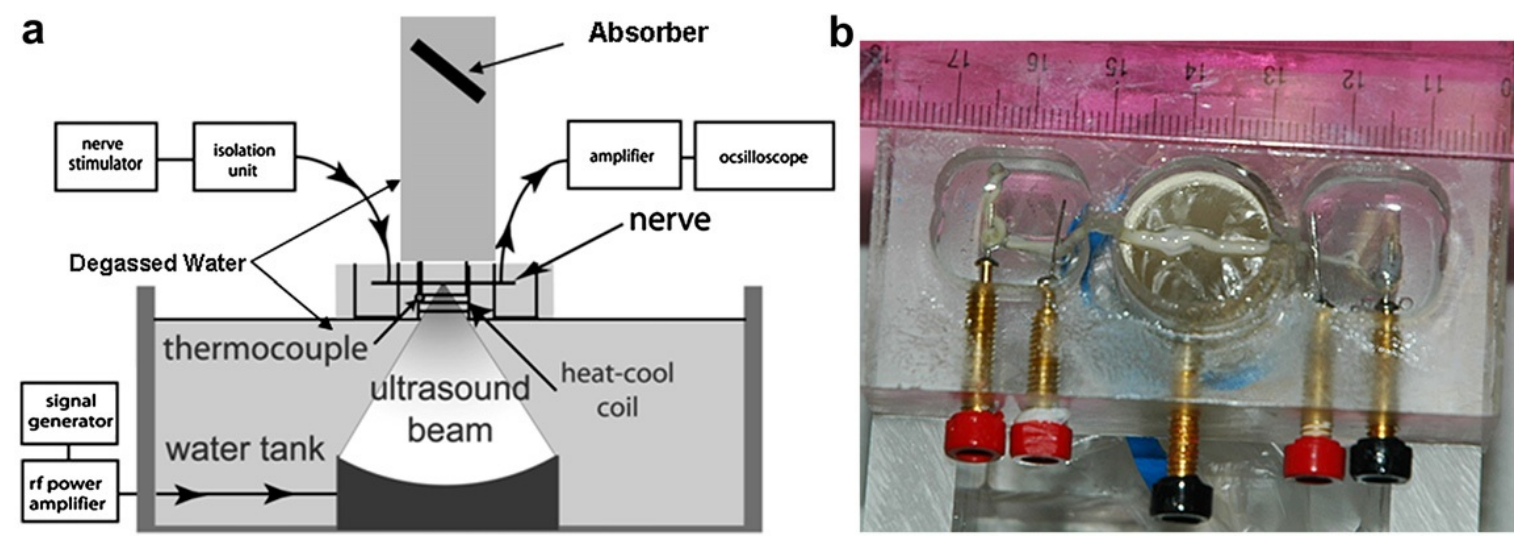

Figure 1.13: Experimental set. a) Schematic vertical cross section of the sonication setup; b)

Photograph of the nerve chamber, from above, showing the nerve mounted on the stimulating and recording electrodes in the lateral pools (Colucci et al. 2009) 


\section{Chapter 1: Background and Introduction}

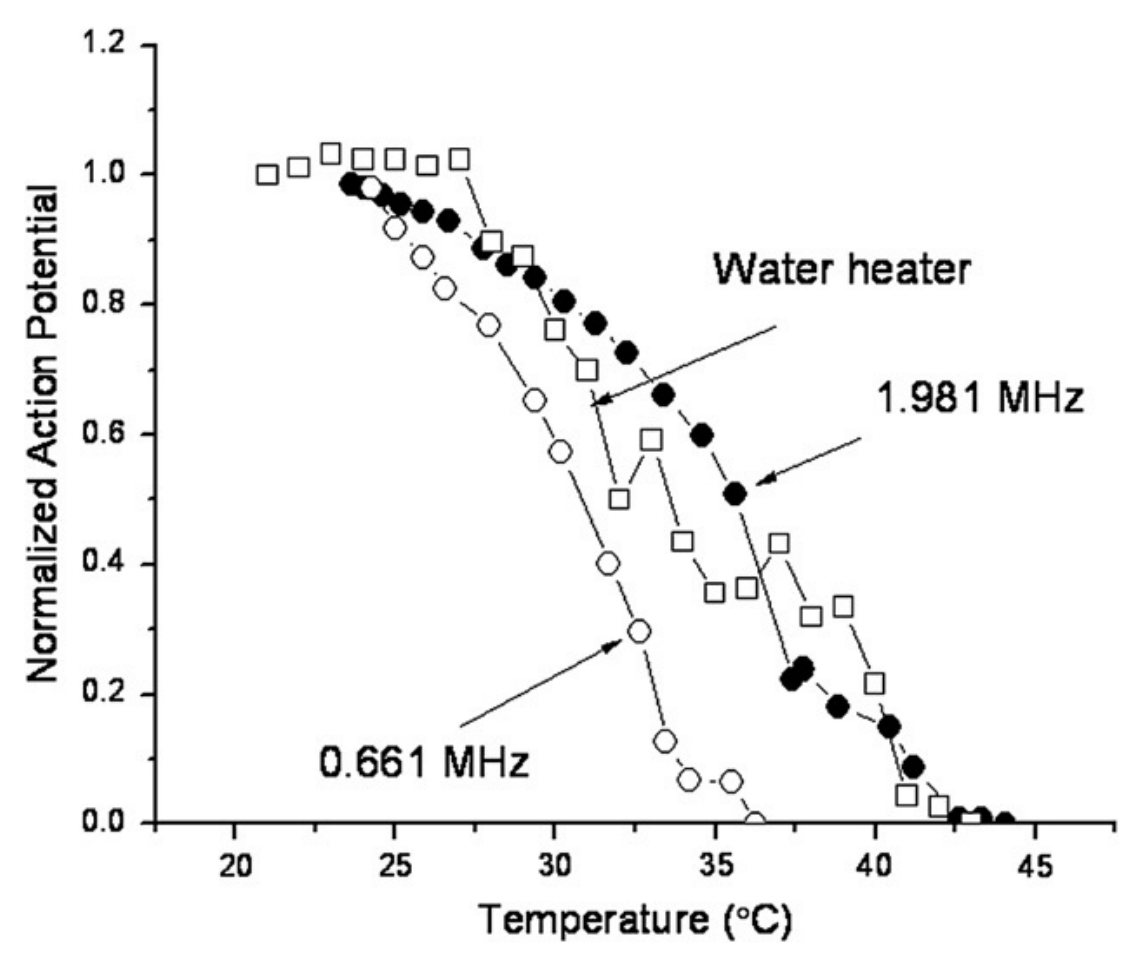

Figure 1.14: Action potential as a function of nerve temperature for the sonicated and water bath heated nerves (on nerve each) (Colucci et al. 2009)

In 2011, Jabbary demonstrated changes in CAP resulting directly from a range of ultrasound intensities applied to lobster's nerve. The ventral nerve cords from 40 lobsters (Homarus americanus) were exposed to 10 seconds of HIFU exposure at intensities of 100, 175, 275, 400, 525 , and $700 \mathrm{~W} / \mathrm{cm}^{2}$. The ventral nerve cords from 40 lobsters (Homarus americanus) were excised and placed into a nerve chamber. A $1.95 \mathrm{MHz}$ HIFU transducer filled with degassed water was used to apply the ultrasound to the nerve. A block diagram of the equipment is illustrated in figure 1.15 and a picture of the experimental setup is shown in figure 1.16. CAP was measured prior to sonication were used as a baseline value to compare CAP measurements that were taken after sonication. A typical CAP waveform before and after sonication is shown in figures 1.17 and figure 1.18 respectively. It was observed that CAP amplitudes post sonication 


\section{Chapter 1: Background and Introduction}

increased for intensities $100-525 \mathrm{~W} / \mathrm{cm}^{2}$ but dramatically decreased after sonications of 700 $\mathrm{W} / \mathrm{cm}^{2}$. Normalized CAP amplitudes vs focal intensity for 10s HIFU exposure are shown in figure 1.19 .

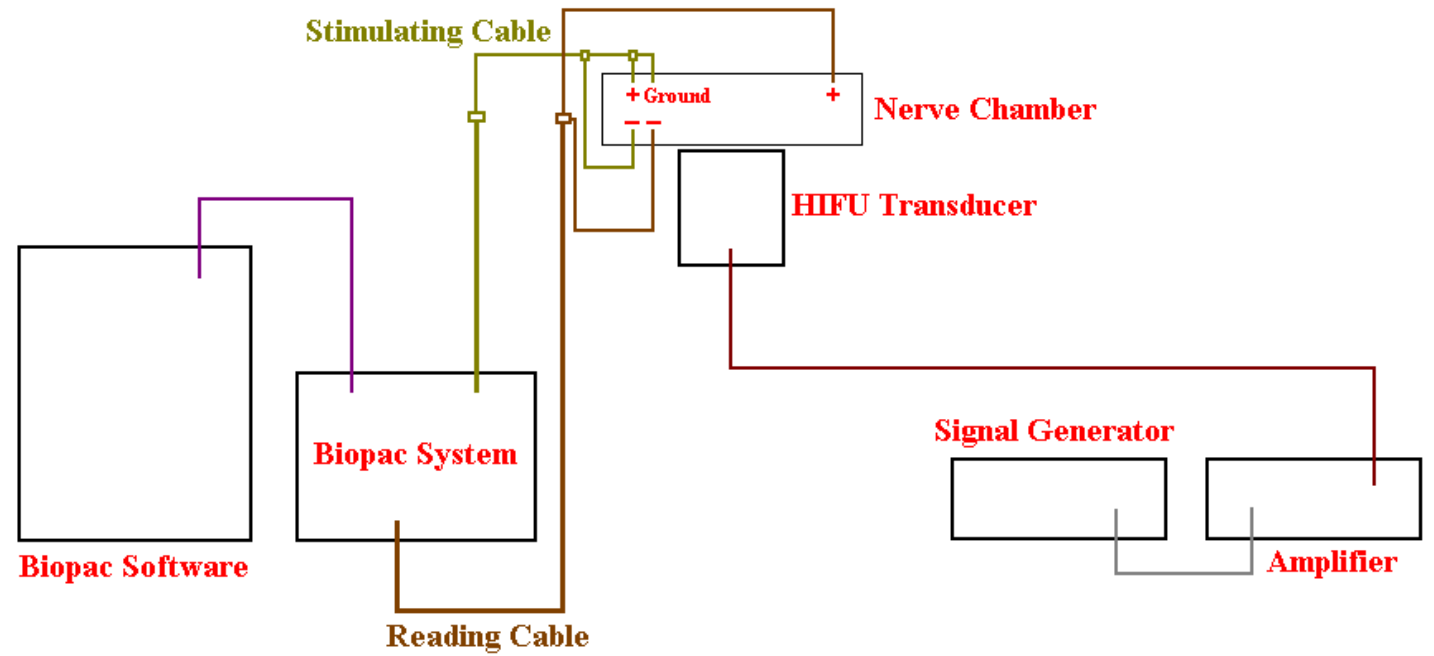

Figure 1.15: Block diagram of the experimental setup (Jabbary 2011)

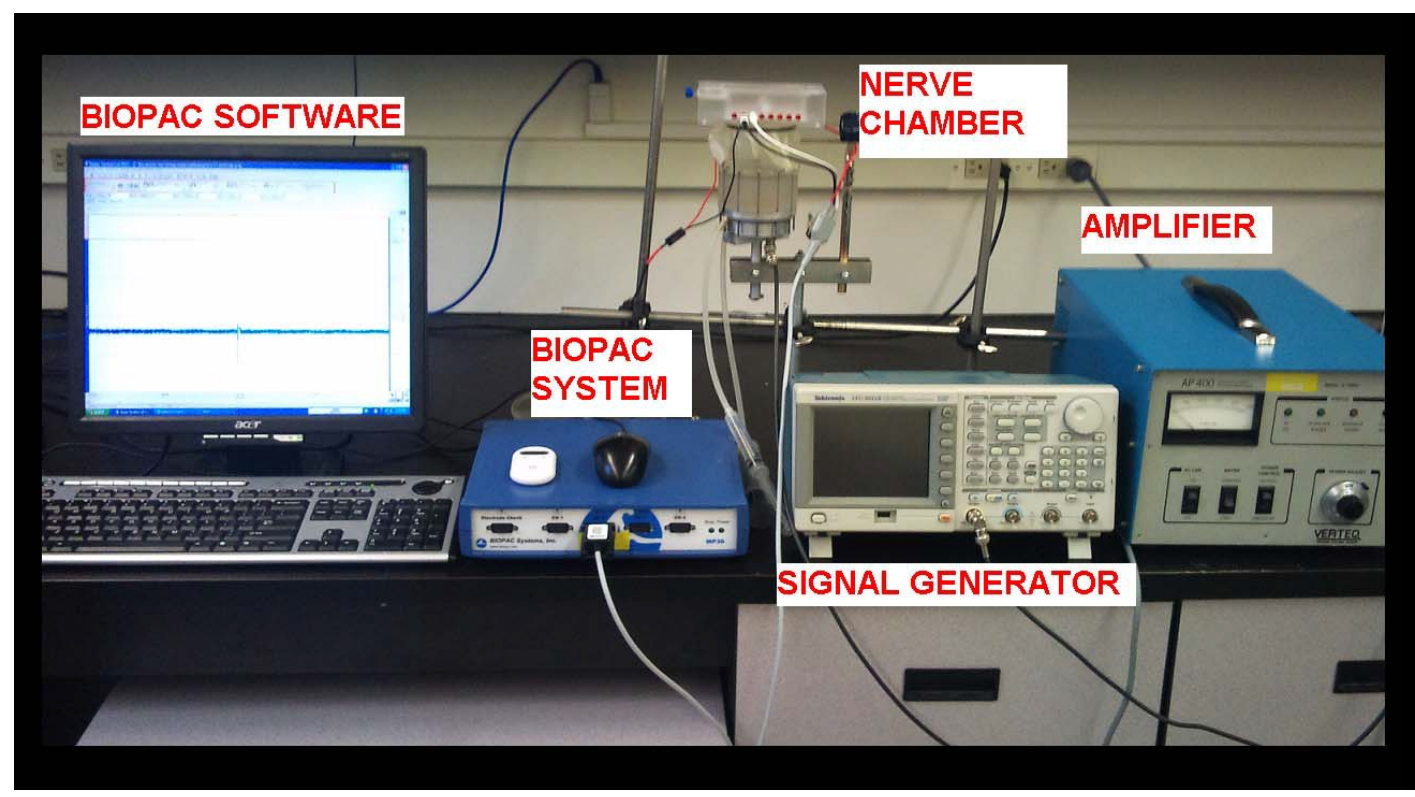

Figure 1.16: Picture of the experimental setup (Jabbary 2011) 


\section{Chapter 1: Background and Introduction}

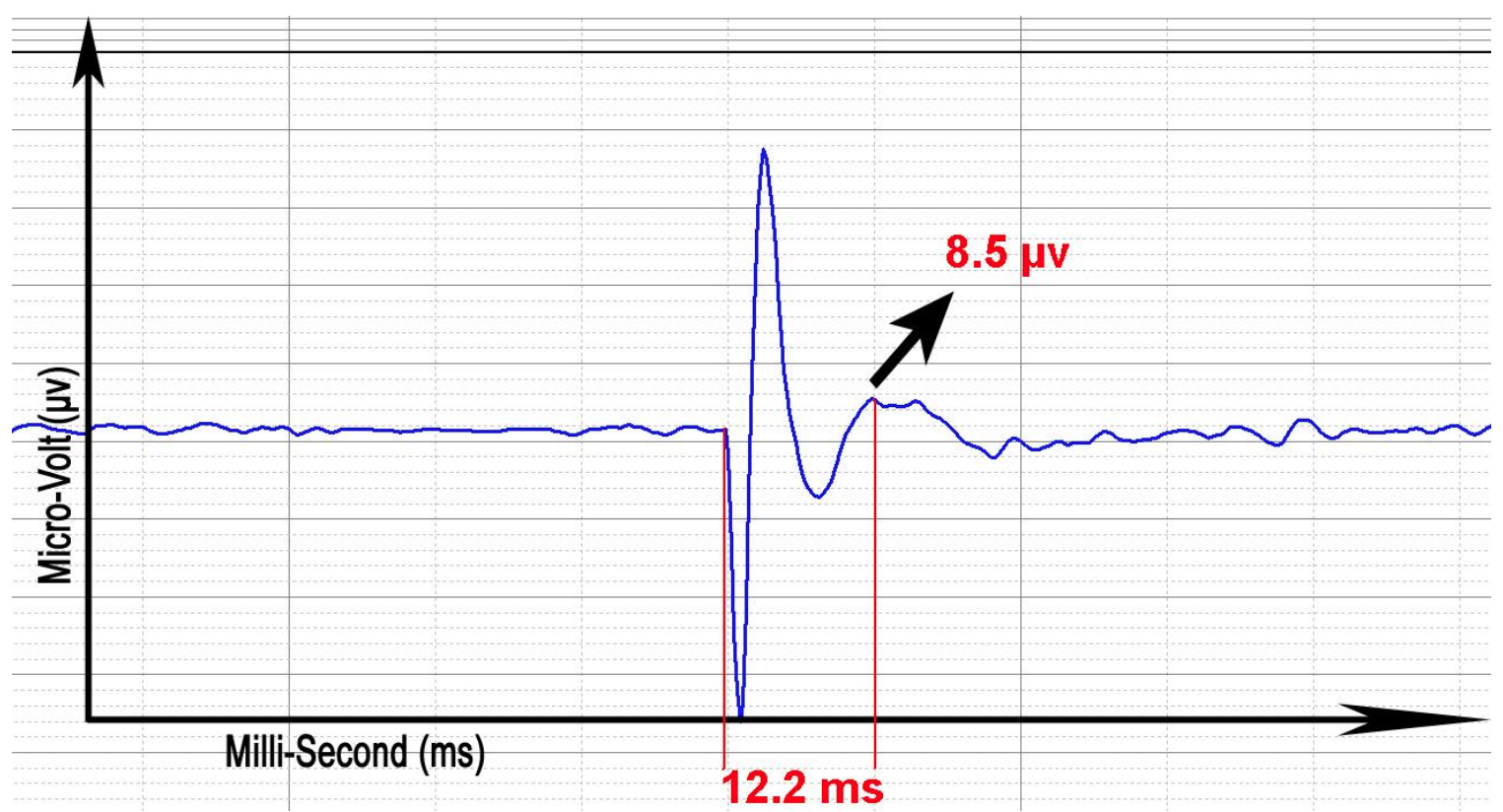

Figure 1.17: Baseline CAP measurement showing the CAP amplitude before the HIFU exposure of $400 \mathrm{~W} / \mathrm{cm}^{2}$ (Jabbary 2011)

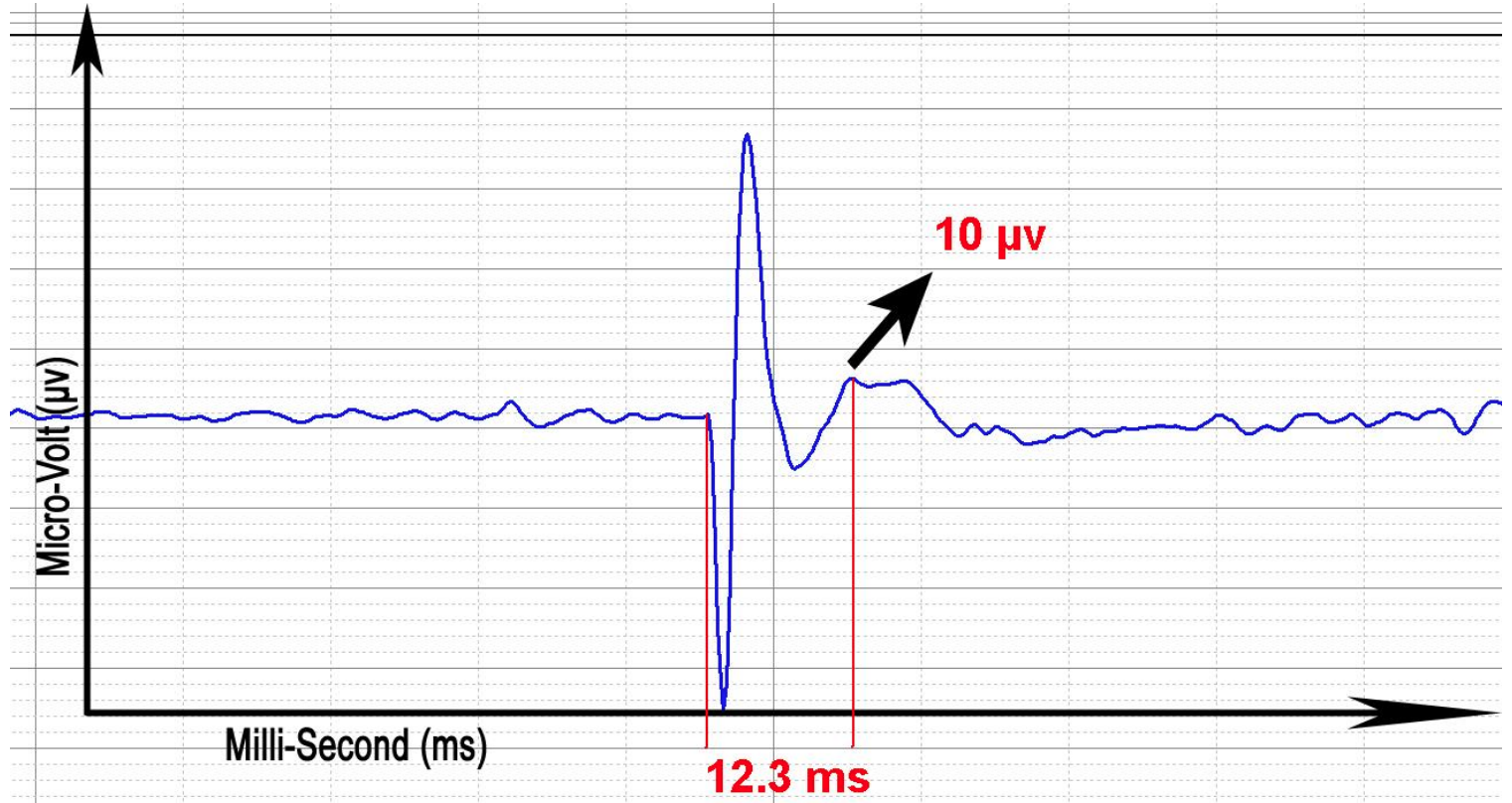

Figure 1.18: CAP measurement showing the CAP amplitude after the HIFU exposure of $400 \mathrm{~W} / \mathrm{cm}^{2}$ (Jabbary 2011) 


\section{Chapter 1: Background and Introduction}

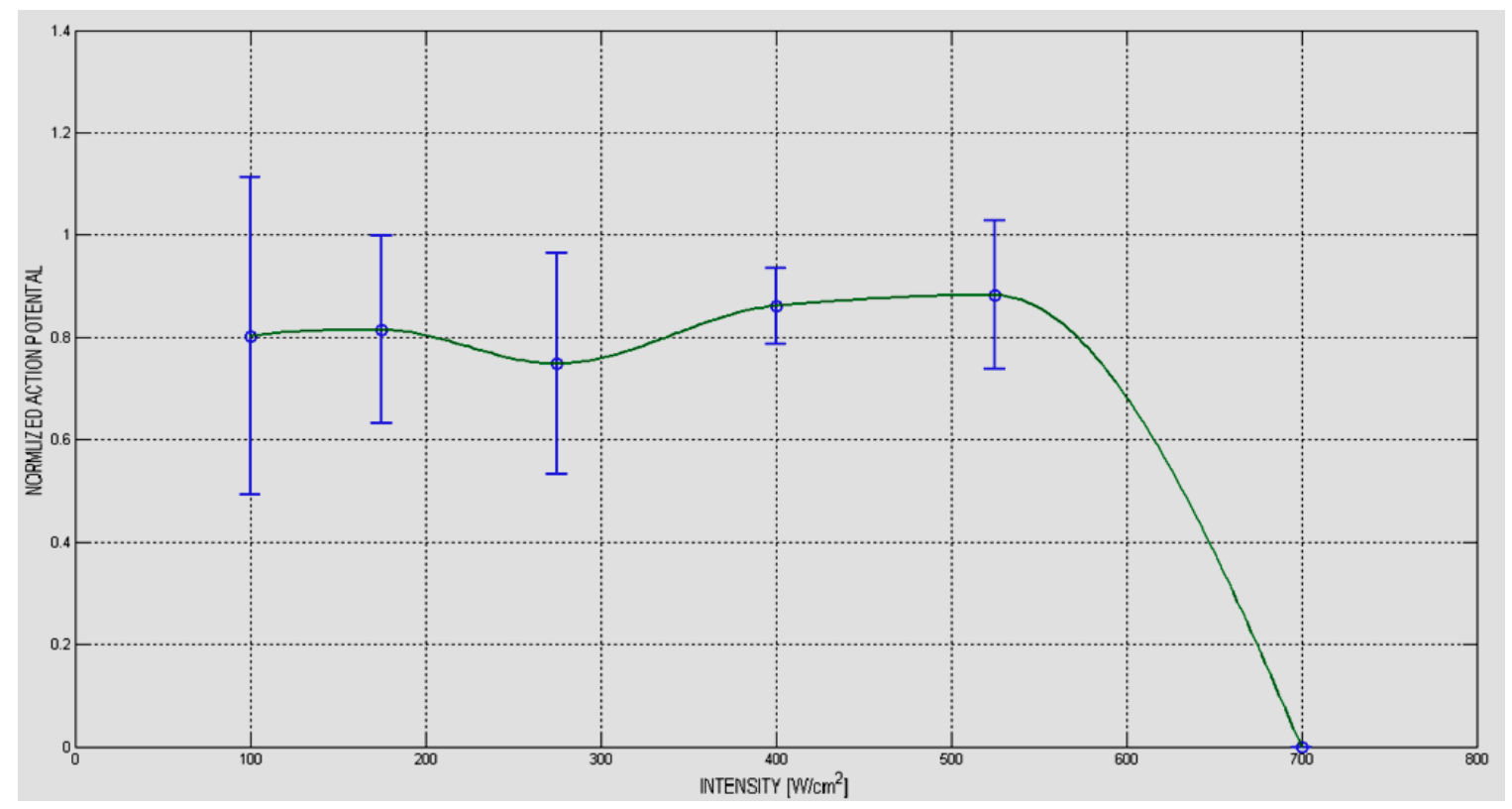

Figure 1.19: Normalized compound action potential (CAP) vs. focal intensity of a 10-s HIFU exposure (Jabbary 2011)

Beginning in 1990, Mihran and colleagues conducted a series of experiments determining the effects of focused pulsed ultrasound on neural tissue of several animals (Mihran et al. 1990a; 1990b; 1996). The animal nerve models used in these studies were the ventral nerve cord of the lobster and the sciatic nerve of the mouse and frog. A schematic of Mihran's experimental setup is shown in figure 1.20. The excised nerve was placed in the bathing medium with the proximal and distal nerve ends coming out of the bathing medium. 


\section{Chapter 1: Background and Introduction}

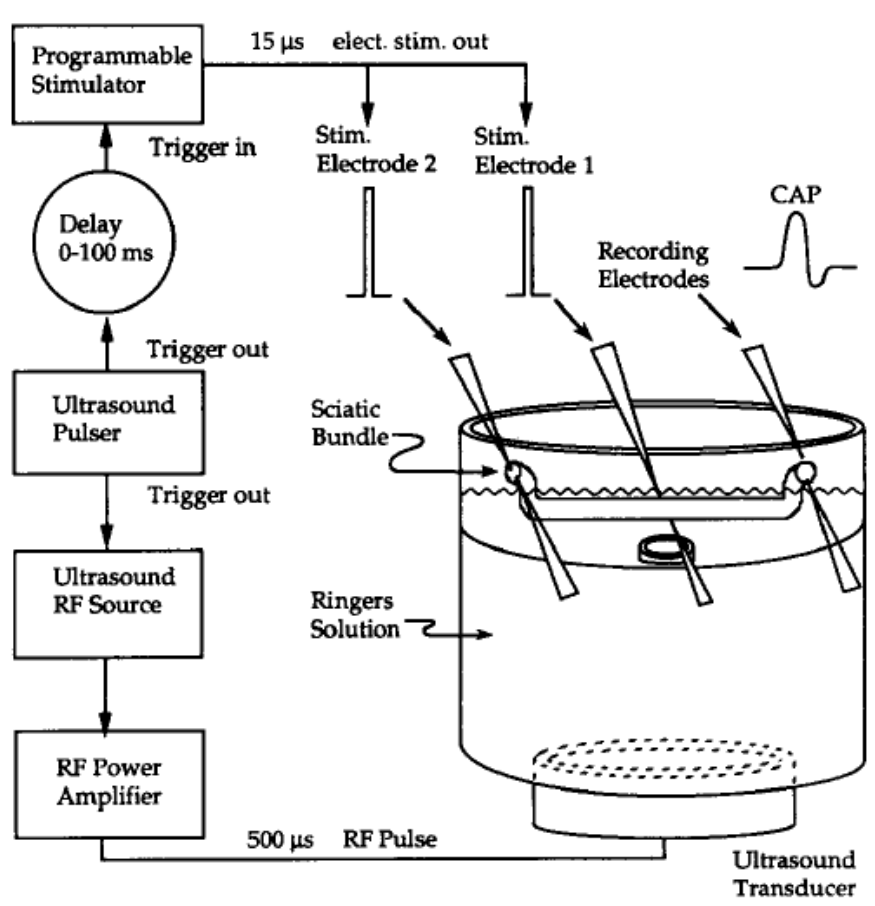

Figure 1.20: Schematic representation of experimental setup (Mihran et al. 1990a; 1990b; 1996)

Mihran et al. observed that frequency had no appreciable effect on CAP amplitude (figure 1.21). In a separate experiment, a standard protocol of a single burst ultrasound, $0.5 \mathrm{~ms}$ exposure time, at intensities of up to $800 \mathrm{~W} / \mathrm{cm}^{2}$ was applied to the nerves of the mouse and frog; CAP amplitudes were immediately measured after sonication. For the lobster experiments, the resting membrane potential of the nerve was recorded using a needle electrode to obtain the voltage difference between the inside versus the outside of the nerve cell. 


\section{Chapter 1: Background and Introduction}

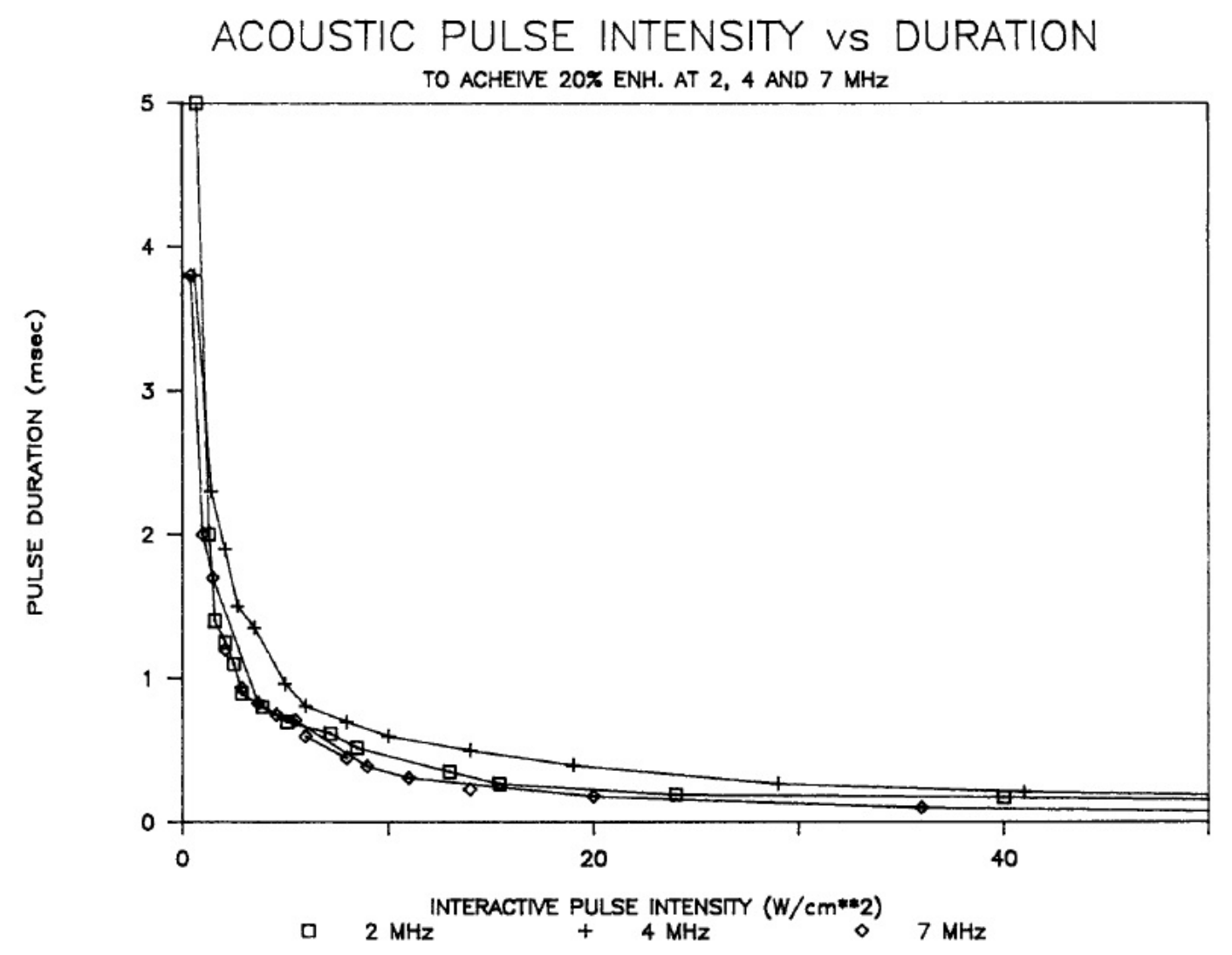

Figure 1.21: Ultrasound pulse intensity-duration plots at 2, 4, and $7 \mathrm{MHz}$; each point represents the pulse duration and ultrasound frequency needed to reduce normalized CAP amplitude by $20 \%$ of baseline value (Mihran et al. 1990a)

The ultrasound induced CAP amplitudes in the frog sciatic displayed either an excitatory or suppressive response even at the same intensity (figure 1.22). An excitatory response identified nerves that had an increase in nerve CAP following ultrasound application. Nerves that displayed a reduction in CAP amplitude were said to exhibit a suppressive response. It was determined by Mihran et al. that whether a nerve exhibited an excitatory response or suppressive response was dependent on the predisposition fibre type composition of the nerve. Nerves with a composition of mostly the faster type-A fibres exhibited a suppressive CAP response while nerves composed mostly of the slower type-B fibres exhibited an excitatory response. The 


\section{Chapter 1: Background and Introduction}

results in figure 1.22 were consistent with the CAP response at other intensities. The sciatic nerve of the mouse is comprised of mostly type A nerve fibres as was seen to exhibit a suppressive CAP response to the ultrasound protocol (figure 1.23). The results from the lobster experiment showed either hyperpolarization or depolarization in resting membrane potential after a single burst of pulsed ultrasound depending on the fibre type composition of the lobster nerve. Larger nerve types exhibited a hyperpolarization response, in that the resting membrane potential became more positive, while the resting membrane potential in smaller nerves became more negative.
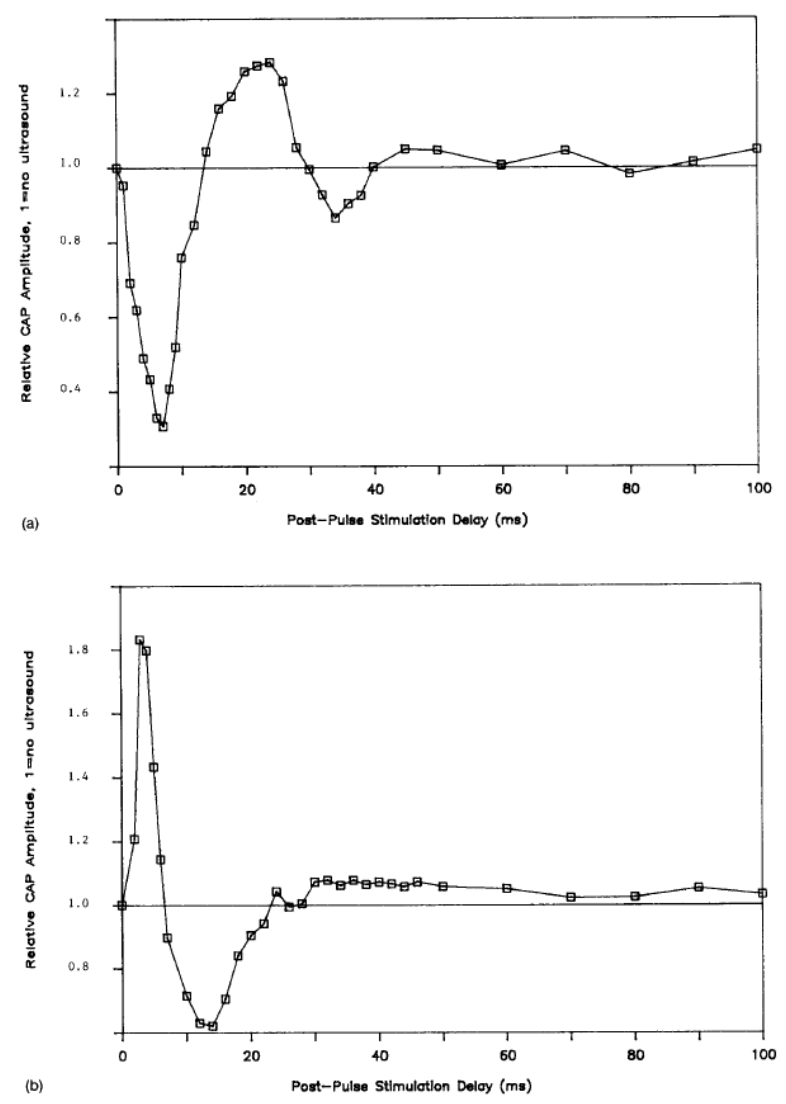

Figure 1.22: CAP amplitude response to pulsed ultrasound of a frog sciatic at $0.5 \mathrm{~ms}, 400$ W/cm2; a) typical suppressive response b) typical excitatory response (Mihran et al. 1990a) 


\section{Chapter 1: Background and Introduction}

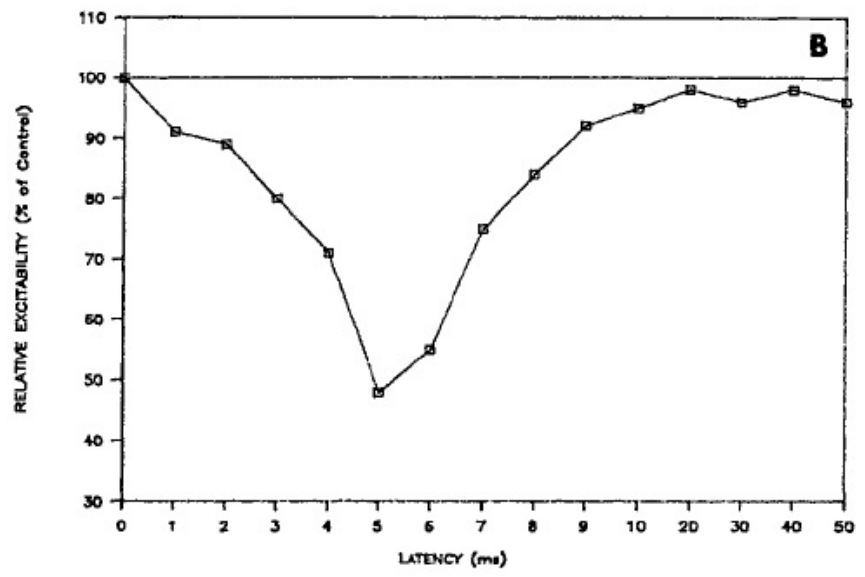

Figure 1.23: CAP amplitude response to pulsed ultrasound of a mouse sciatic (Mihran et al. 1996)

In 2012, Wahab and colleges conducted a study to examine how ultrasonic pressure pulses affect nerves through mechanisms that were neither thermal nor cavitational (Wahab et al. 2012). A neural model consisting of the giant axon of a worm was exposed to trains of pulses from an 825 $\mathrm{Hz}$ focused ultrasound transducer. The anaesthetized earth worms (Lumbricus terrestris) sliced down the ventral side and placed on an exposure apparatus so that the ventral nerve cord was exposed and could be approached from the top. The amplitude and conduction velocity of the nerve was measured using tungsten needle electrodes that were inserted into the worm. A diagram of the experimental apparatus is shown in figure 1.24. 


\section{Chapter 1: Background and Introduction}

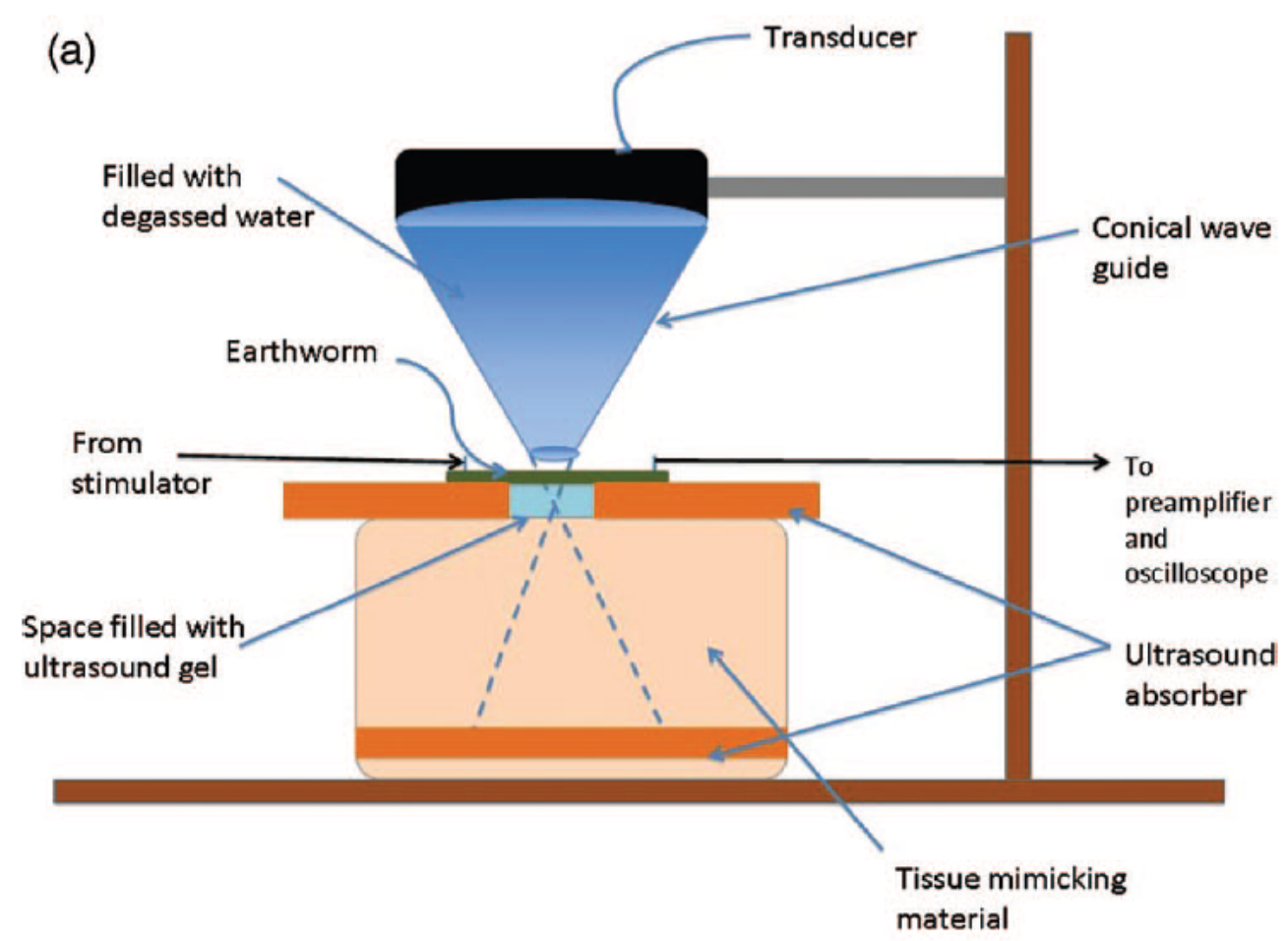

(b)

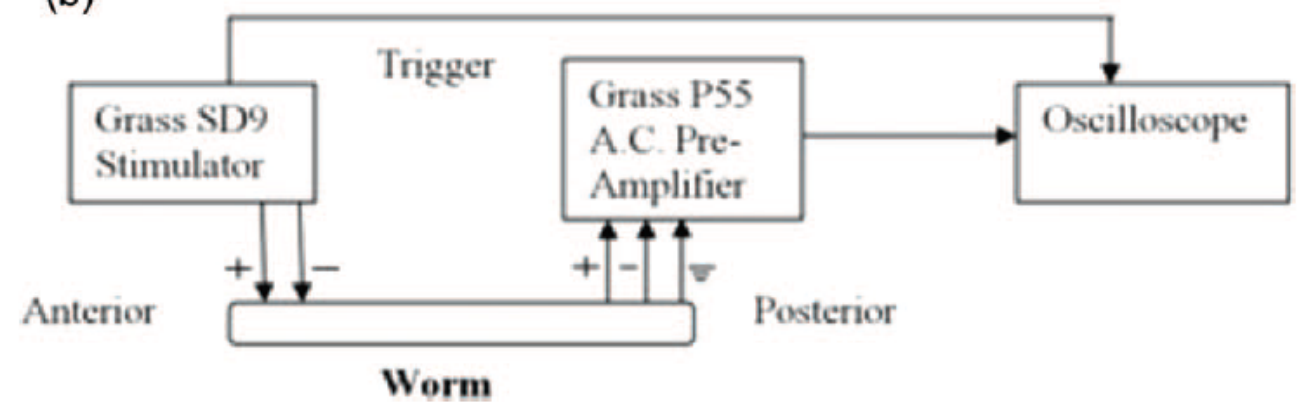

Figure 1.24: a) Experimental setup of worm experiment b) Electrical system used to stimulate and record CAP (Wahab 2012)

To prevent cavitation, the maximum pressure amplitude did not exceed $0.7 \mathrm{MPa}$. A duty cycle of $0.5 \%$ was used during these experiments and it was assumed by Wahab et al. that at this low duty cycle and pressure amplitude the ultrasound was operating in a non-thermal regime. In order to investigate how the action potential amplitude and velocity changed with variations in 


\section{Chapter 1: Background and Introduction}

radiation, the radiation force impulse (RFI) was calculated. RFI is a function of pressure amplitude and the on-time of the applied sonication. The formula used to calculate RFI was,

$$
R F I=\frac{2 \alpha \delta t_{\text {total }}}{\rho_{0} c_{0}^{2}} \frac{1}{T} \int_{0}^{T} p^{2}(t) d t
$$

where; $p(t)$ is the pressure variation, $T$ is the pulse repetition period, $t_{\text {total }}$ is the total length of ultrasound train, $\alpha$ is the attenuation of the worm, $\rho_{0}$ is the density of the worm, $c_{0}$ is the speed of sound in worm, and $\delta$ is the diameter of worm nerve. Data from a total of five separate worms were collected. The results, presented in figure 1.25 and 1.26 , showed a decrease in normalized action potential amplitude and conduction velocity as the cumulative RFI to the nerve increased.

Normalized Amplitude vs Cumulative Radiation-Force Impulse

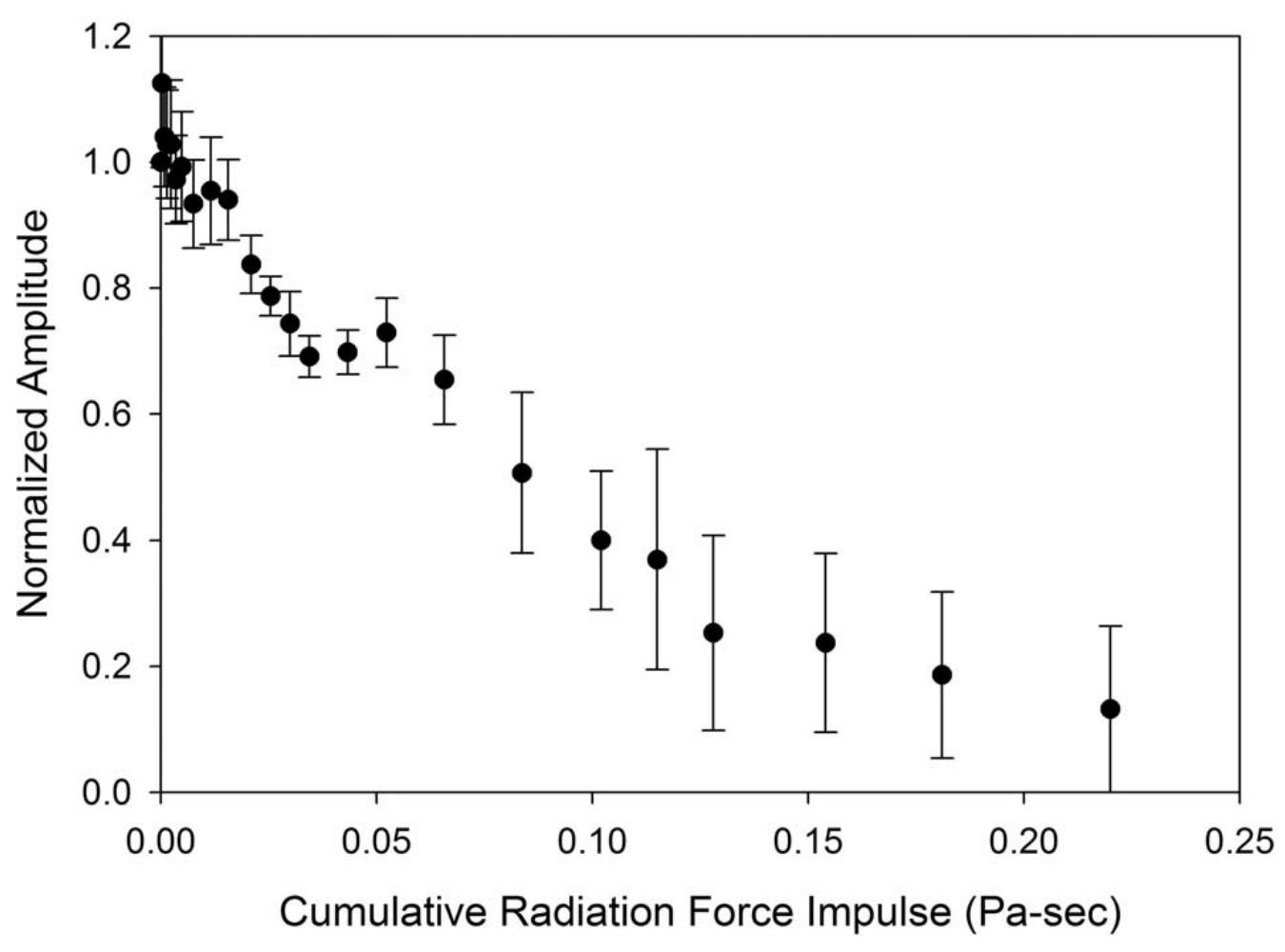

Figure 1.25: CAP response from pulsed ultrasound on a worm nerve (Wahab et al. 2012) 


\section{Chapter 1: Background and Introduction}

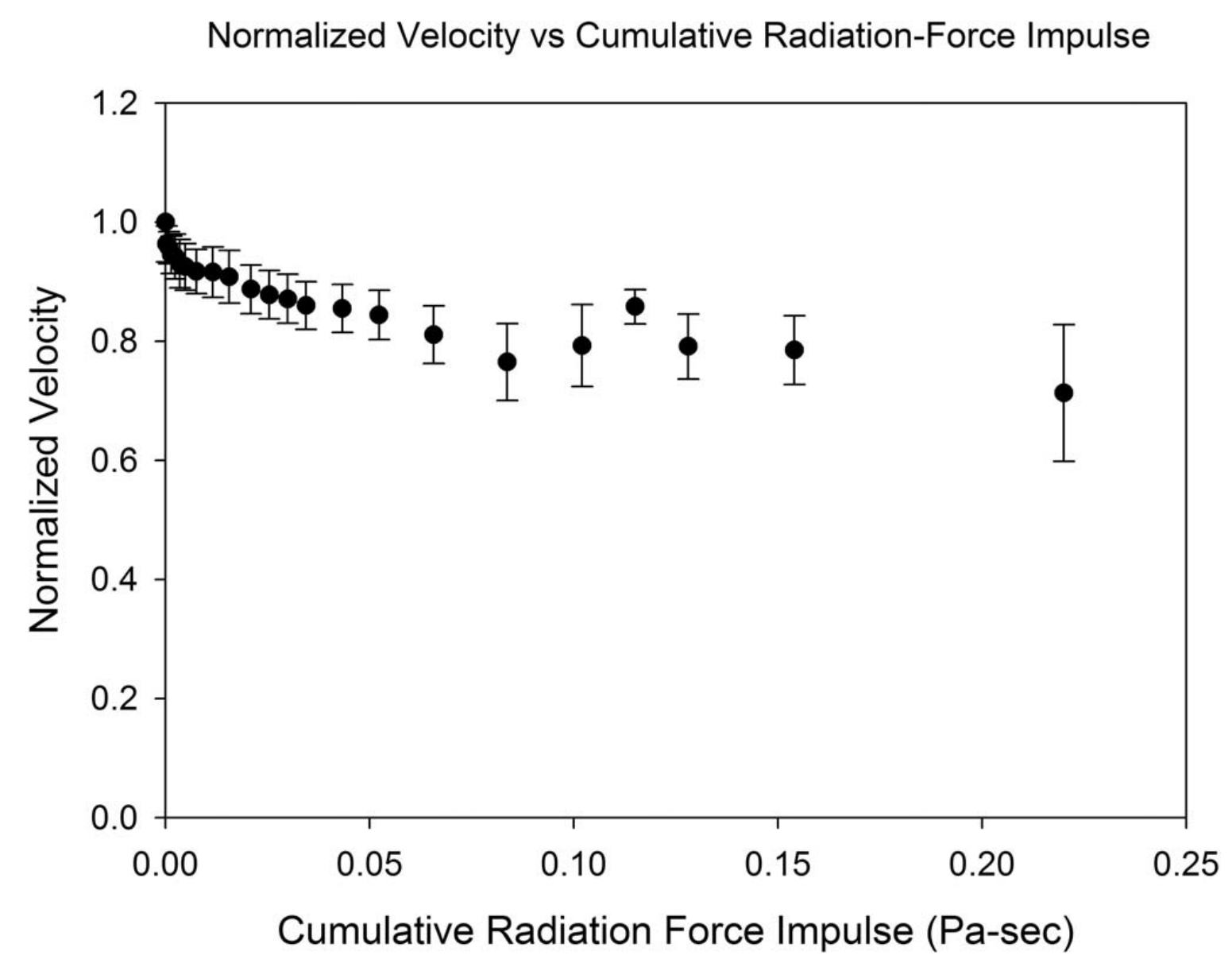

Figure 1.26: Conduction velocity response from pulsed ultrasound on a worm nerve (Wahab et al. 2012)

In addition to the studies reviewed in this section, there have been several more studies using different nerve species and outcome measures. Table 1.3, summarizes a field study of the past experiments that have used ultrasound on nervous tissue. 


\section{Chapter 1: Background and Introduction}

Table 1.3: Field survey of ultrasound-induced effects on nervous tissue

\begin{tabular}{|c|c|c|c|c|}
\hline Species & Nerve Type & Ultrasound Protocol & Nerve Response & Reference \\
\hline $\begin{array}{l}\text { cat (in } \\
\text { vivo) }\end{array}$ & $\begin{array}{l}\text { CNS: cortex } \\
\text { and internal } \\
\text { capsule of } \\
\text { the brain }\end{array}$ & $\begin{array}{c}\text { particle velocities of } 170 \text { - } \\
420 \mathrm{~cm} / \mathrm{sec} ; 1-7 \text { seconds } \\
\text { continuous duration; } 2 \mathrm{MPa}- \\
4.8 \mathrm{MPa} \text { pressure amplitudes }\end{array}$ & $\begin{array}{l}\text { lesions formed in } \\
\text { all cases; survival } \\
\text { times ranged from } \\
2 \text { hours - } 32 \text { days }\end{array}$ & $\begin{array}{l}\text { Bernard et } \\
\text { al. } 1955\end{array}$ \\
\hline $\begin{array}{l}\text { human } \\
\text { (in vivo) }\end{array}$ & $\begin{array}{l}\text { sensory } \\
\text { nerves of } \\
\text { the hand } \\
\text { and inner } \\
\quad \text { ear }\end{array}$ & $\begin{array}{c}\text { frequencies of } 0.48-2.67 \\
\mathrm{MHz} ; 1,10,100 \mathrm{~ms} \text { duration; } \\
\text { intensities increased, up to } \\
1100 \mathrm{~W} / \mathrm{cm}^{2} \text {, until threshold } \\
\text { response seen }\end{array}$ & $\begin{array}{l}\text { sensations of heat, } \\
\text { touch, pain, and } \\
\text { auditory sound } \\
\text { were induced }\end{array}$ & $\begin{array}{c}\text { Gavrilov et } \\
\text { al. } 1996\end{array}$ \\
\hline $\begin{array}{l}\text { bullfrog } \\
\text { (in vitro) }\end{array}$ & $\begin{array}{l}\text { sciatic } \\
\text { nerve }\end{array}$ & $\begin{array}{c}3.5 \mathrm{MHz} \text {; continuous } \\
\text { exposure for } 5 \text { mins; } 1,2 \text {, and } \\
3 \text { watts at a focal beam width } \\
\text { of } 4.8 \mathrm{~mm}\end{array}$ & $\begin{array}{l}\text { conduction velocity } \\
\text { of nerve increased } \\
\text { for all powers; } \\
\text { CAP increased at } 1 \\
\text { W, decreased at } 2 \\
\text { and } 3 \mathrm{~W}\end{array}$ & $\begin{array}{c}\text { Tsui et al. } \\
2005\end{array}$ \\
\hline $\begin{array}{l}\text { rabbit (in } \\
\text { vivo) }\end{array}$ & $\begin{array}{l}\text { sciatic } \\
\text { nerve }\end{array}$ & $\begin{array}{l}\text { 3.2 } \mathrm{MHz} \text {; continuous duration } \\
\text { of } 5 \mathrm{~seconds} ; 1920 \mathrm{~W} / \mathrm{cm}^{2} \\
\text { intensity }\end{array}$ & $\begin{array}{l}\text { lesions formed in } \\
\text { all cases; the mean } \\
\text { force response of } \\
\text { the leg muscle } \\
\text { innervated by the } \\
\text { sciatic nerve } \\
\text { decreased } \\
\text { gradually over a } \\
\text { period of } 14 \text { days }\end{array}$ & $\begin{array}{l}\text { Foley et al. } \\
\quad 2006\end{array}$ \\
\hline
\end{tabular}




\section{Chapter 1: Background and Introduction}

Table 1.3: Field survey of ultrasound induced effects on nerve tissue (continued)

\begin{tabular}{|c|c|c|c|c|}
\hline Species & Nerve Type & Ultrasound Protocol & Nerve Response & Reference \\
\hline $\begin{array}{l}\text { cat (in } \\
\text { vivo) }\end{array}$ & $\begin{array}{l}\text { CNS: cortex } \\
\text { and internal } \\
\text { capsule of } \\
\text { the brain }\end{array}$ & $\begin{array}{l}\text { particle velocities of } 170-420 \\
\mathrm{~cm} / \mathrm{sec} ; 1-7 \text { seconds } \\
\text { continuous duration; } 2 \mathrm{MPa}- \\
4.8 \mathrm{MPa} \text { pressure amplitudes }\end{array}$ & $\begin{array}{l}\text { lesions formed in all } \\
\text { cases; survival times } \\
\text { ranged from } 2 \text { hours } \\
\text { - } 32 \text { days }\end{array}$ & $\begin{array}{c}\text { Bernard et } \\
\text { al. } 1955\end{array}$ \\
\hline $\begin{array}{l}\text { human } \\
\qquad \text { (in } \\
\text { vivo) }\end{array}$ & $\begin{array}{l}\text { sensory } \\
\text { nerves of } \\
\text { the hand } \\
\text { and inner } \\
\text { ear }\end{array}$ & $\begin{array}{l}\text { frequencies of } 0.48-2.67 \\
\mathrm{MHz} ; 1,10,100 \mathrm{~ms} \text { duration; } \\
\text { intensities increased, up to } \\
1100 \mathrm{~W} / \mathrm{cm}^{2} \text {, until threshold } \\
\text { response seen }\end{array}$ & $\begin{array}{l}\text { sensations of heat, } \\
\text { touch, pain, and } \\
\text { auditory sound were } \\
\text { induced }\end{array}$ & $\begin{array}{c}\text { Gavrilov } \\
\text { et al. } 1996\end{array}$ \\
\hline $\begin{array}{l}\text { bullfrog } \\
\qquad \text { (in } \\
\text { vitro) }\end{array}$ & $\begin{array}{l}\text { sciatic } \\
\text { nerve }\end{array}$ & $\begin{array}{l}3.5 \mathrm{MHz} \text {; continuous exposure } \\
\text { for } 5 \mathrm{mins} \text {; } 1,2 \text {, and } 3 \text { watts at } \\
\text { a focal beam width of } 4.8 \mathrm{~mm}\end{array}$ & $\begin{array}{l}\text { conduction velocity } \\
\text { of nerve increased } \\
\text { for all powers; CAP } \\
\text { increased at } 1 \mathrm{~W} \text {, } \\
\text { decreased at } 2 \text { and } \\
3 \mathrm{~W}\end{array}$ & $\begin{array}{c}\text { Tsui et al. } \\
2005\end{array}$ \\
\hline $\begin{array}{l}\text { rabbit } \\
\quad(\text { in } \\
\text { vivo })\end{array}$ & $\begin{array}{l}\text { sciatic } \\
\text { nerve }\end{array}$ & $\begin{array}{l}3.2 \mathrm{MHz} \text {; continuous duration } \\
\text { of } 5 \mathrm{~seconds} ; 1920 \mathrm{~W} / \mathrm{cm}^{2} \\
\text { intensity }\end{array}$ & $\begin{array}{l}\text { lesions formed in all } \\
\text { cases; the mean } \\
\text { force response of the } \\
\text { leg muscle } \\
\text { innervated by the } \\
\text { sciatic nerve } \\
\text { decreased gradually } \\
\text { over a period of } 14 \\
\text { days }\end{array}$ & $\begin{array}{l}\text { Foley et } \\
\text { al. } 2006\end{array}$ \\
\hline
\end{tabular}




\section{Chapter 1: Background and Introduction}

Table 1.3: Field survey of ultrasound induced effects on nerve tissue (continued)

\begin{tabular}{ccccc}
\hline Species & Nerve Type & Ultrasound Protocol & Nerve response & Reference \\
\hline
\end{tabular}

$\begin{array}{cl}\text { rats (in } & \text { sciatic } \\ \text { vivo) } & \text { nerve }\end{array}$

5.7 MHz; continuous exposure for 5 seconds; intensities of 390, 2255, $3310,7890 \mathrm{~W} / \mathrm{cm}^{2}$
CAP amplitude

decreased as

intensities increased;

physical damage

seen during Foley et

histological analysis. al. 2008

CAP amplitude

returned to baseline

at 3 lower intensities

after 28 days

\begin{tabular}{|c|c|c|c|c|}
\hline $\begin{array}{l}\text { toad (in } \\
\text { vitro) }\end{array}$ & $\begin{array}{l}\text { sciatic } \\
\text { nerve }\end{array}$ & $\begin{array}{l}1.2 \mathrm{MHz} ; 5 \mathrm{~min} \text {. of } \\
\text { continuous sonication; } 180 \mathrm{~W} \\
\text { power }\end{array}$ & $\begin{array}{l}\text { CAP amplitude } \\
\text { decreased } \\
\text { significantly after } 26 \\
\pm 3 \text { seconds of } \\
\text { sonication; nerve } \\
\text { CAPs showed some } \\
\text { recoverability if } \\
\text { ultrasound was } \\
\text { stopped prior to } \\
\text { nerve death }\end{array}$ & $\begin{array}{c}\text { Yu et al. } \\
2008\end{array}$ \\
\hline
\end{tabular}




\section{Chapter 1: Background and Introduction}

Table 1.3: Field survey of ultrasound induced effects on nerve tissue (continued)

\begin{tabular}{|c|c|c|c|c|}
\hline Species & Nerve Type & Ultrasound Protocol & Nerve Response & Reference \\
\hline $\begin{array}{l}\text { bullfrog } \\
\qquad \text { (in } \\
\text { vitro) }\end{array}$ & $\begin{array}{l}\text { sciatic } \\
\text { nerve }\end{array}$ & $\begin{array}{l}\text { frequencies of } 0.661-1.981 \\
\mathrm{MHz} ; 30 \text { seconds continuous } \\
\text { sonication; peak focal } \\
\text { intensities up to } 875 \mathrm{~W} / \mathrm{cm}^{2}\end{array}$ & $\begin{array}{l}\text { decrease in } \\
\text { normalized CAP } \\
\text { amplitude as peak } \\
\text { intensity increased, } \\
\text { CAP results show } \\
\text { similarity to } \\
\text { increasing nerve } \\
\text { temp and no } \\
\text { ultrasound }\end{array}$ & $\begin{array}{l}\text { Colucci et } \\
\text { al. } 2009\end{array}$ \\
\hline $\begin{array}{l}\text { lobster } \\
\text { (in } \\
\text { vitro) }\end{array}$ & $\begin{array}{l}\text { ventral } \\
\text { nerve cord }\end{array}$ & $\begin{array}{l}1.94 \mathrm{MHz} ; 10 \text { seconds } \\
\text { continuous sonication; } \\
\text { intensities of: } 100,175,275 \text {, } \\
400,525 \text {, and } 700 \mathrm{~W} / \mathrm{cm}^{2}\end{array}$ & $\begin{array}{l}\text { increase in } \\
\text { normalized CAP } \\
\text { amplitude for } \\
\text { intensities } 100-525 \\
\mathrm{~W} / \mathrm{cm}^{2} \text { and } \\
\text { decreased for } \\
\text { intensites } 525-700 \\
\mathrm{~W} / \mathrm{cm}^{2} \text { with total } \\
\mathrm{CAP} \text { reduction at } \\
700 \mathrm{~W} / \mathrm{cm}^{2}\end{array}$ & $\begin{array}{c}\text { Jabbary } \\
2011\end{array}$ \\
\hline
\end{tabular}




\section{Chapter 1: Background and Introduction}

Table 1.3: Field survey of ultrasound induced effects on nerve tissue (continued)

\begin{tabular}{|c|c|c|c|c|}
\hline Species & Nerve Type & Ultrasound Protocol & Nerve Response & Reference \\
\hline $\begin{array}{l}\text { frogs } \\
\text { (in } \\
\text { vitro) }\end{array}$ & $\begin{array}{l}\text { sciatic } \\
\text { nerve }\end{array}$ & $\begin{array}{l}\text { frequencies of } \\
2-7 \mathrm{MHz} \text {; single bursts of } \\
0.5 \mathrm{~ms} \text {; spatial-peak, pulse } \\
\text { average intensities } 50-800 \\
\mathrm{~W} / \mathrm{cm}^{2}\end{array}$ & $\begin{array}{l}\text { CAP enhancement in } \\
\text { type A nerve fibres; } \\
\text { CAP suppression in } \\
\text { type B nerve fibres; } \\
\text { Effects reversible; } \\
\text { CAP changes occur } \\
\text { in } 50 \text { ms window } \\
\text { following exposure; } \\
\text { frequencies did not } \\
\text { have a significant } \\
\text { effect on CAP } \\
\text { modulation }\end{array}$ & $\begin{array}{l}\text { Mihran et } \\
\text { al. } 1990 \mathrm{a}\end{array}$ \\
\hline
\end{tabular}

Observed changes in resting membrane potential following an ultrasound pulse;

$\begin{array}{cll}\text { lobster } & \text { ventral } & \begin{array}{l}\text { frequencies of 2 MHz; single } \\ \text { (in }\end{array} \\ \text { vitro) } & \text { nerve cord } & \begin{array}{l}\text { pulse of } 0.5 \mathrm{~ms} \text {; spatial-peak, } \\ 800 \mathrm{~W} / \mathrm{cm}^{2}\end{array}\end{array}$
Large fibre types (giant axons) were seen to hyperpolarize; Small Mihran et fibre types depolarized; changes in resting potential lasted only $0-35 \mathrm{~ms}$ after exposure 


\section{Chapter 1: Background and Introduction}

Table 1.3: Field survey of ultrasound induced effects on nerve tissue (continued)

\begin{tabular}{|c|c|c|c|c|}
\hline Species & Nerve Type & Ultrasound Protocol & Nerve Response & Reference \\
\hline $\begin{array}{l}\text { mouse } \\
\text { (in } \\
\text { vitro) }\end{array}$ & $\begin{array}{l}\text { sciatic } \\
\text { nerve }\end{array}$ & $\begin{array}{l}\text { frequencies of } 2 \mathrm{MHz} \text {; single } \\
\text { bursts of } 0.5 \mathrm{~ms} \text {; spatial-peak, } \\
\text { pulse average intensities } 100- \\
800 \mathrm{~W} / \mathrm{cm}^{2}\end{array}$ & $\begin{array}{l}\text { Peak suppression of } \\
\text { CAP amplitudes } \\
\text { were observed 3-4 } \\
\text { ms following } \\
\text { ultrasound burst; } \\
\text { CAP amplitudes } \\
\text { returned to baseline } \\
\text { values within 10-12 } \\
\text { ms }\end{array}$ & $\begin{array}{l}\text { Mihran et } \\
\text { al. } 1996\end{array}$ \\
\hline $\begin{array}{l}\text { worm } \\
\text { (in } \\
\text { vivo) }\end{array}$ & $\begin{array}{l}\text { ventral } \\
\text { nerve cord }\end{array}$ & $\begin{array}{l}\text { frequncy of } 825 \mathrm{kHz} \text {; pressure } \\
\text { amplitude up to } 0.7 \mathrm{MPa} \text {; } \\
\text { increasing exposure times }\end{array}$ & $\begin{array}{l}\text { Normalized action } \\
\text { potential and } \\
\text { conduction velocity } \\
\text { of nerve decreased }\end{array}$ & $\begin{array}{l}\text { Wahab et } \\
\text { al. } 2012\end{array}$ \\
\hline
\end{tabular}

\subsection{Thesis Hypothesis and Contribution}

It is hypothesized that the compound action potential and conduction velocity of a nerve can be modulated by non-thermal mechanisms of ultrasound. Pulsed HIFU at high intensities ( 1000 $\mathrm{W} / \mathrm{cm}^{2}$ ) and low pulse duty cycles $(10 \%)$ will decrease nerve function in the form of compound action potential and conduction velocity.

The experiments in this study can be used as a launching point for the parameters and protocol used to induce temporary suppression of nerve function that is non-thermal and incurs minimal trauma to the nerve compared to already existing continuous ultrasonic therapy, which produce bioeffects primarily caused by thermal energy. The results of this study have clinical relevance to potential ultrasonic therapies that treat pain and spasticity. Additionally, based on this study, it is anticipated that further exploration of pulsed HIFU may lead a therapeutic ultrasound protocol that induces temporary and fully reversible suppression of nerve function 


\section{Chapter 2 : Materials and Methods}

\section{1 pHIFU Transducer Construction and Characterization}

A single element transducer was used in this study. The transducer was made from PZT4 (Boston Peizoptics, Bellingham, USA), a high power piezo-electric ceramic. The transducer was constructed in a spherical concave shape. The transducer element was $50 \mathrm{~mm}$ in aperture diameter and its concave geometry had a radius of curvature of $120 \mathrm{~mm}$. A picture of the transducer is shown in figure 2.1. A plexiglass/metal nose piece houses the element and contains the coupling medium (degassed, deionized water). A $1 \mathrm{~cm}$, circular, opening serves as the exit point of the ultrasound beam; this also aids in locating the beam focal point. The opening was constructed to lie proximally $1 \mathrm{~mm}$ from the actual focal point. The actual focal point was verified in an experiment using a calibrated hydrophone, described in the following section. A drawing of the transducer dimensions is presented in figure 2.2.

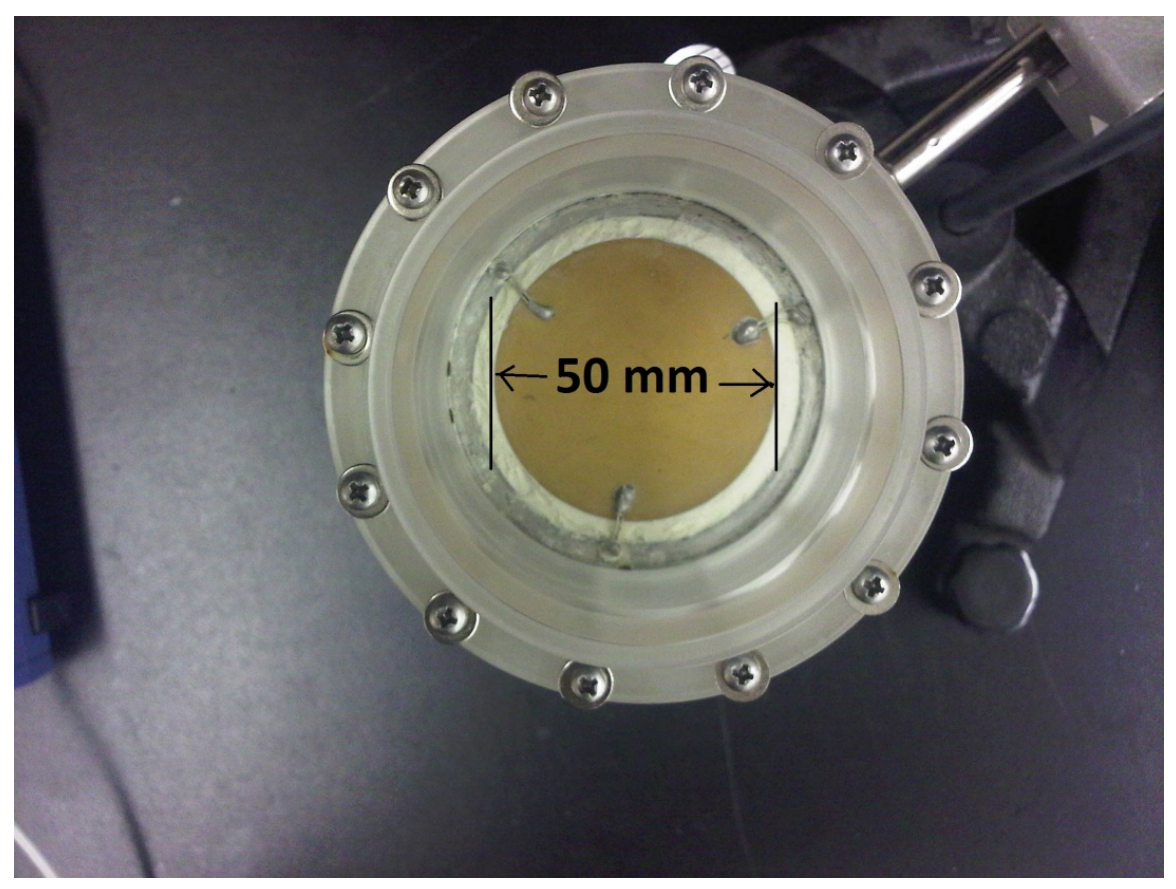

Figure 2.1: Top view of pHIFU transducer 


\section{Chapter 2: Materials and Methods}

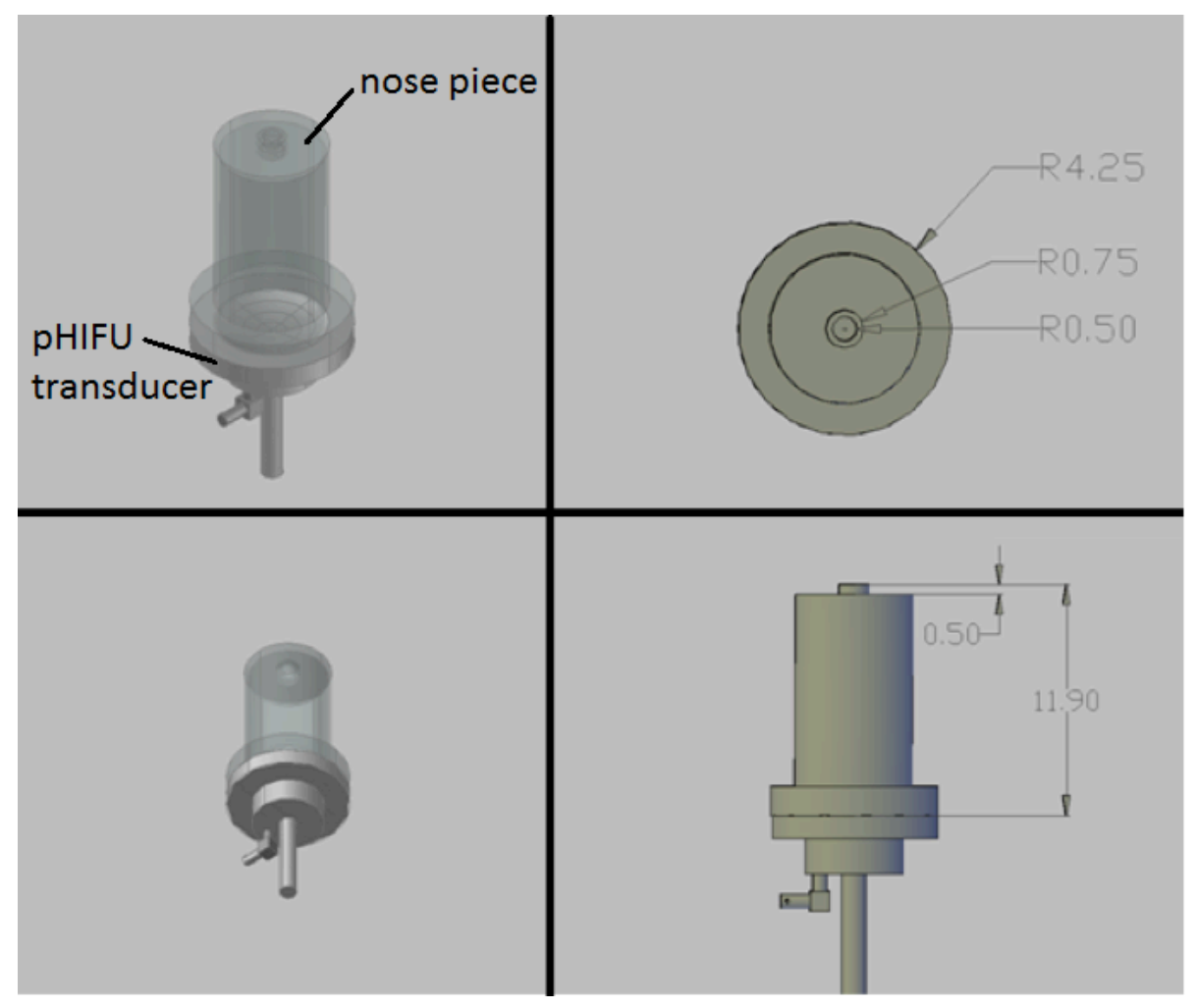

Figure 2.2: pHIFU transducer with plexiglass attachment. Dimensions are in $\mathrm{cm}$

The transducer was powered by a function generator (Tektronix-AFG3022B, Tektronix, Beaverton, USA) via a RF amplifier (2100L, E\&I, Rochester, USA). Waveform and input settings for the ultrasound transducer were controlled on the function generator. For all the experiments described in this thesis, a sinusoidal waveform was used. The waveform frequency was set to $1.95 \mathrm{MHz}$ as it was found to be the resonant frequency of the transducer.

\subsection{Locating the Focal Point of the pHIFU Beam}

To locate the focal point of the ultrasound beam, the pHIFU transducer was placed in a water tank and aimed at the tip of a hydrophone (HNA, ONDA Corp, Sunnyvale, USA). The 


\section{Chapter 2: Materials and Methods}

hydrophone was attached to 3D positioning system that allowed adjustments to the hydrophone location with an accuracy of $\pm 0.1 \mathrm{~mm}$. Figure 2.3 shows the setup of the pHIFU transducer and hydrophone.

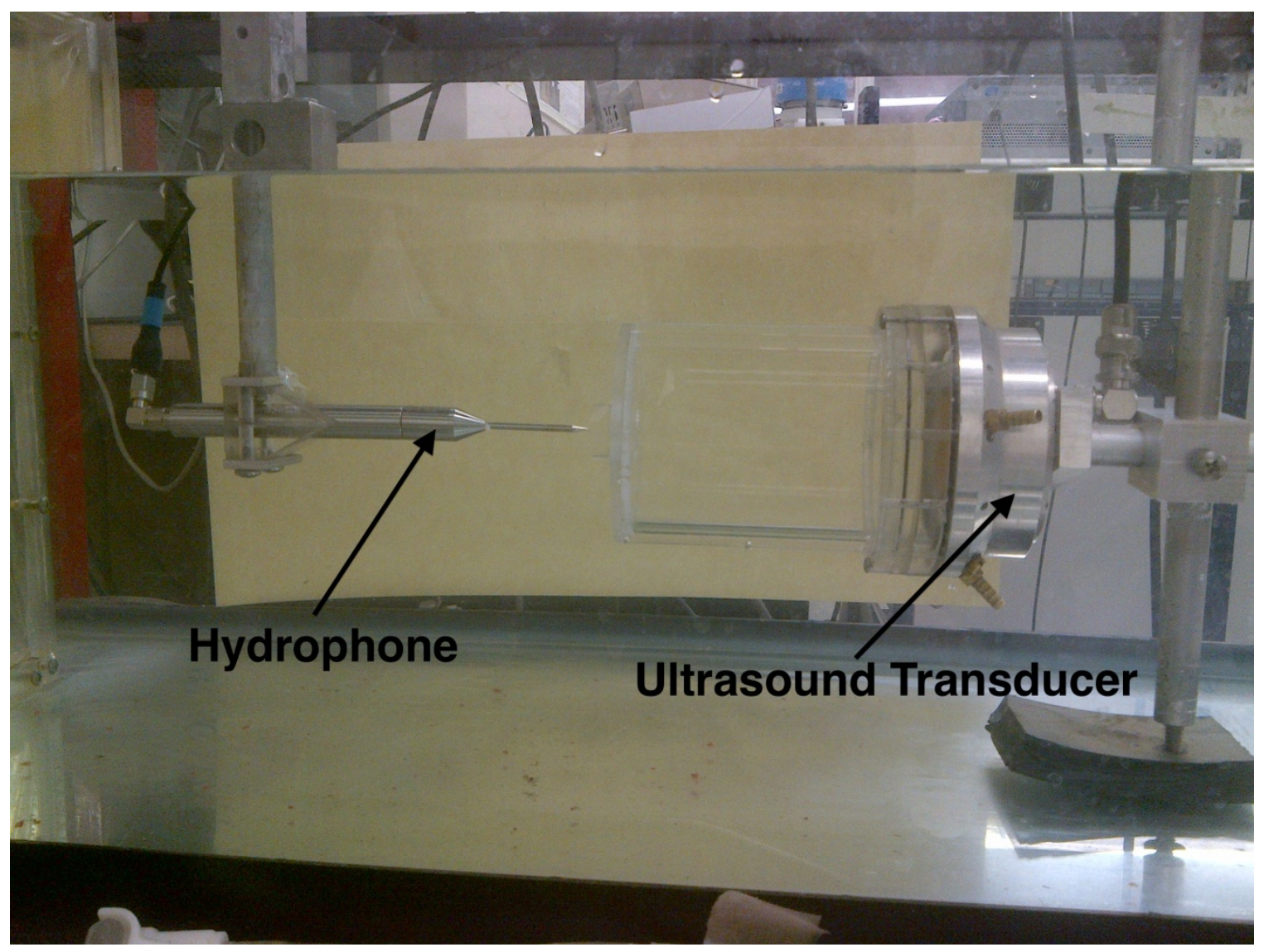

Figure 2.3: Picture showing the pHIFU ultrasound transducer and the hydrophone to determine the focal point of the transducer

The voltage output from the hydrophone was displayed on an oscilloscope (DSO 7032A, Aglient Technologies, Santa Clara, USA) as a way to monitor the sound intensity hitting the hydrophone and thus the location of the focal point. For safety considerations, the ultrasound setting was kept low, $0.4 \mathrm{Vp}-\mathrm{p}$ directly into the transducer, to prevent damage to the hydrophone. Using a combination of automated and manual fine-tuning, the hydrophone was moved to the HIFU 


\section{Chapter 2: Materials and Methods}

beam focal point. It was assumed the hydrophone was at the focal point when the voltage on the oscilloscope had peaked. A snapshot from oscilloscope while the hydrophone was located at the focal point is seen in figure 2.4; the green trace is the voltage sent by the transducer and the yellow trace is the voltage received from the hydrophone.

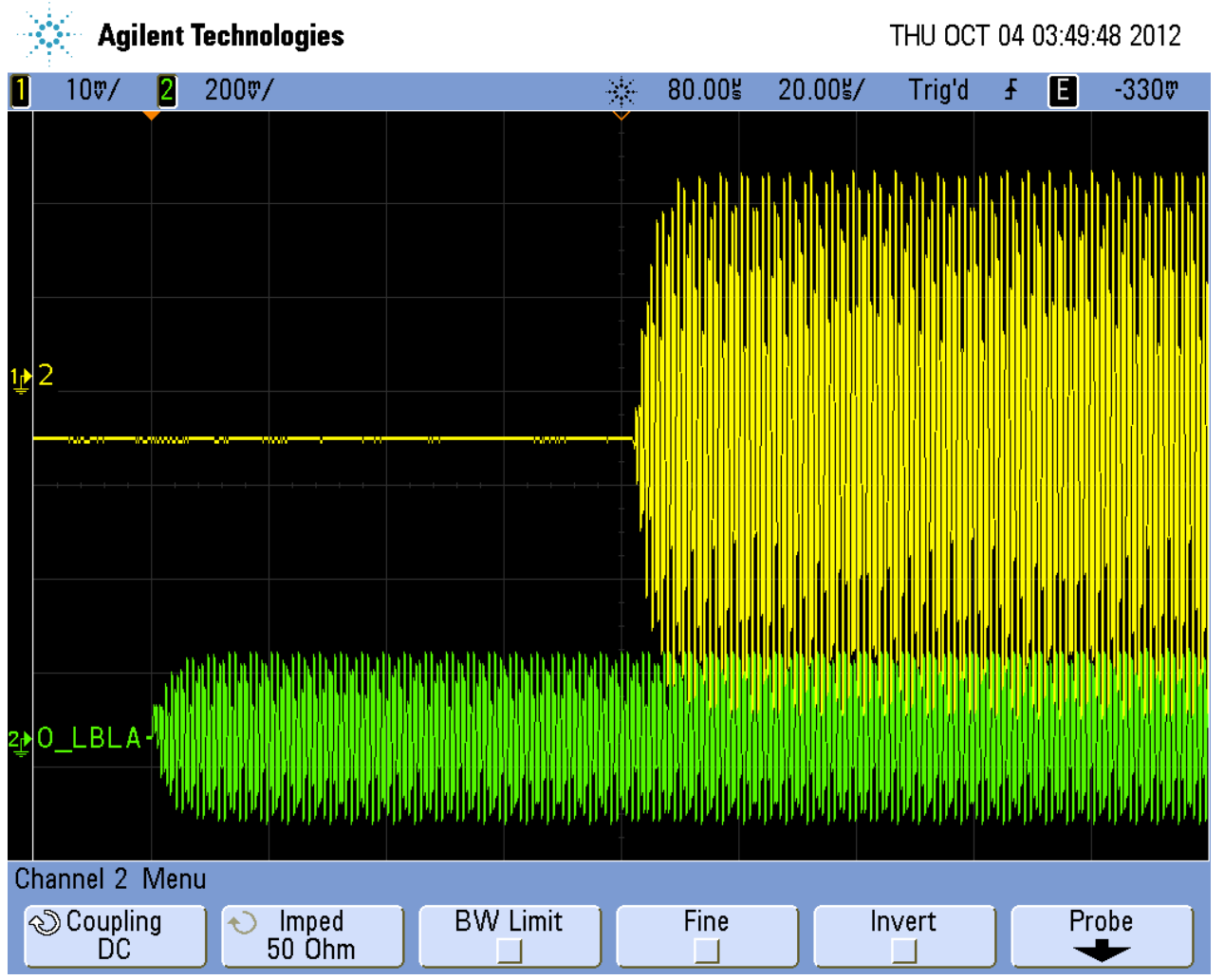

Figure 2.4: Snapshot of oscilloscope showing time of flight of ultrasound beam to hydrophone

Once the location of the hydrophone was set to the focal point, the time of flight of the ultrasound beam to the hydrophone was read from the oscilloscope and used to calculate the axial location of the focal spot. The location of the focal spot with respect to the transducer's surface was found using the following equation

$$
d=v t
$$




\section{Chapter 2: Materials and Methods}

where $d$ is the axial distance of focal spot from the surface of the transducer, $v$ is the speed of sound in the water medium, and $t$ is the time of flight of the ultrasound beam from the transducer to the hydrophone tip. The speed of sound in water was approximated to be $1500 \mathrm{~m} / \mathrm{s}$ and the time of flight read from the oscilloscope was $8.1 \times 10^{-6}$ seconds. Using equation 2.1 , the focal spot of the pHIFU system was found to be $122 \mathrm{~mm}$ along the axial centre of the transducer; this number is agreeable with the $120 \mathrm{~mm}$ radius of curvature value given by the manufacturer. The calculations used to work out the focal spot location can be found in Appendix A6.

\subsection{Effect of the Nose Piece on the pHIFU Beam}

A radiation force balance (RFB) (RFB-2000, ONDA, Sunnyvale, USA) was used to calibrate the pHIFU system. Due to the physical dimensions of the pHIFU system, the transducer with its nose piece was not able to be used with the RFB so calibration of the pHIFU system was done without the nose piece attached; thus it was necessary to investigate the effect of the nose piece on the ultrasound beam as compared to scenario without the nose piece. Similar to the setup used for localizing the actual focal point, the pHIFU transducer and hydrophone were submerged in a water tank with the hydrophone positioned at the transducer focal point. The ultrasound beam was then turned on at increasing power intervals and sonicated the hydrophone. The voltage output of the hydrophone was feed to an oscilloscope where the peak-to-peak voltage values were recorded. This was done under two conditions: 1) with the nose piece attached and 2) without the nose piece. The recorded hydrophone measurements from both conditions were compared to each other. A comparison of the two setups can be seen in figure 2.5. The results of the two setups are presented in section 3.1. 


\section{Chapter 2: Materials and Methods}

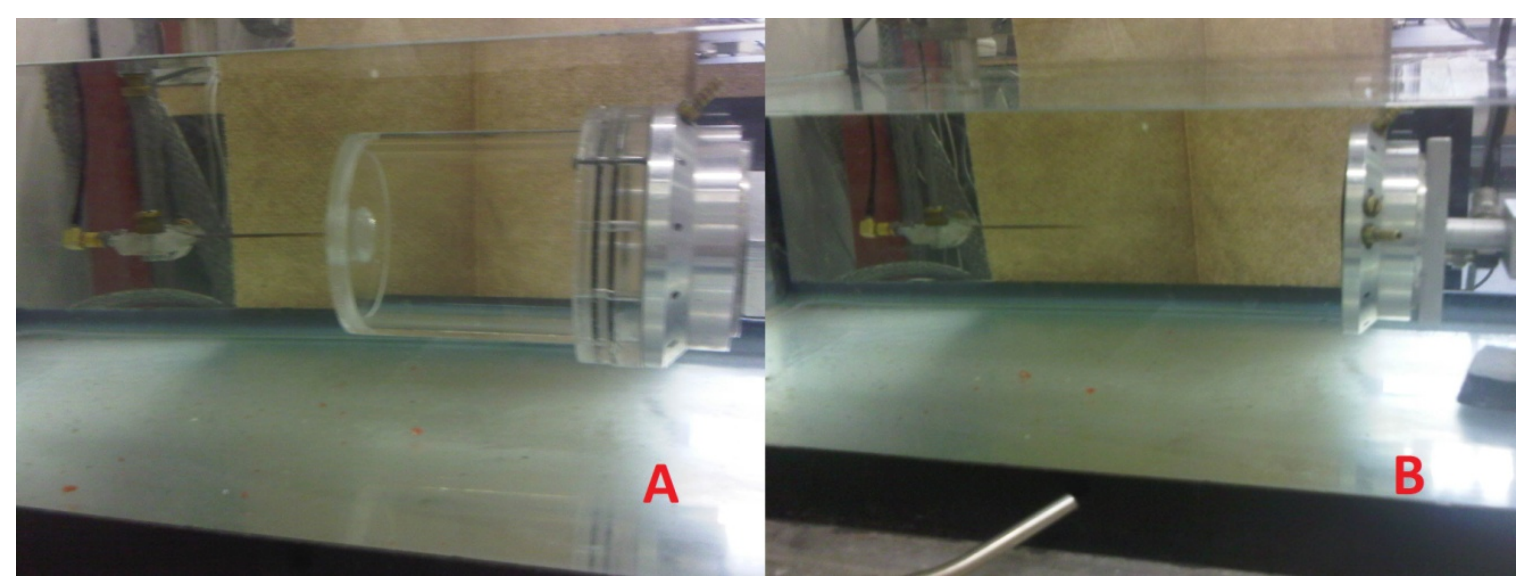

Figure 2.5: Comparison of the 2 conditions used to determine the effect of water jacket

\section{4 pHIFU Transducer Calibration}

Calibration of the pHIFU transducer started with finding the total acoustic power (TAP) produced by the transducer. This acoustic power is typically determined using radiation force techniques, in which the force in the direction of propagation, also called the axial force, on a target is measured. A calibrated RFB-2000 radiation force balance was used to obtain the total acoustic power output from the pHIFU transducer.

The data from the RFB radiation force balance was recorded to a computer through a USB connection. Degassed water was used as the coupling medium between the ultrasound and RFB target. The brush target of the RFB was placed approximately $5 \mathrm{~cm}$ from the surface of the transducer so that the target was placed in the near field of the ultrasound beam as per the instructions (Ohmic Instruments Company 2006). The components of the RFB system are shown in figure 2.6. A picture of the actual equipment setup is shown in figure 2.7. The measurement uncertainty and technical specifications of the RFB-2000 can be found in Appendix A1. 


\section{Chapter 2: Materials and Methods}

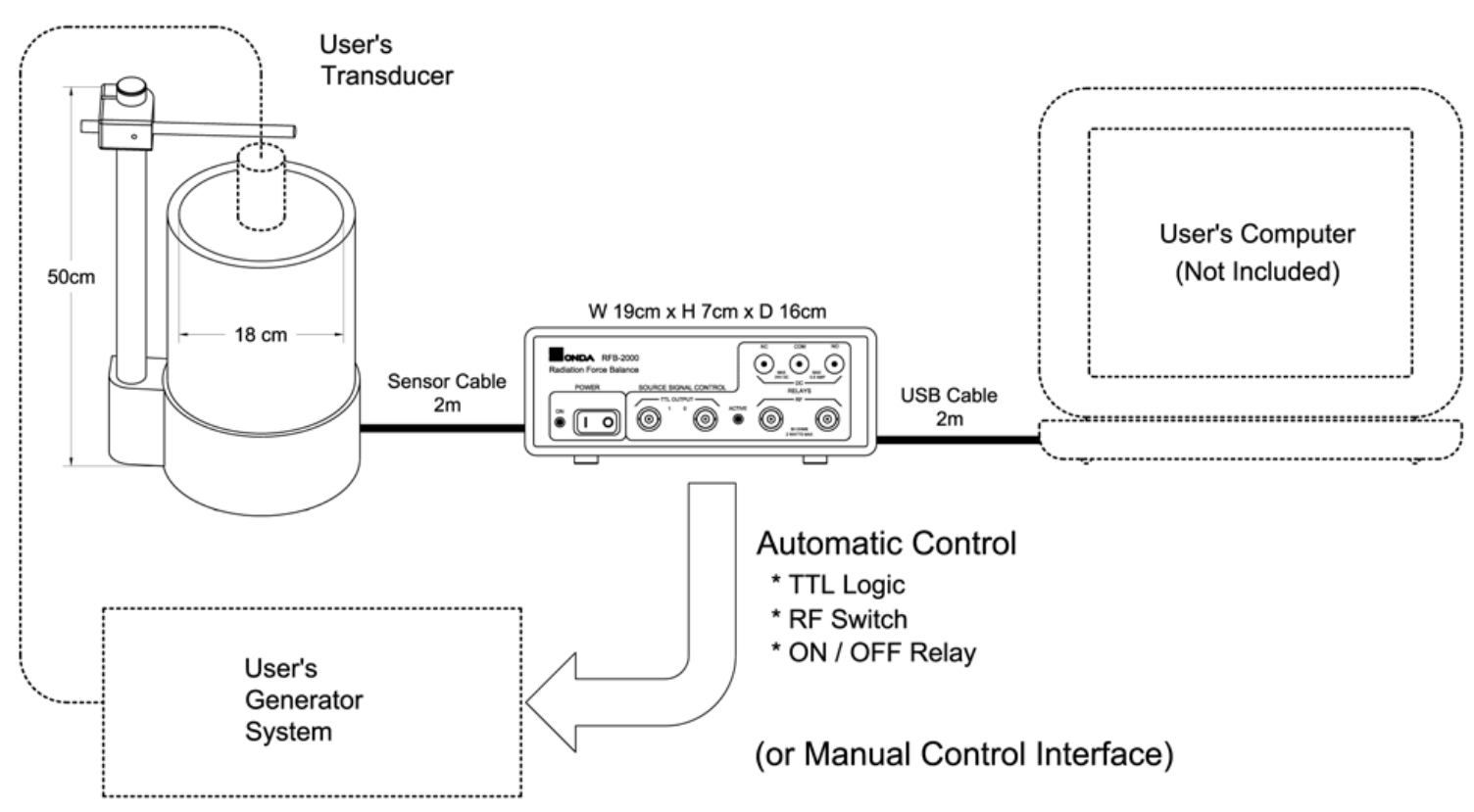

Figure 2.6: Setup of the ONDA RFB-2000 system for TAP measurement

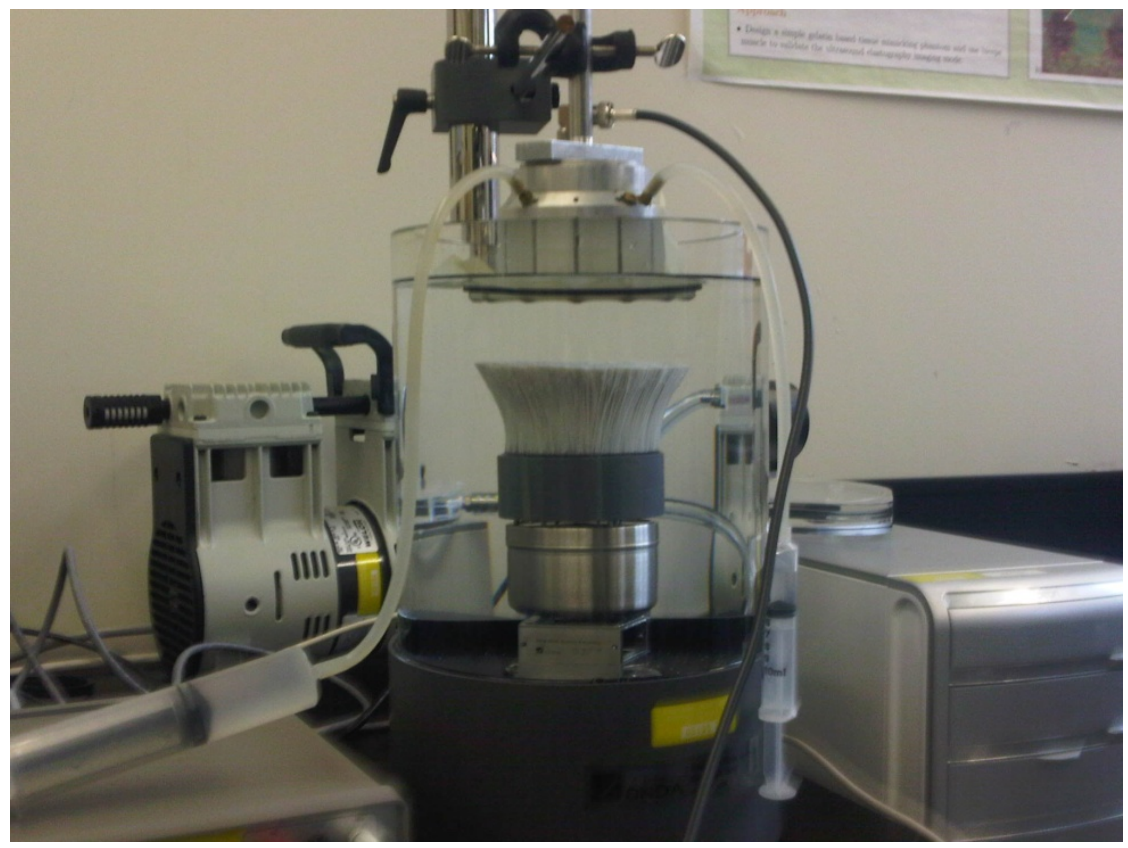

Figure 2.7: The pHIFU transducer (F\# 2.4) being calibrated by the ONDA RFB-2000 radiation force balance 


\section{Chapter 2: Materials and Methods}

The acoustic power measurement from the RFB system was recorded at several input voltage levels on the function generator to create the calibration curve. Each data point on the calibration curve represented an average of 20 repeated measurements. This procedure was repeated on two separate days and the results from the 2 occasions were averaged to produce the acoustic power calibration curve. This information, along with the dimensional properties of the transducer was inputted into an ultrasound beam simulation program (Butt 2011a) to obtain the focal intensity at the various input settings and the corresponding intensity beam profiles. The focal intensities were calculated using an approximated form of the Rayleigh-Sommerfeld integral. Acoustic pressure amplitude was then calculated with the equation (Wu 2006)

$$
p=\sqrt{I 2 \rho c}
$$

where $p$ is the pressure amplitude, $I$ is the time-averaged intensity, $\rho$ is the density of the medium, and $c$ is the speed of sound in the medium.

\subsubsection{Theory of measuring ultrasound power using a radiation force method}

A radiation force balance was used to measure the acoustic power output of the ultrasound transducer. An ultrasonic beam consists of two pressure components. The first is an alternating pressure that varies according to changes in medium's density. The second is the direct or static pressure (Ohmic Instruments Company 2006). Although both components are present at the same time, it is the direct pressure that is measured. This is because the average alternating pressure per cycle is zero. The direct pressure $\left(P_{\tau}\right)$ or pressure of radiation can be expressed as a function of intensity $(I)$ and speed of sound in the propagating medium $(c)$, as

$$
P_{\tau}=I / c
$$

Assuming a uniform plane wave and non-absorbent medium, the intensity is the same for all points in a wave; the following equation is valid for the intensity of the ultrasound

$$
I=c E
$$




\section{Chapter 2: Materials and Methods}

where $E$ is the energy density per unit volume $\left[j o u l e s / \mathrm{cm}^{3}\right]$. Combining the two equations yields,

$$
P_{\tau}=E
$$

From here the measured force $(F)$ from the RFB system is related to the temporal-average acoustic power $\left(P_{T A}\right)$ through the equation

$$
P_{T A}=c F
$$

where $F$ is the measured radiated force produced by the sound wave.

\subsubsection{Linear acoustic field simulator}

A linear acoustic field simulator was used to find the focal intensity (Butt 2011a; 2011b). The simulator assumes a source that is composed of many smaller rectangular shaped elements, each emitting its own wavelet; any point in the field can then be calculated as the summation from all contributing source elements (Ocheltree et al. 1989). Pressure is therefore expressed as

$$
p_{0}=\frac{j \rho c \Delta w \Delta h}{\lambda} \sum_{n-1}^{N} \frac{v_{n} e^{(-(\alpha+j k) R)}}{R} \operatorname{sinc}\left(\frac{k x \prime_{n} \Delta w}{2 R}\right) \operatorname{sinc}\left(\frac{k x_{n} \Delta h}{2 R}\right)
$$

where $j=\sqrt{-1}, \rho$ is the density of medium, $c$ is the speed of sound in medium, $\Delta w$ is the width of a single element that comprises the source, $\Delta h$ is the height of single element that comprises the source, $\lambda$ is the wavelength of the sound, $N$ is the number of elements, $v_{n}$ is the velocity amplitude, $\alpha$ is the attenuation coefficient, $k$ is the wave number $(2 \pi / \lambda)$, and $R$ is the distance from an element of the acoustic source to a point in the acoustic field. Figure 2.8 shows the physical definitions of some of the variables used in equation 2.7, where $\mathrm{P}$ is the point of interest in the acoustic field and dS is the size of an element comprising the acoustic source. In this study, the point of interest was the focal spot. 


\section{Chapter 2: Materials and Methods}

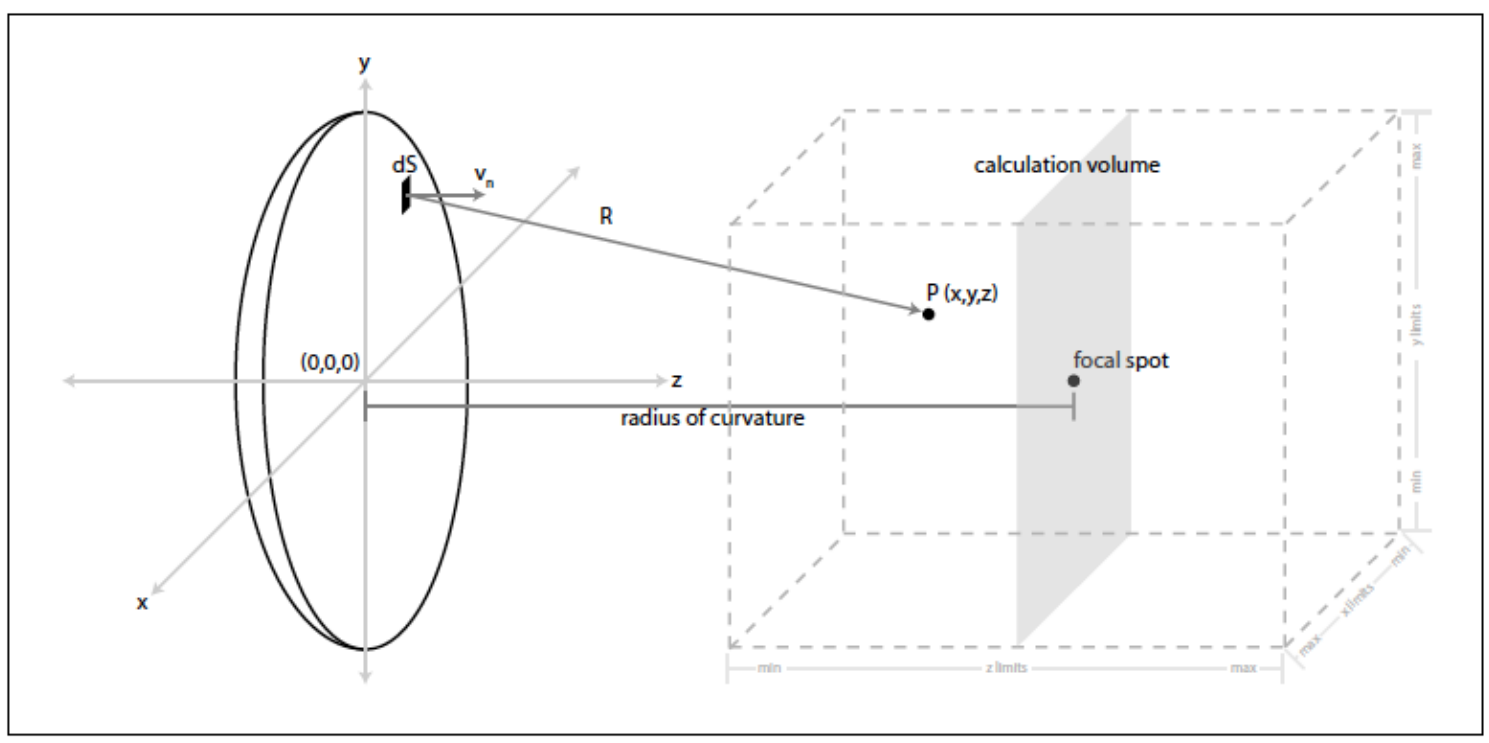

Figure 2.8: representation of variable used in equation 1.7 (Butt 2011)

The parameters that were used to simulate the intensity field are presented in table 2.1. Diffraction and reflection are not factored into the simulation and is a limitation when using the program.

Table 2.1: Parameters used in calculation of intensity field

\begin{tabular}{lr}
\hline \multicolumn{2}{c}{ Transducer Properties } \\
\hline centre frequency & $1.95 \mathrm{MHz}$ \\
integration factor & 20 \\
element size & $0.5 \mathrm{~mm}$ \\
element spacing & $0.5 \mathrm{~mm}$ \\
lateral size of transducer & $50 \mathrm{~mm}$ \\
transducer radius of curvature & $120 \mathrm{~mm}$ \\
\hline \multicolumn{2}{c}{ Medium Properties } \\
\hline speed of sound & $1500 \mathrm{~m} / \mathrm{s}$ \\
density & $1000 \mathrm{~kg} / \mathrm{m}^{3}$ \\
attenuation coefficient & $0.008015 \mathrm{~dB} / \mathrm{cm}^{*} \mathrm{MHz}$ \\
attenuation frequency dependency & 1.9925
\end{tabular}




\section{Chapter 2: Materials and Methods}

\subsection{Lobster Nerve}

\subsubsection{Lobster dissection}

The ventral nerve cord of lobsters (Homarus Americanus) was used as the nerve model for this study. Live lobsters were purchased from nearby supermarkets and weighted between 0.404 $0.718 \mathrm{~kg}$. Dissection of the ventral nerve cord was performed by first incapacitating the lobster by driving a knife down the sagittal lane of the head. The lobster was then tuned ventral side up and a window was cut in the abdomen using kitchen shears and a scalpel. The abdomen was peeled back and the exposed ventral nerve cord was excised from the lobster. A picture of the exposed lobster nerve is shown in figure 2.9. Special care was taken during dissection to make sure the ventral nervous cord was not damaged or stretched or pulled unnecessarily.

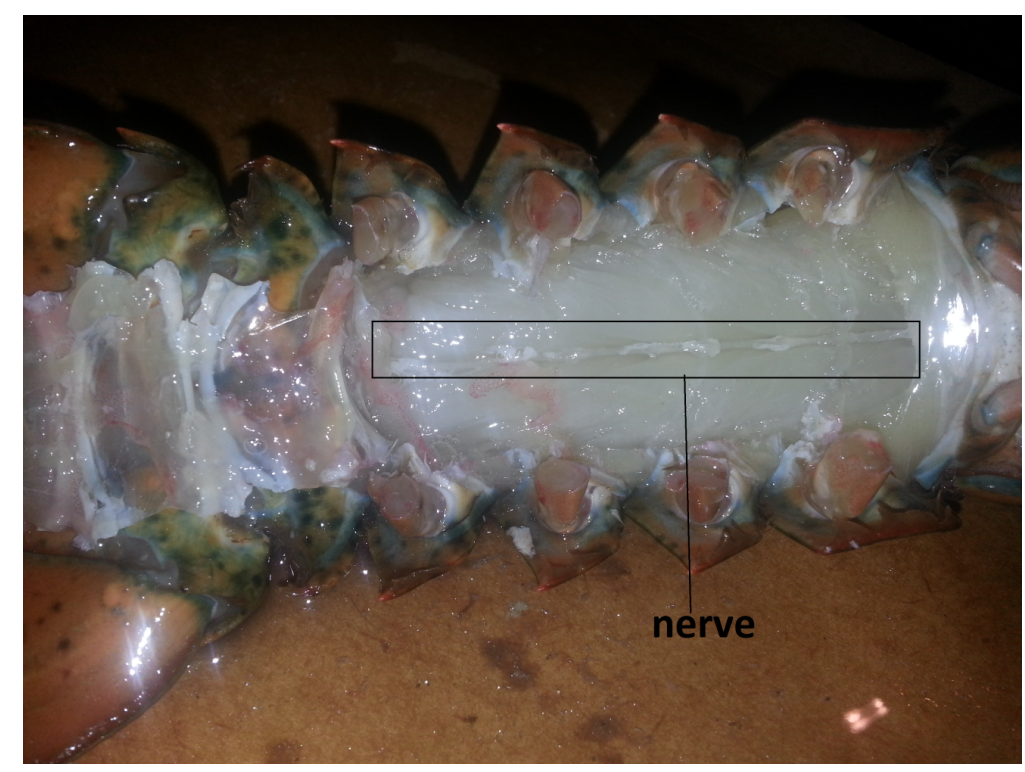

Figure 2.9: Dorsal view of an exposed lobster ventral nerve cord 


\section{Chapter 2: Materials and Methods}

Lobster Ringer's solution was applied to the lobster nerve immediately after dissection and throughout the experimental procedure to maintain the availability of interstitial ions, which are vital for proper nerve function. The Ringer's solution ingredients can be found in Appendix A2.

\subsubsection{BIOPAC $®$ nerve electrophysiology system}

The nerve compound action potential (CAP) and conduction velocity (CV) were measured using a BIOPAC $^{\circledR}$ nerve electrophysiology system (BIOPAC Inc., Goleta, USA). The pHIFU transducer was placed directly underneath the nerve chamber and centred in such a way that would allow the pHIFU beam travel unimpeded by the metal wires of the nerve chamber. A drawing of the nerve chamber on top of the pHIFU transducer is shown in figure 2.10. The ultrasound beam is depicted as a yellow cone. The electrode pin outs are seen along the side of the chamber in red. Ultrasound gel was applied below and above the nerve to allow the ultrasound beam to travel through to the nerve. The excised lobster nerve was placed in the nerve chamber with the length of the nerve running perpendicular to the metal pins. Because the excised nerve contains both efferent and afferent nervous fibres, the nerve could be placed on the nerve chamber without consideration for the direction of the nerve conduction. A pair of stimulation and recording wires ran from the control module to the nerve chamber. Data obtained by the control module was displayed and saved on a computer. The control module obtains voltage from the pins of the nerve chamber and also supplies stimulation current to the nerve chamber. The stimulation inputs were connected to provide a stimulation voltage at one end of the nerve. At the other end of the nerve, pair of recording wires was connected to the nerve chamber in order to record CAP of the nerve. The stimulation and recording pins were placed on either side of the pHIFU beam opening. Figure 2.11 shows the configuration of the stimulation and recording pin-outs. CAP stimulation and acquisition was controlled and saved using the software program BSL PRO version 3.6.6 (BIOPAC Inc., Goleta, USA). 


\section{Chapter 2: Materials and Methods}

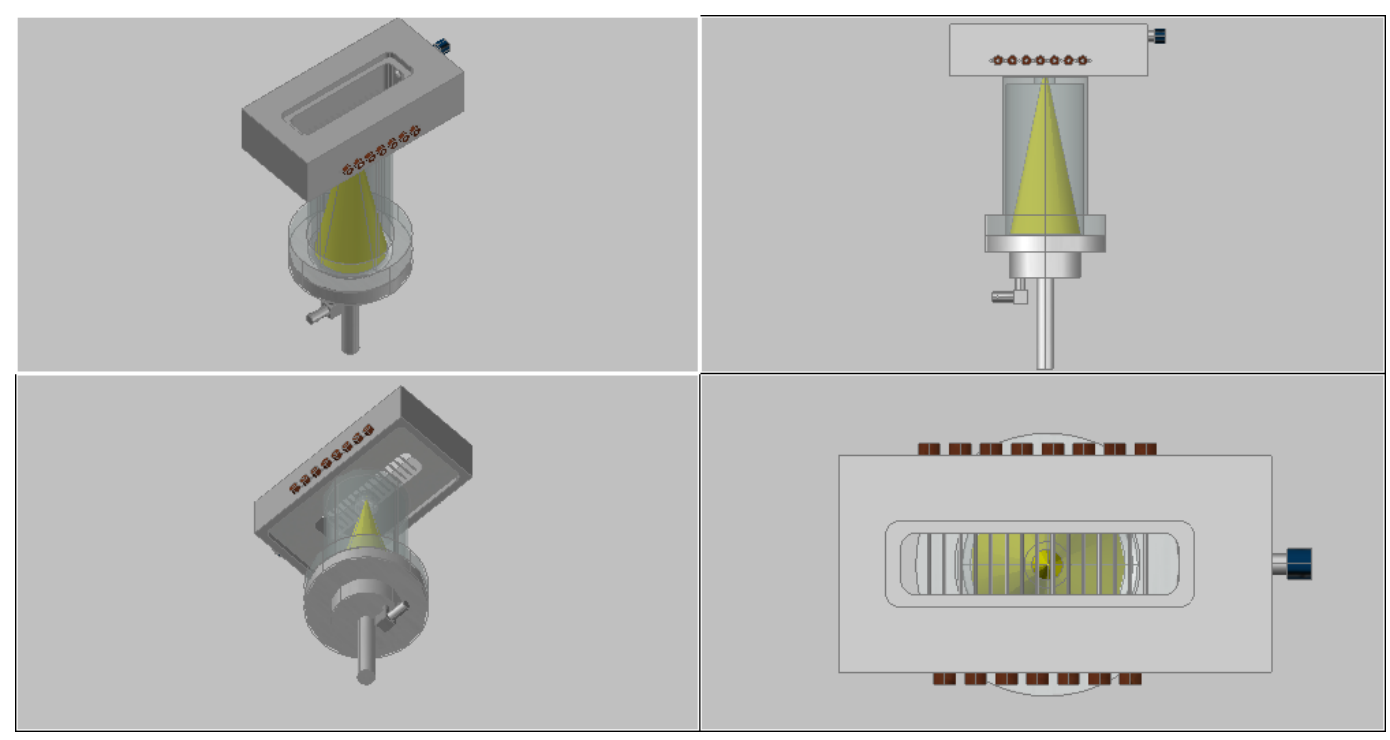

Figure 2.10: Drawing showing the placement of the pHIFU transducer and nerve chamber

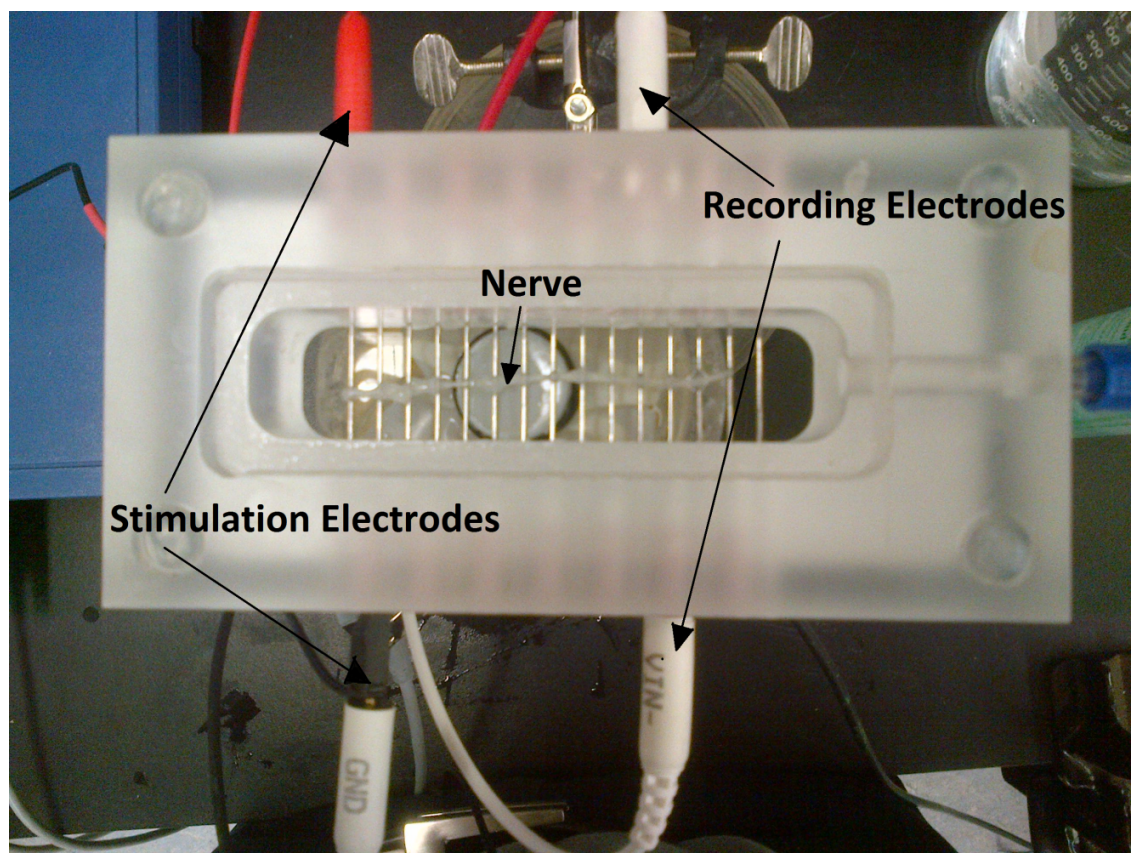

Figure 2.11: Close-up of the nerve chamber showing the pin out configuration 


\section{Chapter 2: Materials and Methods}

\subsubsection{Stimulation Artifact}

Due to the electrical coupling of the stimulation and recording electrodes and their close proximity to each other, stim artifacts are seen preceding each CAP. The appearance of this artifact denoted by a sharp fall/rise in voltage; in comparison nerve CAPs have a more curved shape. Successive CAP recordings are also more variable is shape and amplitude whereas the shape and amplitude of stim artifacts remain unchanged throughout the recordings. A typical stim artifact is shown in figure 2.12. The upper graph represents the stim channel. The lower graph represents the recording voltage. A piece of string was wetted with tap water to allow the flow of electricity through, much like a nerve would. Nerve CAPs are produced by the coordinated activation of ion channels along the nerve membrane. Since a wetted string is electrically conductive but obviously lacks ion channels, it produces a stim artifact without producing a nerve CAP.
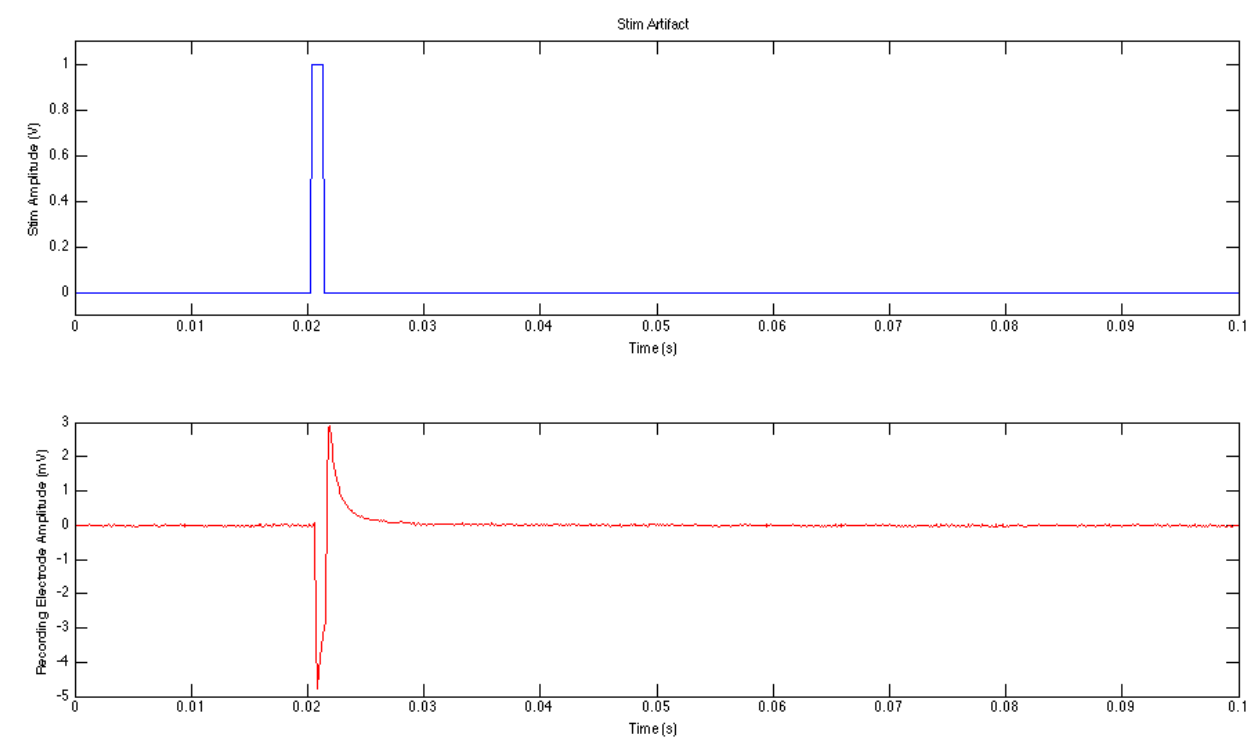

Figure 2.12: Typical stimulation artifact produced by putting a wetting string in the BIOPAC nerve chamber 


\section{Chapter 2: Materials and Methods}

\subsubsection{Experimental Settings}

The excised lobster nerve was centered in the middle of the BIOPAC nerve chamber. Care was taken to touch the nerve as little as possible during the experimental protocol. Any adjustment to nerve position in the BIOPAC nerve chamber was done with forceps; to minimize physical damage to the nerve, only the ends of the nerve were touched. The recording electrodes were set at least $5 \mathrm{~mm}$ from the nerve ends. As a way to normalize across all the nerve specimens, a stimulation voltage of half saturation was used. This stimulation voltage was determined by applying an arbitrarily small single stimulation pulse of low voltage amplitude to the nerve; its subsequent CAP response was then recorded with the BIOPAC ${ }^{\circledR}$ system. The stimulation voltage was then incrementally increased until its CAP response saturated. Once the stimulation voltage was determined the ultrasound system was positioned underneath the nerve chamber in between the stimulation and recording pins so that the pHIFU beam would line up with the nerve. Ultrasound gel was applied to the area of sonication to act as a medium for the ultrasound going from the water filled nose piece to the nerve.

To provide a synchronization of the pHIFU exposures with the nerve CAP measurements, the output from the function generator was split and one end was fed into the BIOPAC control module as a separate channel. A block diagram showing the connections of all the equipment used is shown in figure 2.13 . 


\section{Chapter 2: Materials and Methods}

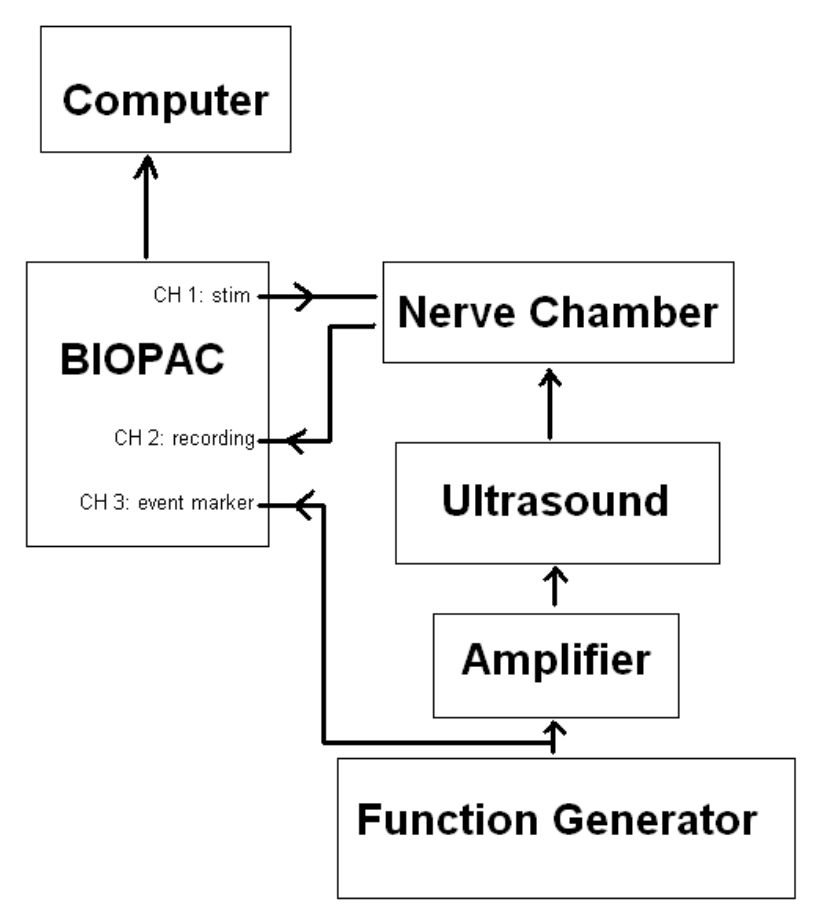

Figure 2.13: Block diagram of the experimental setup

Using the stimulation, acquisition, and pHIFU settings listed in table 2.1, the BIOPAC ${ }^{\circledR}$ system was firstly turned on to begin electrical nerve stimulation and CAP recording. The pHIFU was then turned on and allowed to sonicate the nerve at 3 exposure durations: $1 \mathrm{sec}$, then an additional 5 seconds, and then another additional 10 seconds; the effective exposure times for a single nerve were: $1,6,16$ seconds. The exposure times were composed of a train of pHIFU pulses. Each pulse was $50 \mathrm{~ms}$ in length and followed by an off-time of $450 \mathrm{~ms}$. An exposure time of 1 second meant the nerve was sonicated with a train of 2 pulses, 10 pulses would've hit the nerve during an exposure time of 5 seconds, and 20 pulses was applied to a nerve that had been subjected to a pHIFU exposure time of 10 seconds. There was approximately 30 seconds in between sonication times when the data was saved and the program was setup for the next recording; ringer's solution was also applied to the nerve at this time to prevent the nerve from drying out. A diagram of the timing sequence of the data acquisition is presented in figure 2.14. 


\section{Chapter 2: Materials and Methods}

Data from the BIOPAC ${ }^{\circledR}$ system was exported to Matlab (Mathworks Inc., Natick, USA) for offline processing and analysis.
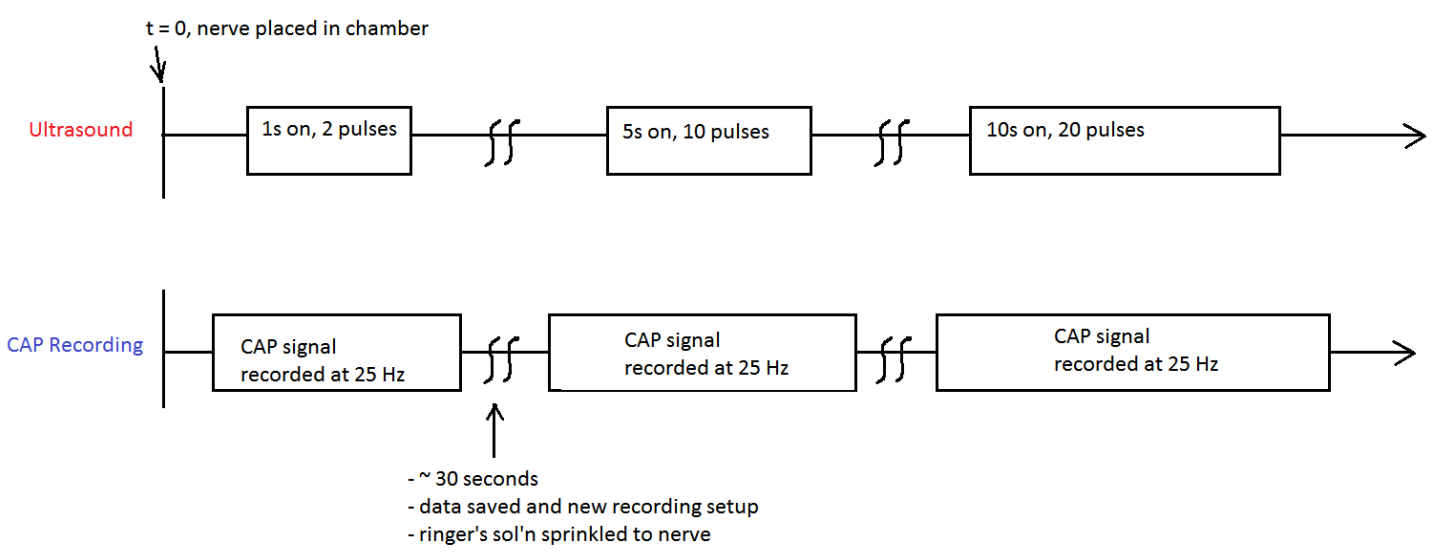

Figure 2.14: Timing sequence diagram for pHIFU exposure showing method used to sonicate nerves

A stimulation pulse of $1 \mathrm{~ms}$ was applied to the nerve to initiate a nerve CAP response. This stim was applied to the nerve at a rate of $25 \mathrm{~Hz}$, resulting in a CAP amplitude acquisition every 0.04 seconds. The stimulation, CAP acquisition, and ultrasound parameters are summarized in table 2.1 .

Table 2.2: Equipment setting for lobster experiments

\begin{tabular}{lr}
\hline \multicolumn{2}{c}{ Electrical Stimulation Settings } \\
\hline $\begin{array}{lr}\text { Pulse length } \\
\text { CAP acquisition }\end{array}$ & $1 \mathrm{~ms}$ \\
$25 \mathrm{~Hz}$ \\
Voltage & set to half of CAP saturation \\
& {$[1.0-3.2 \mathrm{~V}]$} \\
\hline \multicolumn{1}{c}{ pHIFU Settings } \\
\hline frequency & $1.95 \mathrm{MHz}$ \\
focal average intensity & $1010 \mathrm{~W} / \mathrm{cm}^{2}$ \\
indiviual pulse width & $50 \mathrm{~ms}$ \\
duty cycle & $10 \%$ \\
length of pHIFU trains & $1,6,16 \mathrm{~s}$
\end{tabular}




\section{Chapter 2: Materials and Methods}

CAP was measured by taking the peak voltage following each stimulation pulse. A typical nerve CAP is shown in figure 2.15 .

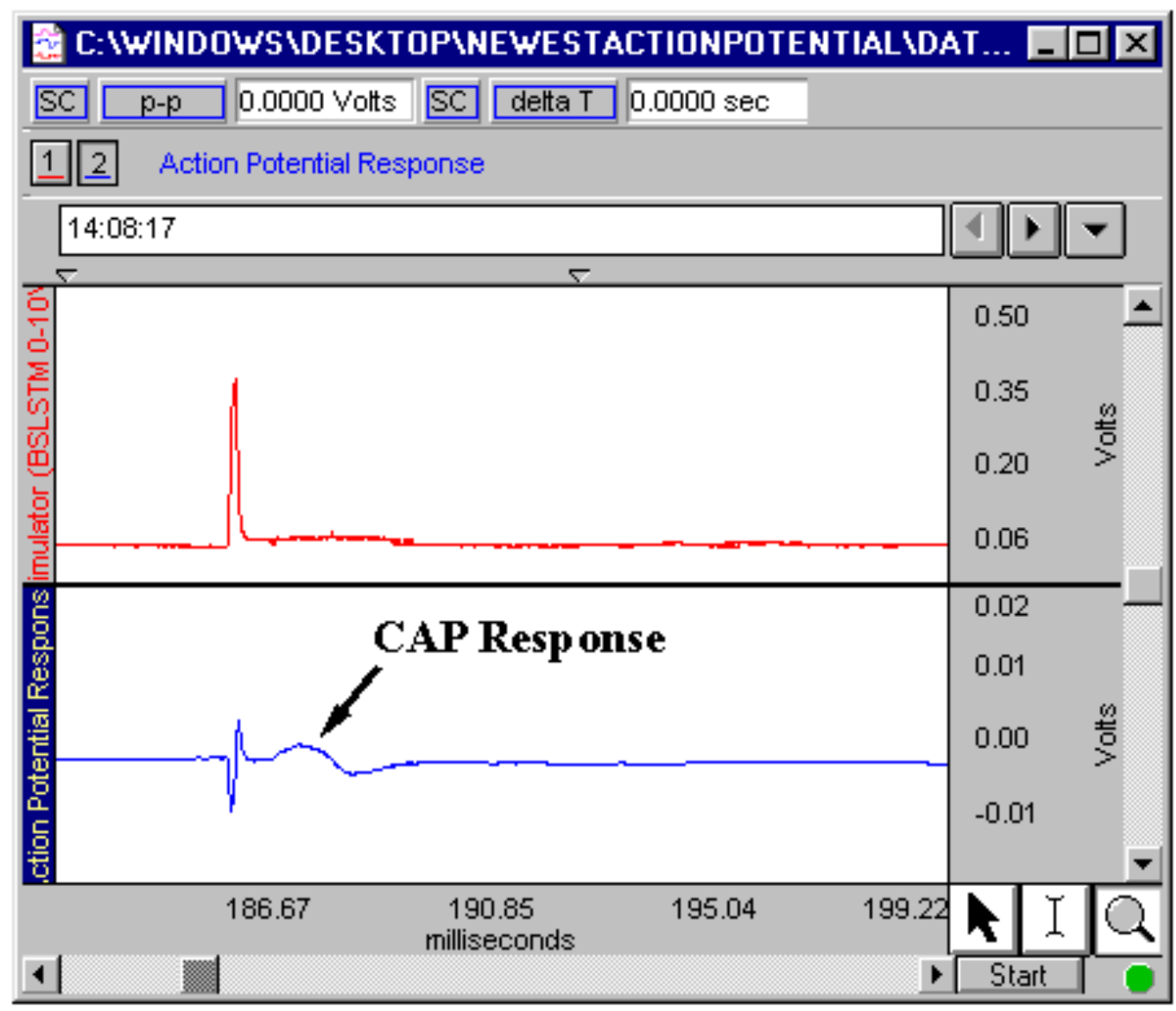

Figure 2.15: BIOPAC software showing CAP 


\section{Chapter 2: Materials and Methods}

In addition to nerve CAP being measured, nerve conduction speed was determined using the following equation

$$
C V=\frac{d_{\text {stim }}}{t_{\text {lat }}}
$$

where $C V$ is the conduction velocity of the nerve signal, $d_{\text {stim }}$ is the distance between stimulating and recording electrode, and $t_{\text {lat }}$ is the latency time between stim artifact and CAP peak.

\subsubsection{Temperature Rise in Nerve Caused by Ultrasound}

After all the data had been collected, a thermal camera (FLIR Systems, ThermoVision A4, Wilsonville, USA) was used to validate the assumption the ultrasound used in this thesis operated within the non-thermal regime, that is the temperature rise of the nerve did not exceed the threshold for thermal bioeffects. The experimental protocol was performed on a typical lobster nerve while the thermal camera was positioned approximately $30 \mathrm{~cm}$ above the nerve. Ultrasound gel was applied to the sonicated area of the nerve to mimic the experimental protocol. The thickness of the gel on top of the nerve was approximately $2 \mathrm{~mm}$. The thermal camera is capable of measuring temperatures from $-40{ }^{\circ} \mathrm{C}$ to $120{ }^{\circ} \mathrm{C} \pm 2{ }^{\circ} \mathrm{C}$ and has a sampling rate of 60 Hz. The technical specifications of the ThermoVision A4 thermal camera are listed in Appendix A7. A thermal image of the nerve in the BIOPAC nerve chamber is shown in figure 2.16.

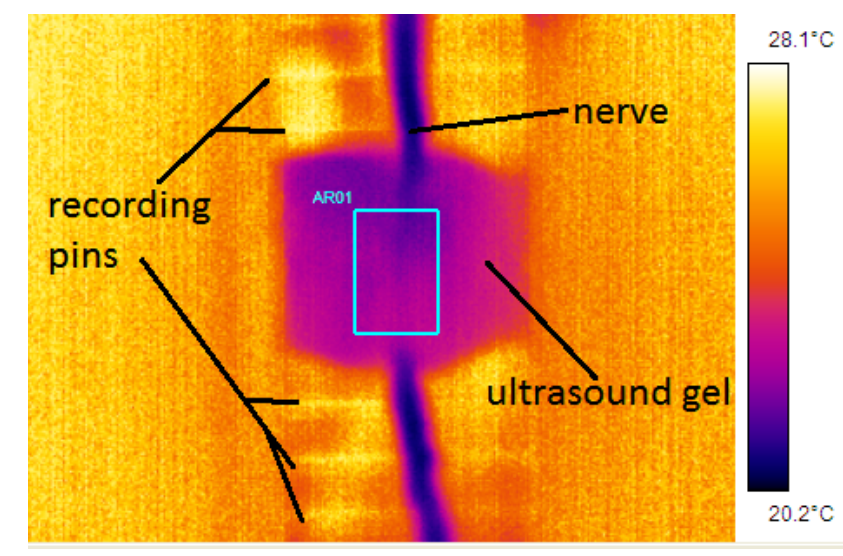

Figure 2.16: Temperature map of a lobster nerve using the thermal camera 


\section{Chapter 3 : Results}

\subsection{Effect of the Modified Nose Piece}

Electrical input powers of up to $15 \mathrm{~W}$ were applied to the pHIFU transducer. Voltage readings from a hydrophone located at the transducers focal point were recorded at each input under the conditions: 1) with the nose piece and 2) without the nose piece. The results are plotted in figure 3.1. The raw data from the hydrophone can be found in Appendix A3. Inspection of the results shows the hydrophone readings from the pHIFU transducer with the nose piece and the hydrophone readings differ by $5.8 \%$.

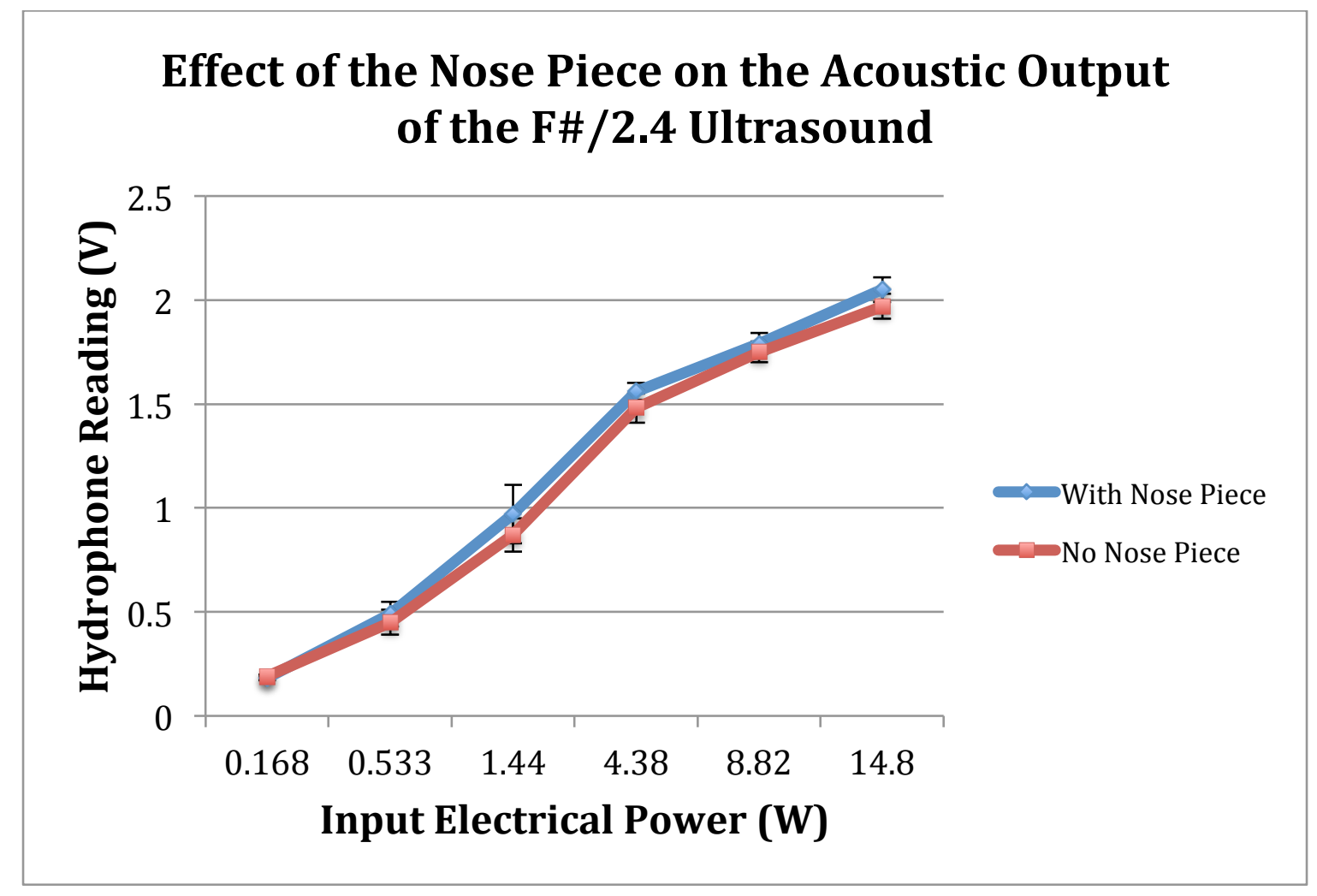

Figure 3.1: Effect of the nose piece on the acoustic output of the pHIFU transducer 


\section{Chapter 3: Results}

\subsection{Output Acoustic Calibration using the Radiation Force Balance}

The ONDA radiation force balance was used to calibrate the acoustic power output from the pHIFU ultrasound transducer. The output acoustic power readings from the RFB device were recorded for a range of input voltages on the function generator. Input voltages ranging from 25$600 \mathrm{mV}$ peak-to-peak were used to produce the power calibration; this relationship is presented in figure 3.2 .

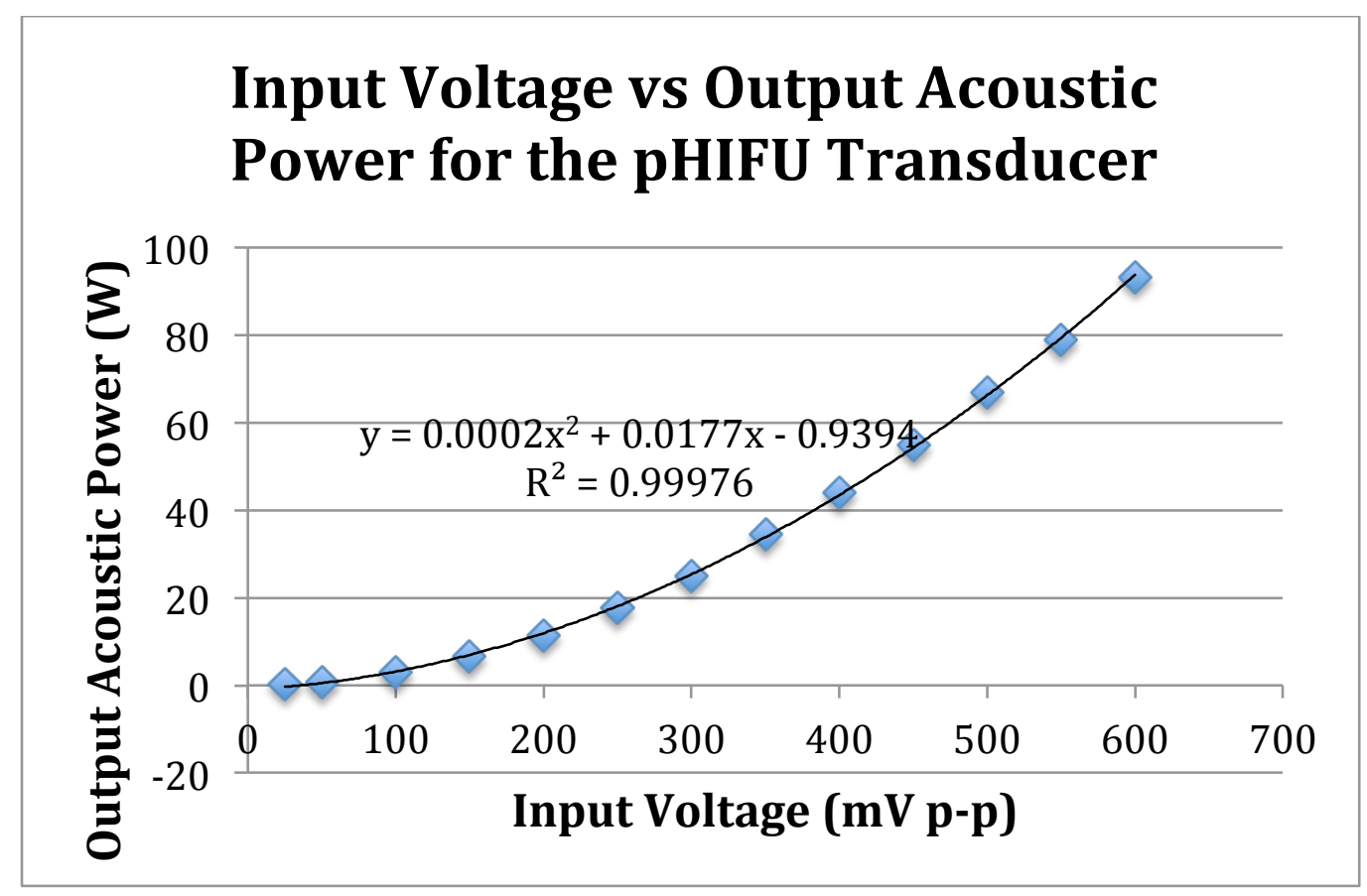

Figure 3.2: Input voltage to the ultrasound system vs. output acoustic power measured from the ONDA RFB power meter

A $2^{\text {nd }}$ order polynomial curve was fitted over the data points. The $\mathrm{R}^{2}$-value is 0.9997 . This suggests the curve closely models the data and it is implied that the relationship between the input voltage and output acoustic power follows a $2^{\text {nd }}$ order polynomial and follows the equation

$$
y=0.0002 x^{2}+0.0177 x-0.9394
$$




\section{Chapter 3: Results}

where $y$ is the acoustic power of produced by the ultrasound transducer in Watts and $x$ is the input voltage to the ultrasound system in $\mathrm{mV}$ p-p. The recorded numbers can be found in Appendix A5, along with all the other measures related to calibration of the pHIFU transducer.

\subsection{Intensity Simulation Results}

The acoustic power from the RFB was inputted into the intensity field simulation program (Butts 2011a) to get the focal intensity. The output of the simulation is shown in figure 3.3. This intensity was then converted to pressure using the equation 2.2. The resulting calibration is shown in figure 3.4. Based on our calibration, it was determined that $400 \mathrm{mV}$ p-p input on our function generator corresponded to an output focal intensity of $1010 \mathrm{~W} / \mathrm{cm}^{2}$ and a focal pressure of $5.51 \mathrm{MPa}$.

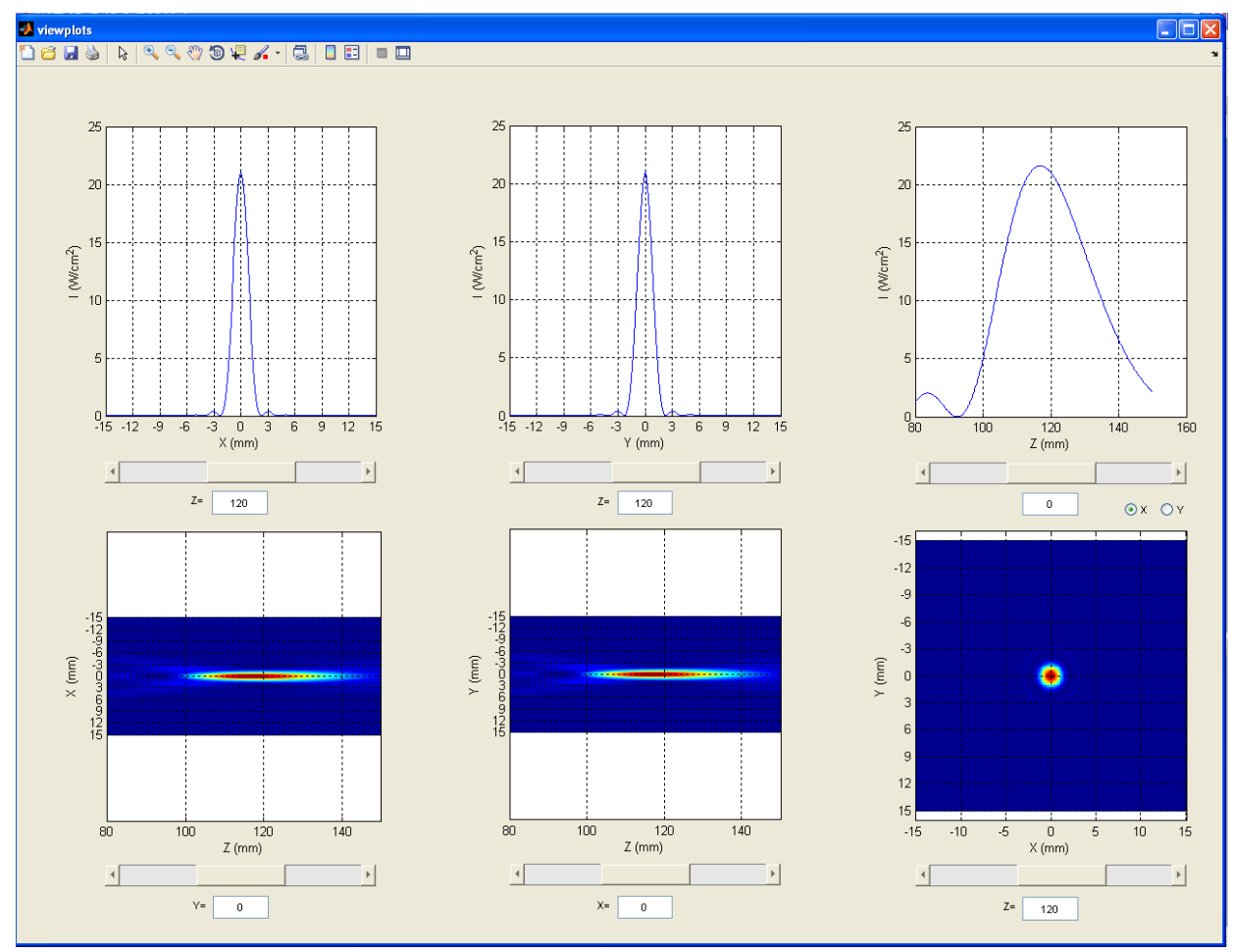

Figure 3.3: Simulated intensity profiles of the pHIFU beam 


\section{Chapter 3: Results}

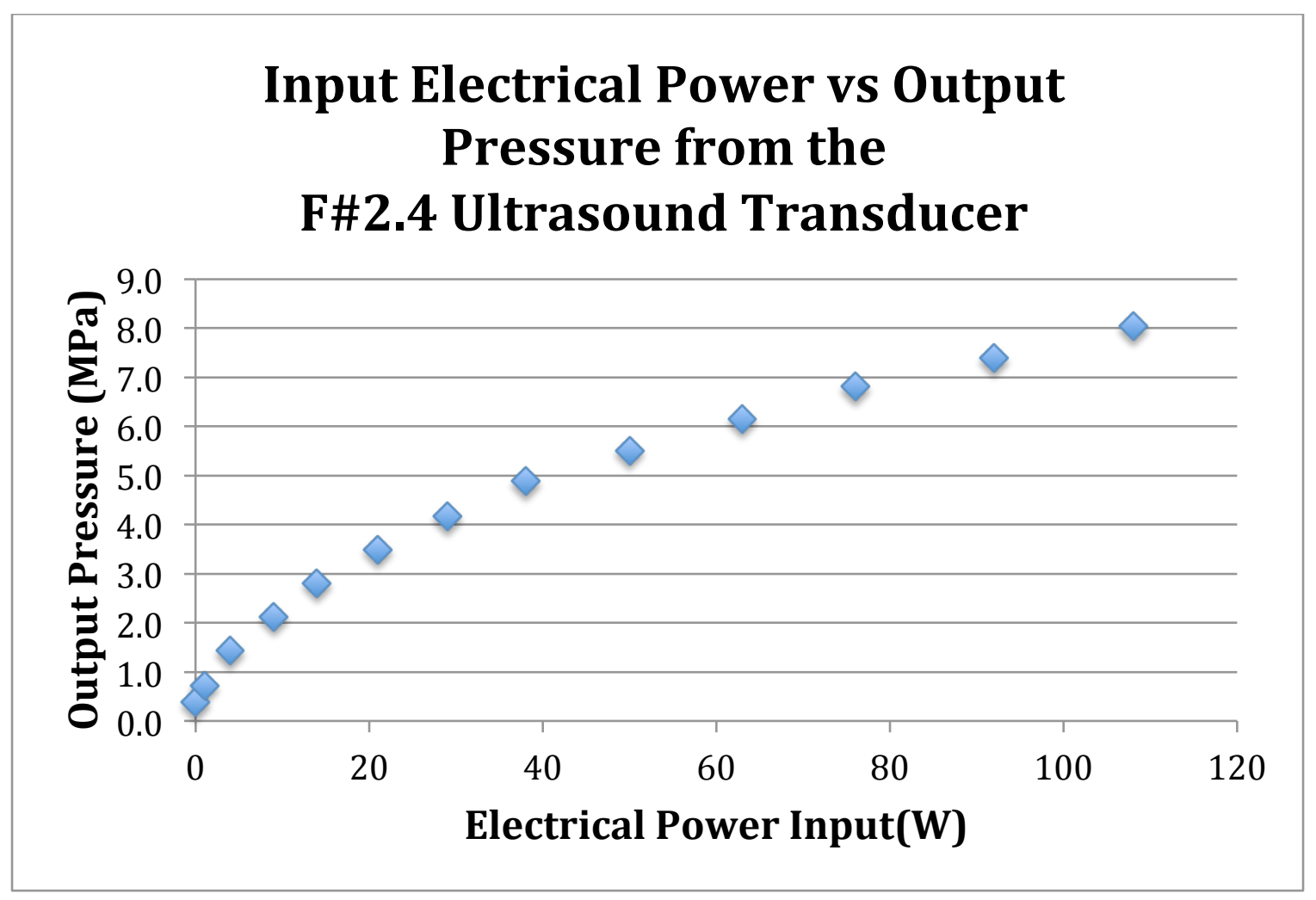

Figure 3.4: Output focal pressure vs input electrical power to the ultrasound system

\subsection{Thermal Camera Results}

The temperature of the nerve was observed to be colder than its surroundings; this is likely due to the fact the lobster was held in a water tank prior to dissection. The temperature of the water tank is cooler than the temperature of the room where the experiment was conducted. It was also noticed the ultrasound gel on top of the nerve may have masked inferred signal emitted by the nerve. This could cause the measurements from the thermal camera to be lower than what should be expected. The nerve reached a maximum temperature of $27.32{ }^{\circ} \mathrm{C}$, which corresponds to a rise in temperature of $0.65{ }^{\circ} \mathrm{C}$. The change in temperature of the nerve is presented in figure 3.5. The upper plot shows the ultrasound timing, where values of 1 indicate the ultrasound was 


\section{Chapter 3: Results}

on and a value of 0 indicates the ultrasound was off. The bottom plot shows the temperature of the nerve measured by the thermal camera.
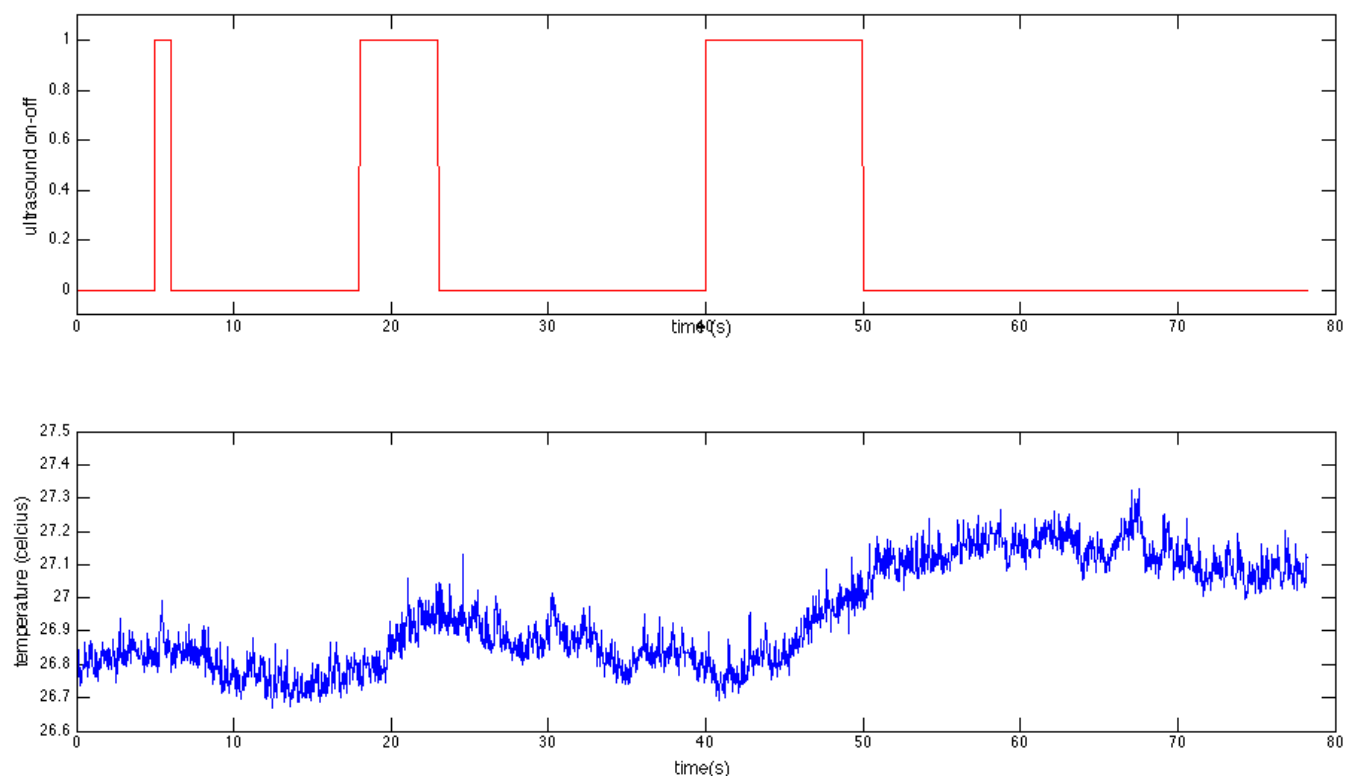

Figure 3.5: Temperature change of a typical nerve using the thermal camera during the experimental procedure

The threshold at which bioeffects must be considered is a $1.5{ }^{0} \mathrm{C}$ rise in temperature above normal (Fowlkes 2008). Because the temperature rise measured by the thermal camera experiment is lower than $1.5{ }^{\circ} \mathrm{C}$, the assumption the pHIFU parameters used in this thesis will not cause significant heating is valid.

\subsection{Lobster Nerve Compound Action Potential}

The lobster nerve CAP responses were categorized under three conditions. These conditions were based on the percentage of baseline CAP after sonication. Nerves that recovered up by $90 \%$ or higher of their baseline CAP amplitude were labeled $\mathrm{B}_{90}$. Nerves that reached $10 \%$ or 


\section{Chapter 3: Results}

less of its baseline CAP amplitude were classified as $\mathrm{B}_{10}$. The category $\mathrm{B}_{90-10}$ was assigned to nerves CAPs that recovered $10-90 \%$ of its baseline values. A bar graph of the classification results is presented in figure 3.6. The average compound action potential following 1 second of ultrasound sonication was $102 \%$ of the initial baseline CAP value of the 'healthy', unsonicated nerve with a standard deviation (SD) of 3.12\%. The nerve was then sonicated for an additional 5 seconds; the average CAP value of this group of nerves was observed to be $76 \%(\mathrm{SD}=30 \%$ ) of its baseline value (following the 1 second sonication but prior to the 5 second sonication). After an additional 10 seconds the average CAP was $26 \%$ of baseline $(\mathrm{SD}=31 \%)$. The CAP results for the three exposure times are presented in figure 3.7. The range of CAP values for each exposure time are summarized in table 3.1.

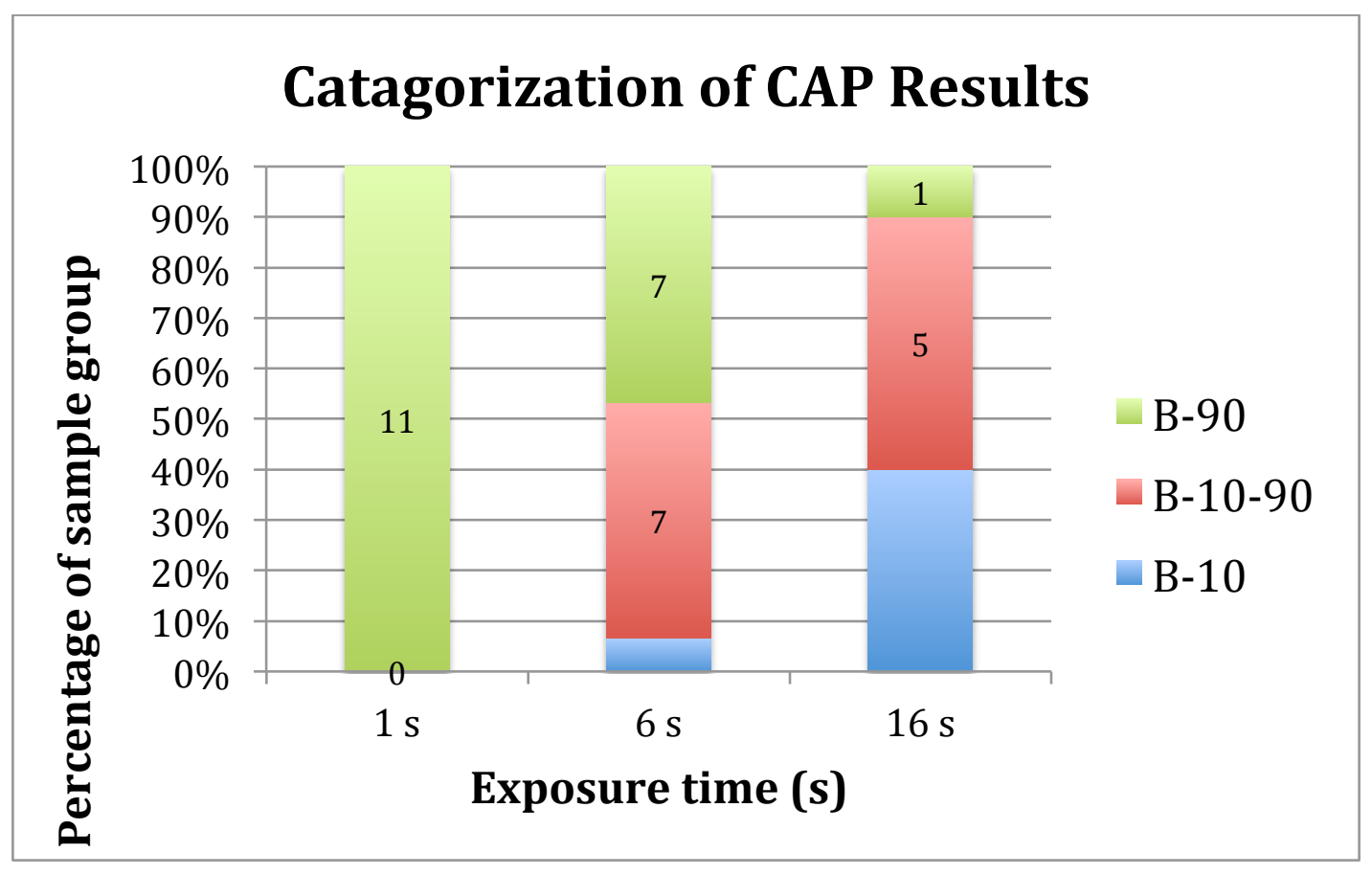

Figure 3.6: Categorization of nerve CAP results following sonication 


\section{Chapter 3: Results}

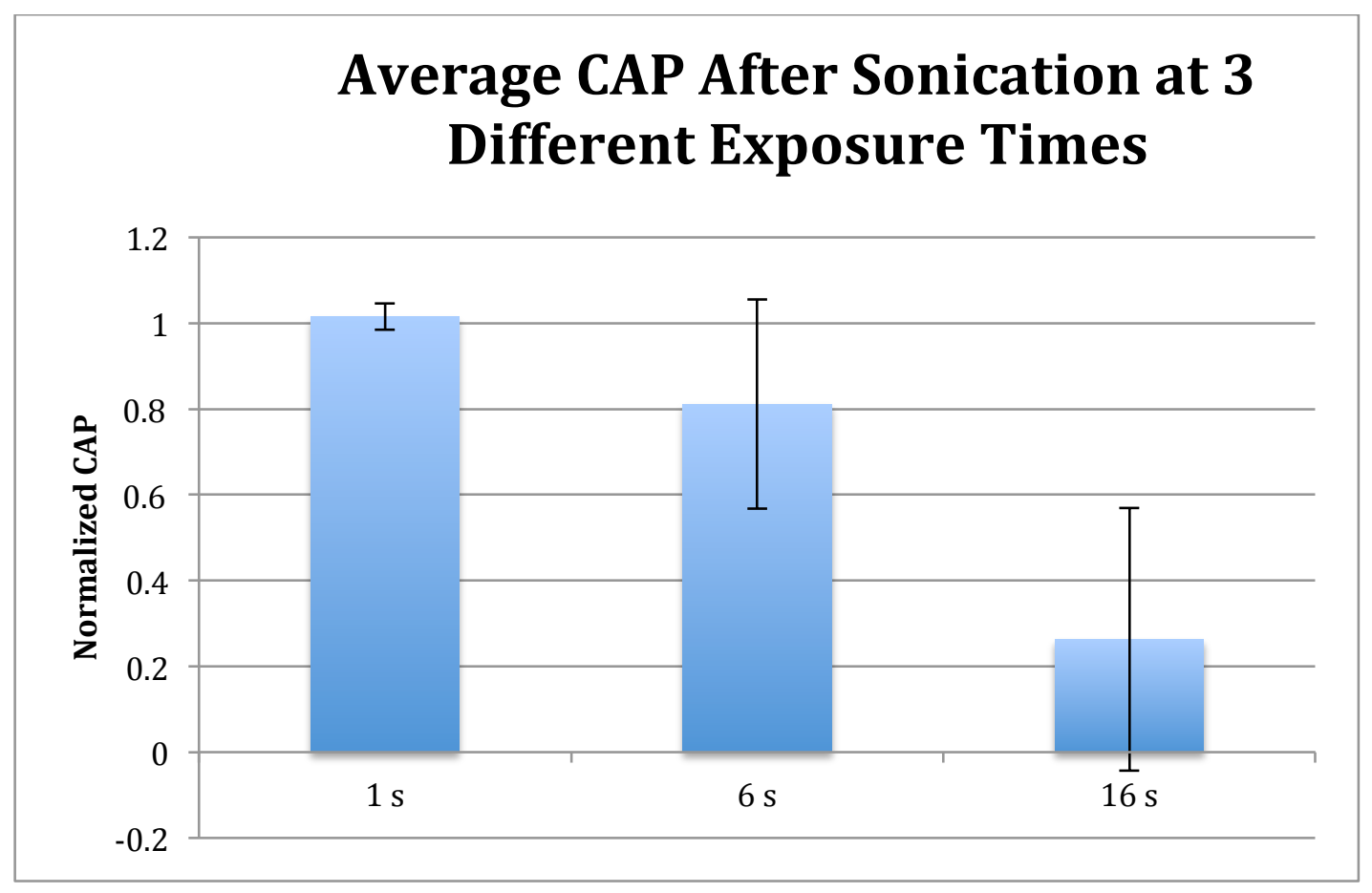

Figure 3.7: Average normalized CAP values following sonication of a nerve for 1 second $(n=11)$, 6 seconds $(n=15)$, and 16 seconds $(n=10)$

Table 3.1: Summary of normalized CAP nerve results after 1,6 , and 16 seconds of pHIFU exposure

\begin{tabular}{ccccc}
\hline $\begin{array}{c}\text { Exposure } \\
\text { Time }\end{array}$ & $\begin{array}{c}\text { Max. CAP } \\
\text { Observed }\end{array}$ & $\begin{array}{c}\text { Min. CAP } \\
\text { Observed }\end{array}$ & Average CAP & $\begin{array}{c}\text { Standard } \\
\text { Deviation of CAP }\end{array}$ \\
\hline 1 seconds & 1.09 & 0.975 & 1.02 & 0.031 \\
6 seconds & 1.02 & -0.01 & 0.764 & 0.303 \\
16 seconds & 0.897 & -0.011 & 0.263 & 0.306
\end{tabular}

Instances where the minimum observed CAP level was less than zero indicate nerves that have died and no longer produce any amount of CAP. The noise-level of the recording electrodes causes the voltage to fluctuate about zero; this sometimes results in negative CAP amplitude. 


\section{Chapter 3: Results}

\subsection{Lobster Nerve Conduction Velocity}

The average baseline conduction velocity of all nerves used in this thesis was found to be 11.26 $\mathrm{m} / \mathrm{s} \pm 1.14 \mathrm{~m} / \mathrm{s}$. The average conduction velocity (CV) following 1 second of ultrasound sonication was $101 \%(\mathrm{SD}=4 \%)$ of the initial baseline $\mathrm{CV}$ value of the 'healthy', unsonicated nerve. The average $\mathrm{CV}$ after 6 seconds of sonication was $90 \%(\mathrm{SD}=16 \%)$. After 16 seconds of sonication the average $\mathrm{CV}$ was $59 \%$ of baseline $(\mathrm{SD}=31 \%)$. The $\mathrm{CV}$ results for the three exposure times are presented in figure 3.8. The range of $\mathrm{CV}$ values for each exposure time are summarized in table 3.2. The normalized CV average of all 3-exposure times is plotted against its corresponding normalized CAP average in figure 3.9.

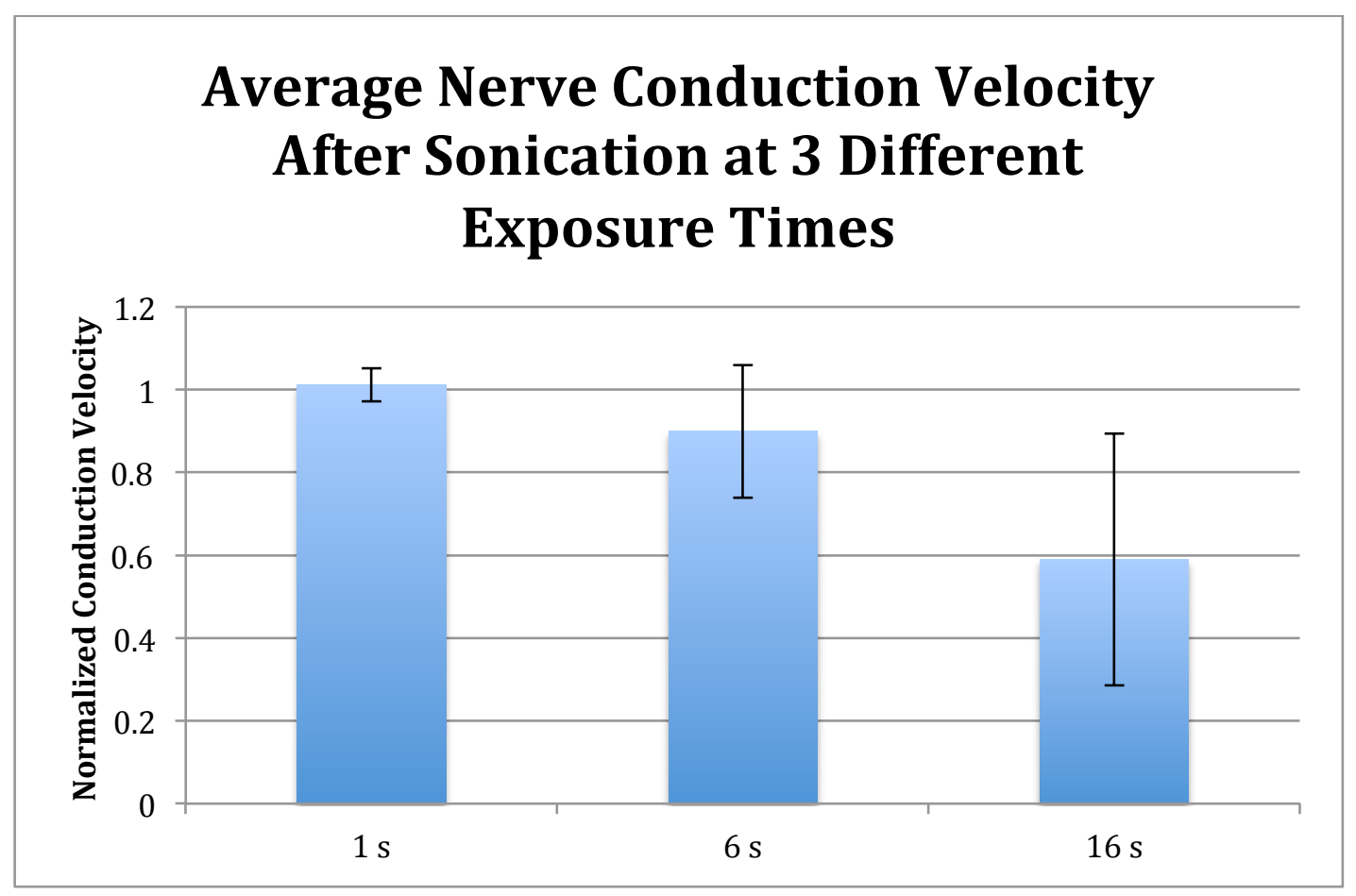

Figure 3.8: Average normalized CV values following sonication of a nerve for 1 second $(n=11)$, 5 seconds $(n=15)$, and 10 seconds $(n=10)$ 


\section{Chapter 3: Results}

Table 3.2: Summary of normalized CV nerve results after 1, 6, and 16 seconds of pHIFU exposure

\begin{tabular}{ccccc}
\hline $\begin{array}{c}\text { Exposure } \\
\text { Time }\end{array}$ & $\begin{array}{c}\text { Max. CV } \\
\text { Observed }\end{array}$ & $\begin{array}{c}\text { Min. CV } \\
\text { Observed }\end{array}$ & Average CV & $\begin{array}{c}\text { Standard } \\
\text { Deviation of CV }\end{array}$ \\
\hline 1 seconds & 1.11 & 0.968 & 1.01 & 0.04 \\
6 seconds & 1.12 & 0.615 & 0.9 & 0.161 \\
16 seconds & 1.09 & 0.277 & 0.59 & 0.305
\end{tabular}

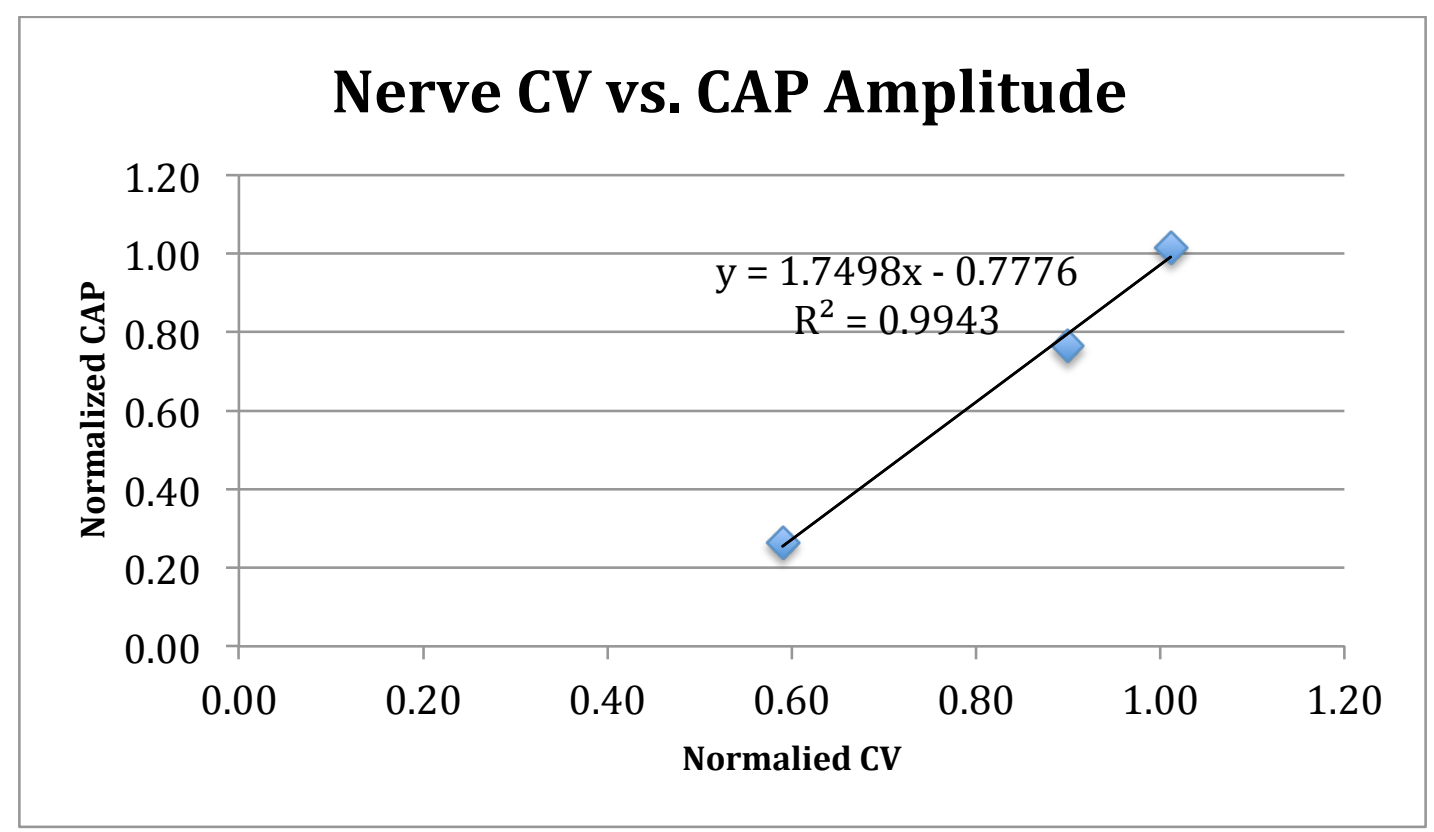

Figure 3.9: Normalized nerve conduction velocity vs. normalized nerve compound action potential at 3 sonication times

\subsection{Long Term Effect on CAP After Sonication}

pHIFU's long term effect on CAP was investigated. The CAP amplitudes of a nerve were recorded for 3.5 minutes after it had been sonicated. A newly dissected nerve was sonicated for 10 seconds with the parameters summarized in table 2.1. Any changes in CAP amplitude during the 3.5 minutes were of 


\section{Chapter 3: Results}

particular interest. A plot of the CAP amplitudes during and after ultrasound exposure is presented in figure 3.10 .

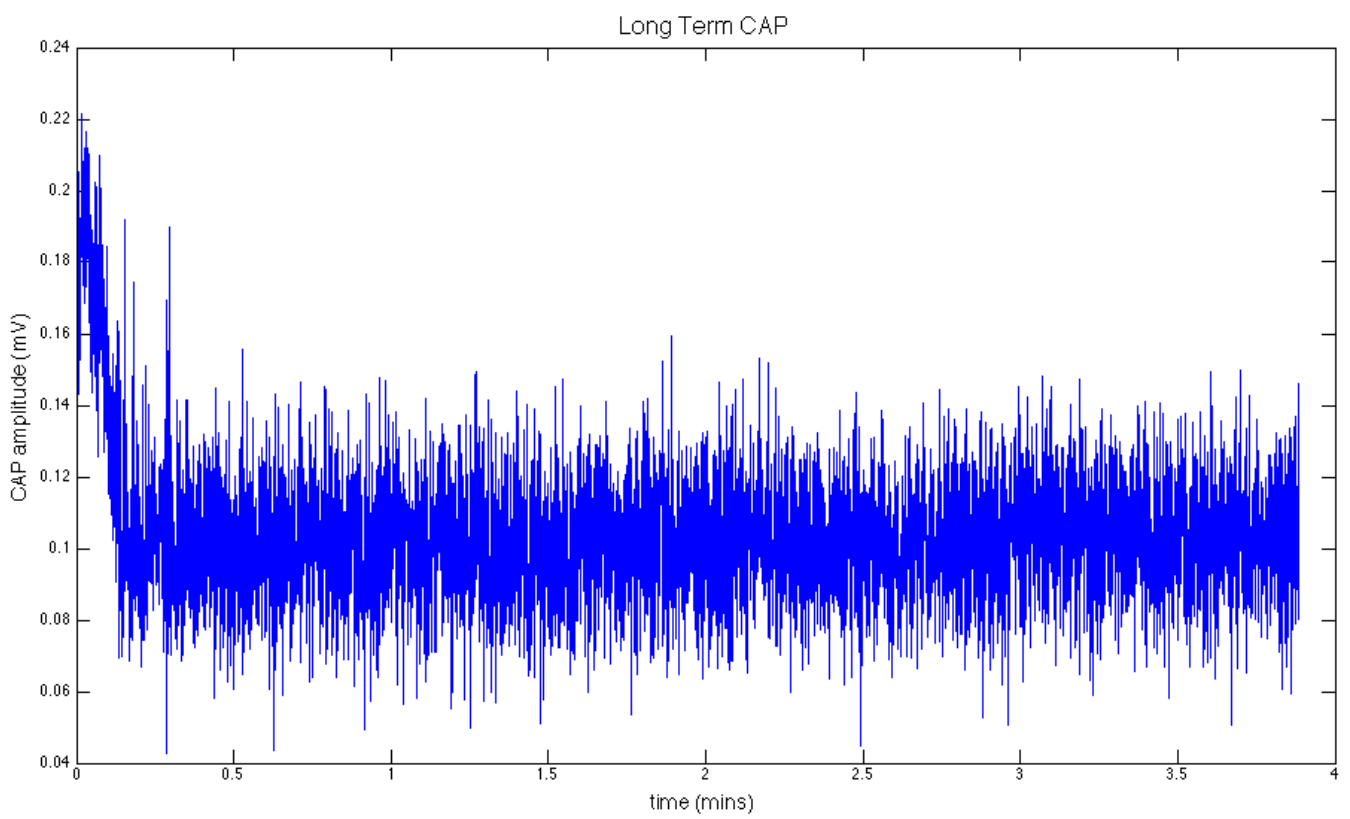

Figure 3.10: Changes in nerve CAP amplitude 3.5 minutes following sonication

\subsection{CAP During Ultrasound Sonication}

CAP amplitudes were acquired from the nerves during sonication. The results below show typical CAP responses during pHIFU sonication. The nerve CAPs during 1 second of pHIFU exposure is shown in figure 3.11. No obvious changes in CAP were seen when the nerve was sonicated for 1 second. 


\section{Chapter 3: Results}
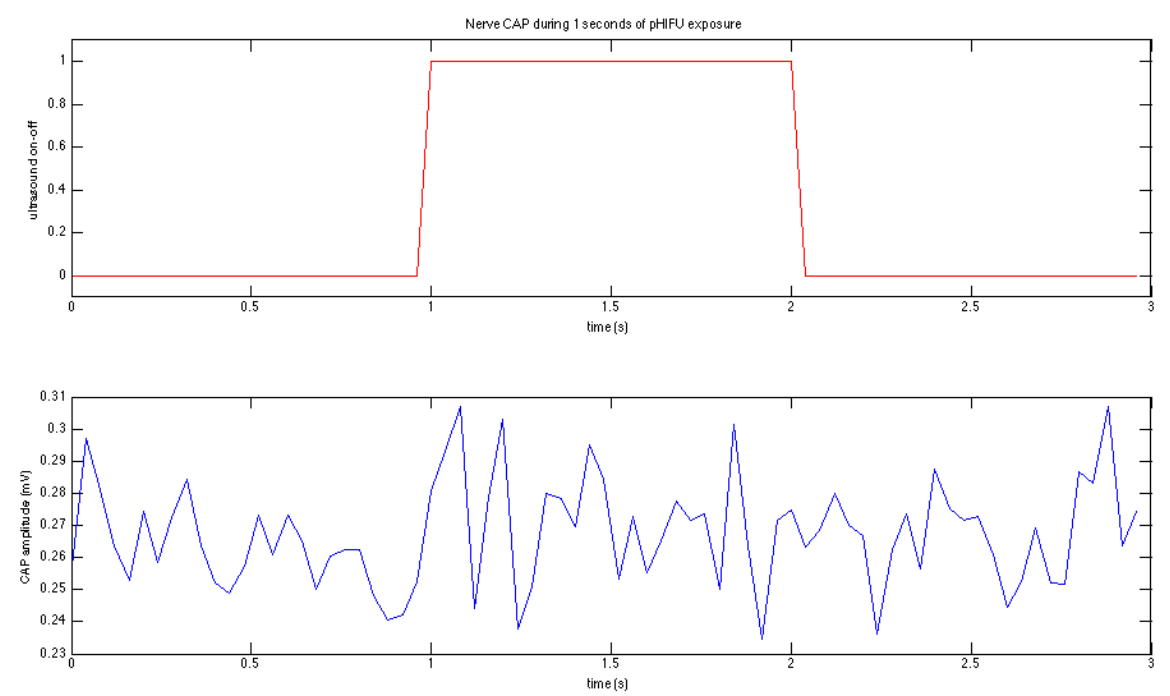

Figure 3.11: Nerve CAP amplitude during 1 second of pHIFU exposure

A decrease in CAP amplitude was seen in the nerve during the 5 seconds sonication (figure 3.12).
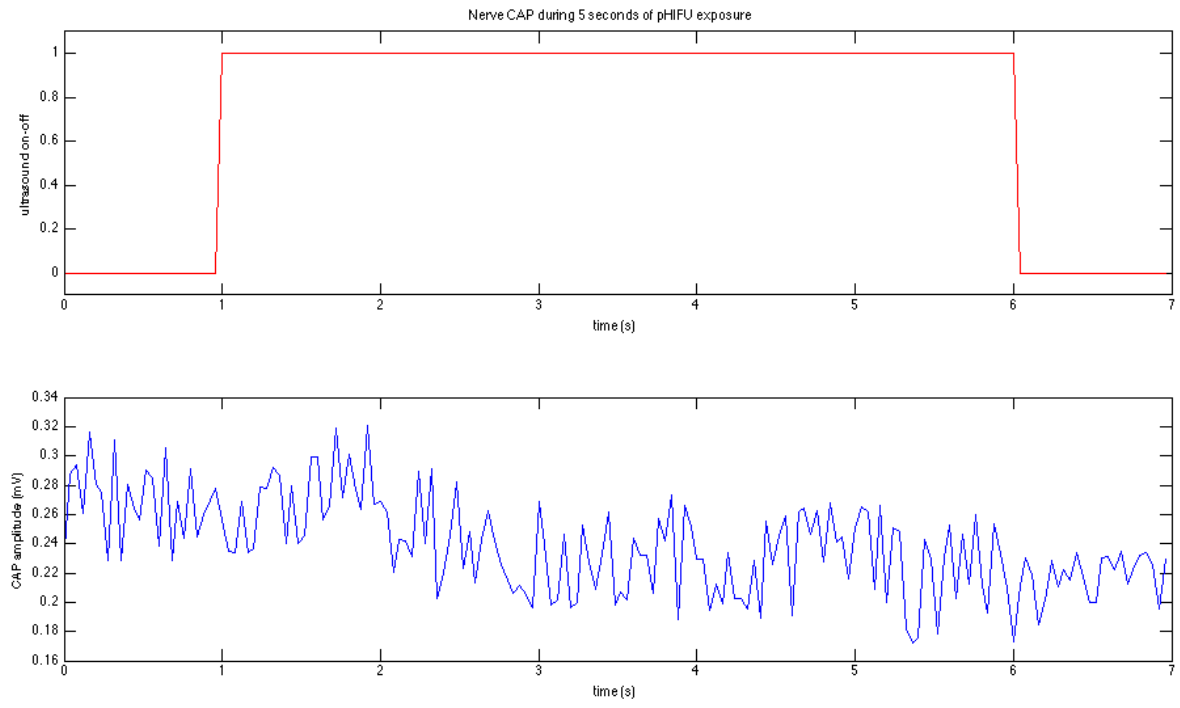

Figure 3.12: Nerve CAP amplitude during 5 seconds of pHIFU exposure 


\section{Chapter 3: Results}

The CAP amplitude was observed to decrease to a much lower value and at a faster rate during the 10 seconds trials (figure 3.13). The normalized nerve CAP amplitude decreased by an average of $3.94 \% / \mathrm{sec}$ during the 5 second sonication trial compared to $4.61 \% / \mathrm{sec}$ during 10 second sonication trial. This rate was calculated using the equation

$$
\text { rate }=(1-A) / t
$$

where $A$ is the average normalized CAP amplitude of the nerves after sonication and $t$ is the sonication time applied to the nerve.
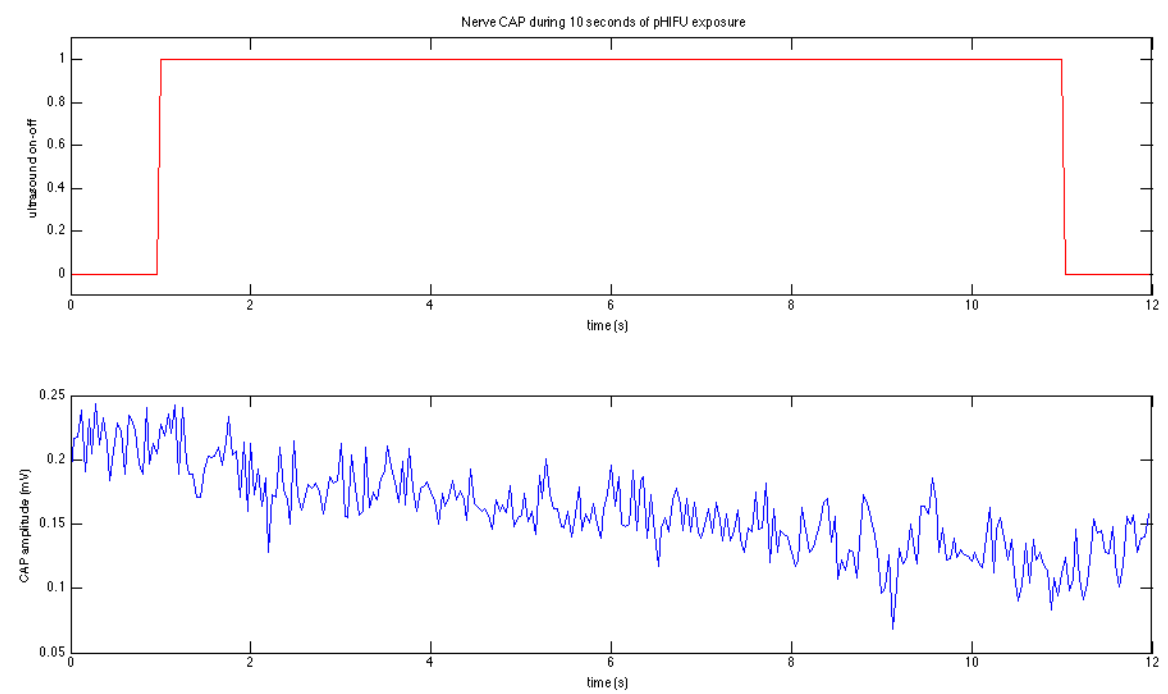

Figure 3.13: Nerve CAP amplitude during 10 seconds of pHIFU exposure 


\section{Chapter 4 : Discussion}

\subsection{Effect of Modified Nose Piece}

The distribution of acoustic energy in an enclosed space, as it is the case with the modified nose piece used in this study, depends on the size and geometry and on the combined effects of the reflection, diffraction, and absorption properties of the nose piece barriers (Fahy 1995; Long 2005). It is possible that due to beam reflection from the inner walls of the nose piece and a possible lens effect of the membrane used in its opening, ultrasound waves that are emitted from the transducer are being funnelled through this aperture. This may explain the greater pressures measured by the nose piece. It is also possible measurement errors in the electronic equipment contributed to the differing pressures.

\subsection{Comparison of Conduction Velocities}

Wright et al., indicated conduction velocities of the lobster nerve cord in lobsters in the range of $18-20 \mathrm{~m} / \mathrm{s}$. An experiment conducted using the nerve cord of Homarus americanus observed conduction velocities between $3.5-15 \mathrm{~m} / \mathrm{s}$ (Swartz 1978). The average conduction velocity observed in this thesis was $11.26 \mathrm{~m} / \mathrm{s} \pm 1.14 \mathrm{~m} / \mathrm{s}$. This CV is lower than the one stated by Wright et al. but within the range of values measured by Swartz.

\subsection{Appearance of CAP Waveforms}

As stated in section 1.4.2, the CAP waveforms are expected to exhibit a downward deflection following the positive deflection that forms the CAP; this is referred to as a biphasic CAP. The negative phase of the CAP is due to the method used to measure CAP. The CAP waveforms in this experiment did not appear to display a biphasic response (figure 4.1). In comparison to other studies, the nerve CAPs seen by Jabbary (figure 4.2) and Wahab et al. (figure 4.3) also do not 


\section{Chapter 4: Discussion}

appear to exhibit biphasic waveforms. This is in contrast to the waveforms seen by Tsui et al. (figure 4.4) which exhibit a biphasic CAP response.

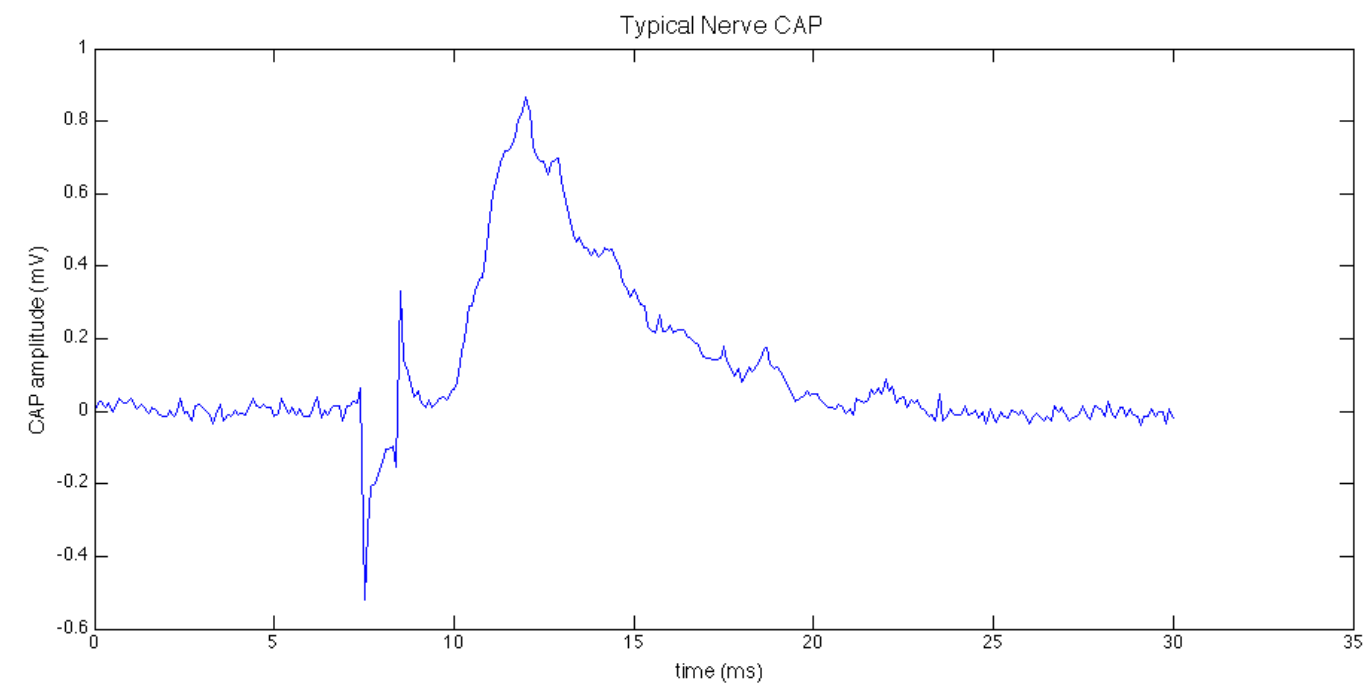

Figure 4.1: Typical nerve CAP waveform measured in this thesis

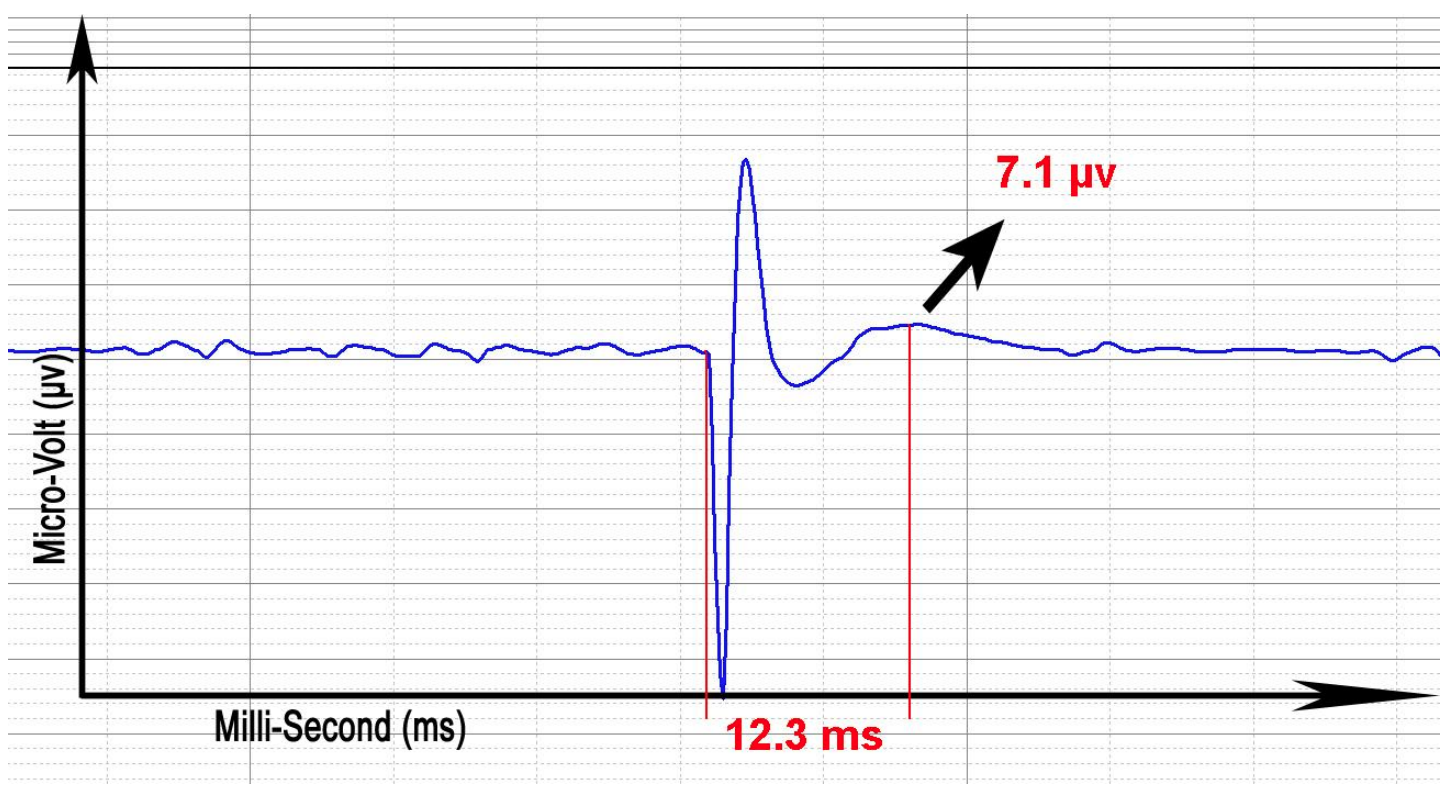

Figure 4.2: Typical nerve CAP waveform measured by Jabbary 2011 68 


\section{Chapter 4: Discussion}

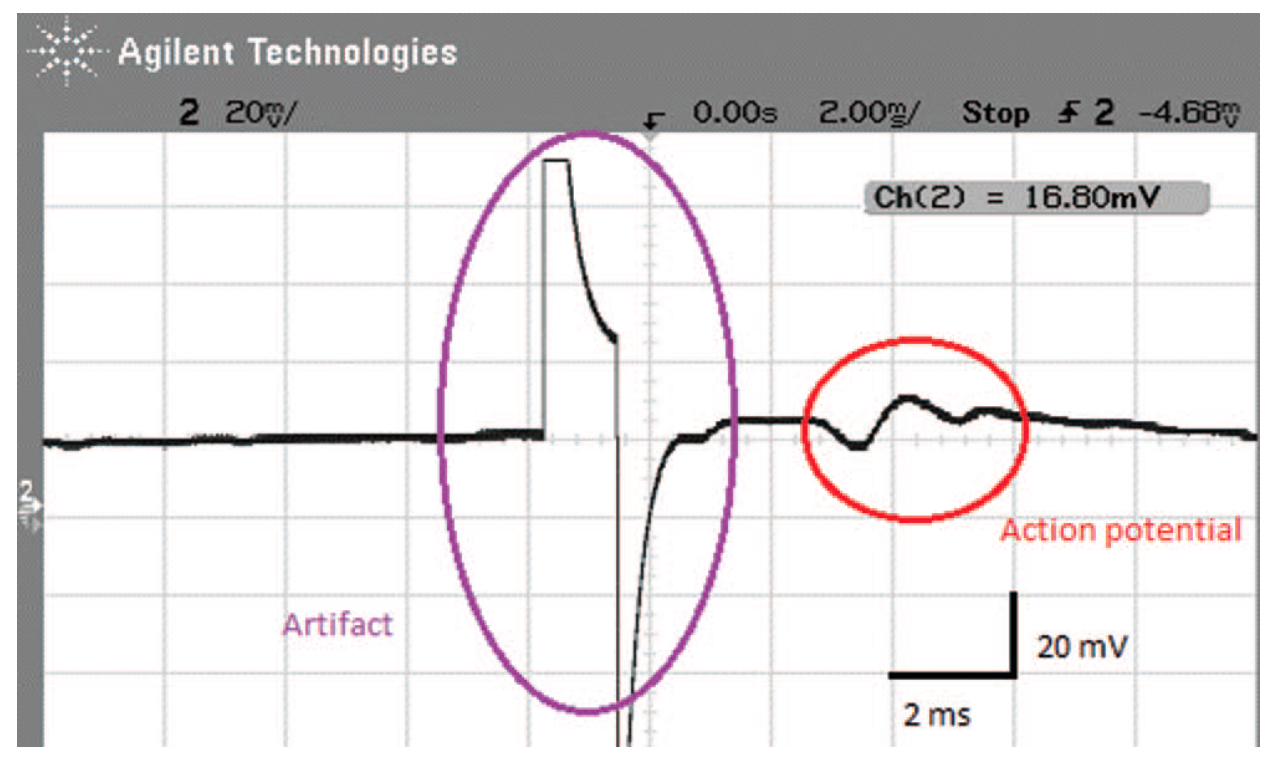

Figure 4.3: Typical nerve CAP waveform measured by Wahab et al. 2012

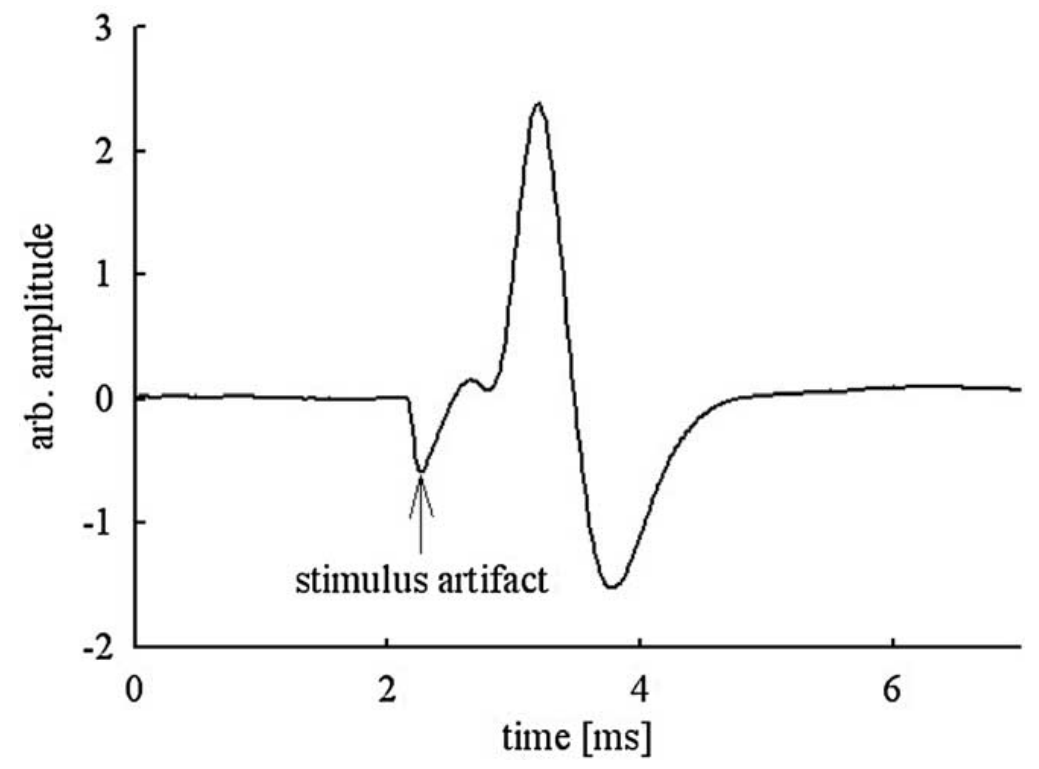

Figure 4.4: Typical nerve CAP waveform measured by Tsui et al. 2005 


\section{Chapter 4: Discussion}

If the recording electrode distance is not large, it is possible that the CAP will not have passed the first electrode before reaching the second and would cause the two phases to not be of equal amplitude (BIOPAC 2005). This could result in the appearance of a monophasic CAP waveform like the ones seen in this thesis.

\subsection{Effect of Nerve CAP Amplitude During pHIFU Sonication and the Long Term Effects after Sonication}

The slope, rate of change, of the CAP during sonication varied greatly between nerves. This is not surprising considering the inherent variability of biological specimens. However, it was noted that CAP seemed decreased more rapidly at higher sonication times within the same nerve. This suggests ultrasound can have a cumulative effect on nerve CAP modulation. This finding is also seen by Wahab, 2012.

Nerve CAPs were observed to settle $<1 \mathrm{~s}$ after termination of the ultrasound. No appreciable change in CAP was observed for 3.5 minutes after ultrasound exposure. This would suggest the gap in time in between the sonication exposures $(1 \mathrm{~s}, 5 \mathrm{~s}, 10 \mathrm{~s})$ is non-consequential, as CAP does not change within 3.5 minutes after sonication. Nerves were observed to be viable for at 20 minutes starting from the time the first CAP was measured. This is lower than the 30 minutes reported by Jabbary. The difference could be due to the handling of the nerve during the experiments. Dissection of the nerve is a delicate procedure and damage to the nerve is easily done. Also, the nerves in Jabbary's study were exposed to ultrasound at a lower intensity than the nerves of this thesis. Exposure to ultrasound at higher intensity could affect the nerve's ability to maintain viability. 


\section{Chapter 4: Discussion}

\subsection{Comparison of the Intensity used by Mihran (1990)}

The relative efficiency of different frequencies to illicit CAP change was studied by comparing the acoustic pulse energies required to decrease CAP by $20 \%$ of it half maximal CAP amplitude, at $7 \mathrm{~ms}$ after ultrasound termination (figure 1.21). Higher frequencies would be assumed to be more effective at eliciting change in CAP due to fact absorption in biological tissue increases at higher frequencies; therefore Mihran expressed the findings in figure 1.21 in terms of interactive intensity. Interactive intensity was defined as,

$$
I_{\text {int }}=I_{0}\left(1-e^{-2 a z f}\right)
$$

where $I_{i n t}$ is the interactive intensity, $I_{0}$ is the incident intensity, $a$ is the attenuation coefficient of the nerve trunk, $z$ is the nerve trunk diameter, and $f$ is the frequency of ultrasounic beam. Observation of the equation 4.1 reveals interactive intensity to be inherently smaller than the incident intensities reported in this thesis. Mihran et al. showed that interactive intensities of 2$42 \mathrm{~W} / \mathrm{cm}^{2}$ could suppress normalized CAP. Using an attenuation coefficient of $0.03 / \mathrm{cm} * \mathrm{MHz}$, a nerve trunk dimeter of $0.2 \mathrm{~cm}$ (Mihran 1990), and frequency of $1.95 \mathrm{MHz}$, these values correspond to incident intensities from $87-1818 \mathrm{~W} / \mathrm{cm}^{2}$. It should noted that the CAP changes seen by Mihran et al. were transient occurances and nerve CAP recovered back to baseline within a time window of $<50 \mathrm{~ms}$. In contrast, the intensity used in this thesis resulted in longer lasting ( $>3.5$ mins) CAP suppression.

\subsection{Effect of Ultrasound on Lobster Nerve CAP and CV}

The results of this thesis show nerve CAP and CV decrease with increasing pHIFU exposure. As stated in section 1, therapeutic ultrasound induces bioeffects through the production of heat and/or mechanical effects. Past studies have shown that heat energy alone modulates nerve CAP (Colucci 2009; Klumpp 1980; Letcher 1968). With regards to the mechanical mechanisms of ultrasound, the effect of compression or crushing a nerve has been well documented (Rydevik 


\section{Chapter 4: Discussion}

1980; Ochoa 1972; Denny-Brown 1944; Causey 1943; Bentley 1943; Guntfest 1935); as well, stretching of a nerve has been shown to decrease CAP (Stecker 2011; Ochs 2000).

For the experiments in this study, the duty cycle set purposefully low to $10 \%$, to prevent any heat accumulation and ensure any changes to nerve function would be a result of the mechanical mechanism of ultrasound only. It has been hypothesized that ultrasound induced CAP changes are caused by changes in the ion channel permeability of the neuronal cell membranes that make up the nerve (Tyler 2011; Mihran 1996; Khraiche 2008; Foley 2008). More specifically, ultrasound has been shown to make fibroblast cells increase in $\mathrm{Ca}^{2+}$ intake (Dinno 1989). This effect was shown to be temporary as all the excess $\mathrm{Ca}^{2+}$ was pumped out after a short amount of time. $\mathrm{Ca}^{2+}$, in addition to $\mathrm{Na}^{+}$and $\mathrm{K}^{+}$, are major components in the formation of action potentials. $\mathrm{Ca}^{2+}$ is an important component in nerve function in lobsters as evidenced by its inclusion in the ringer's solution recipe. Changes to the regulation of action potential forming ions, such as $\mathrm{Ca}^{2}+$, would undoubtedly affect CAP.

In addition to acting on the ion channels, ultrasound can alter the cell membrane permeability. Ultrasound-induced microjets have the ability to modulate cell membrane permeability and affect action potential (Sundarum 2003). This phenomenon has been studied and utilized in past studies that investigate mediated drug delivery to cells (Mitragotri 2005; Unger 2004; Kremkau 1976)

Nerve myelination is a major factor in nerve signal conduction speed (Kardong 2006); however, because unmyelinated lobster nerves were used in this study, myelination cannot explain the decrease in nerve $\mathrm{CV}$. It is possible that ultrasound exposure affected the $\mathrm{Na}^{+}$channels of the nerve. In $2008 \mathrm{Del} \mathrm{Col}$ et al, demonstrated the availability of $\mathrm{Na}+$ channels played a significant role in the conduction velocity $(\mathrm{CV})$ in unmyelinated rat nerves. Del Col's study showed a decrease in $\mathrm{CV}$ as the number of working $\mathrm{Na}+$ channels in the nerve decreased. 


\section{Chapter 4: Discussion}

As Figure 3.9 shows, CAP and CV decreased at the same time. It is plausible that ultrasound exposure to the lobster nerve is affecting the ion channels and membrane permeability of the nerve, as doing so has been shown to affect both CAP and CV at the same time. 


\section{Chapter 5 : Conclusions and Future Work}

\subsection{Conclusions}

The CAP amplitude and CV of a lobster ventral nerve cord can be modulated using pulsed HIFU. At an intensity $=1010 \mathrm{~W} / \mathrm{cm}^{2}$, pulse length $=50 \mathrm{~ms}$, and duty cycle of $10 \%$, thermal effects to the tissue are mitigated resulting in changes to nerve CAP and CV by exclusively mechanical mechanisms. Nerve CAP and CV decreases as the exposure time of the nerve to a train of ultrasound pulses increases.

\subsection{Recommendations and Future Directions}

The lack of myelin sheath in lobsters presents a major limitation when trying to relate the findings from this thesis toward applications in humans. The logical next step is to investigate the effects of pHIFU on myelinated nerves. Another area of improvement involves fine-tuning the ultrasound settings to produce a specific and desired outcome. Parameters such as pressure amplitude, duty cycle, pulse length, and exposure time can be changed to investigate the potential of pulsed high intensity focused ultrasound to produce reversible suppression of nerve CAP to a desired amount of time. The clinical applications for this extend to pain management and spasticity. Extending analysis of these results to a histological analysis could also be explored. In past studies heat generated by ultrasound has been a primary factor in nerve damage. A lower duty cycle can mitigate heat accumulation, however a histological analysis of the sonicated nerve is needed to confirm whether or not structural damages has occurred and if it is significant enough to explain the changes in CAP and CV. Also, the use of various chemical blockers may confirm the effects that ultrasound has on specific ion channel in the nerve. Chemicals such as tetrodotxin and saxitonxin can be used to block and quarantine $\mathrm{Na}+$ channels

of the neuron. Using chemicals such as amiodarone and dofetilide can block the $\mathrm{K}+$ channels. Establishing the specific ion channel responsible for CAP and CV modulation would help to give 


\section{Chapter 5: Conclusions}

a greater biophysical understanding of ultrasound induced nerve CAP modulation. Finally, for the purposes of clinical relevance, there is motivation to move research from an ex vivo study to one that is in vivo. Considerations for coupling and recording technique become more important as the anatomy of living systems doesn't always provide a straight path from the ultrasound to the target tissue or direct access for the recording electrodes to the target. Strategies to solve these issues are the first steps to move an ex vivo nerve study like the one in this thesis to a more clinically relevant in vivo setting. 


\section{Chapter 6 : Appendices}

\section{A1: Technical Specifications for the ONDA RFB-2000 Power Meter}

- Power ranges: $1 \mathrm{~mW}^{*}$ to $2 \mathrm{~W}$ with standard absorbing target

- Up to $30 \mathrm{~W}$ with cone target (RFB-CTK) and up to $100 \mathrm{~W} \uparrow$ with brush target (RFB-BTK)

- Display Resolution: $>4$ digits

- Typical measurement uncertainty*: $< \pm 5 \%$ at $95 \%$ confidence level

- Measurement cycle time: adjustable from $4 \mathrm{~s}$ (default) to $120 \mathrm{~s}$

- Maximum beam diameter: $5 \mathrm{~cm}$

- Low Frequency Limit: $1 \mathrm{MHz}$ (usable at lower frequency with decreased accuracy)

* Extended averaging may be required, depending on local vibration and power level

$\dagger$ Depending on beam parameters

\section{A2: Ingredients for the Lobster Ringers Solution}

\begin{tabular}{|l|l|}
\hline Ingredient & Concentration $(\mathrm{mM})$ \\
\hline $\mathrm{NaCl}$ & 462 \\
\hline $\mathrm{KCl}$ & 16 \\
\hline $\mathrm{CaCl} 2$ & 26 \\
\hline $\mathrm{MgCl} 2$ & 8 \\
\hline Hydroxymethyl & 10 \\
\hline Maleic Acid & 10 \\
\hline Glucose & 11 \\
\hline
\end{tabular}




\section{Chapter 6: Appendices}

\section{A3: List of Equipment Used in the Study}

\begin{tabular}{|c|c|c|}
\hline equipment & model & serial\# \\
\hline amplifier & E\&I 2100L & 1051 \\
\hline function generator & Tektronix-AFG3022B & C033689 \\
\hline $\begin{array}{l}\text { handheld ultrasound } \\
\text { transducer }\end{array}$ & Prototype \#2, F\#/2.4 & \\
\hline hydrophone & ONDA-HNA & \\
\hline $\begin{array}{l}\text { nerve measurement } \\
\text { system }\end{array}$ & BIOPAC BSL PRO & \\
\hline oscilloscope & $\begin{array}{l}\text { Aglient Technologies } \\
\text { DSO 7032A }\end{array}$ & MY48260247 \\
\hline radiation force balance & ONDA RFB-2000 & 1016 \\
\hline thermal camera & $\begin{array}{c}\text { FLIR ThermoVision } \\
\text { A40 }\end{array}$ & 25000952 \\
\hline
\end{tabular}

\section{A4: Hydrophone Results to Compare the Effect of the Nose Piece}

\begin{tabular}{|c|c|c|c|c|c|c|c|}
\hline \multicolumn{8}{|c|}{ With Nose Piece } \\
\hline \multirow{2}{*}{$\begin{array}{c}\text { Input } \\
\text { Volt(mV) }\end{array}$} & \multirow{2}{*}{$\begin{array}{l}\text { Input } \\
\text { Power } \\
\text { (W) }\end{array}$} & \multicolumn{4}{|c|}{ Hydrophone Voltage (V) } & \multirow{2}{*}{$\begin{array}{c}\text { Average } \\
\text { Hydrophone } \\
\text { (V) }\end{array}$} & \multirow{2}{*}{$\begin{array}{c}\text { St. } \\
\text { Deviation }\end{array}$} \\
\hline & & trial 1 & trial 2 & trial 3 & trial 4 & & \\
\hline 10 & 0.168 & 0.183 & 0.1682 & 0.184 & 0.192 & 0.18 & 0.01 \\
\hline 25 & 0.533 & 0.457 & 0.5832 & 0.456 & 0.456 & 0.49 & 0.06 \\
\hline 50 & 1.44 & 0.905 & 0.902 & 1.182 & 0.904 & 0.97 & 0.14 \\
\hline 100 & 4.38 & 1.512 & 1.592 & 1.602 & 1.546 & 1.56 & 0.04 \\
\hline 150 & 8.82 & 1.809 & 1.81 & 1.828 & 1.715 & 1.79 & 0.05 \\
\hline 200 & 14.8 & 2.033 & 2.131 & 2.016 & 2.016 & 2.05 & 0.06 \\
\hline
\end{tabular}




\section{Chapter 6: Appendices}

\begin{tabular}{|r|r|r|r|r|r|r|r|}
\hline \multicolumn{7}{|c|}{ No Nose Piece } \\
\hline \multirow{2}{*}{$\begin{array}{c}\text { Input } \\
\text { Volt(mV) }\end{array}$} & $\begin{array}{c}\text { Input } \\
\text { Power } \\
(\mathrm{W})\end{array}$ & \multicolumn{3}{|c|}{ Hydrophone Voltage (V) } & $\begin{array}{c}\text { Average } \\
\text { Hydrophone } \\
\text { (V) }\end{array}$ & $\begin{array}{c}\text { St. } \\
\text { Deviation }\end{array}$ \\
\cline { 5 - 9 } & trial 1 & trial 2 & trial 3 & trial 4 & 0.19 & 0.01 \\
\hline 10 & 0.168 & 0.17385 & 0.194 & 0.18003 & 0.197 & 0.45 & 0.06 \\
\hline 25 & 0.533 & 0.387 & 0.463 & 0.52 & 0.422 & 0.87 & 0.08 \\
\hline 50 & 1.44 & 0.967 & 0.8673 & 0.768 & 0.879 & 0.87 & 0.07 \\
\hline 100 & 4.38 & 1.589 & 1.447 & 1.445 & 1.444 & 1.48 & 0.05 \\
\hline 150 & 8.82 & 1.766 & 1.709 & 1.808 & 1.698 & 1.75 & 0.06 \\
\hline 200 & 14.8 & 1.983 & 2.01 & 2 & 1.87 & 1.97 & \\
\hline
\end{tabular}

\section{A5: ONDA Acoustic Power Calibration Results}

\begin{tabular}{|c|c|c|c|c|c|c|}
\hline Vin (mV p-p) & $\begin{array}{c}\text { Pf } \\
(\mathrm{W})\end{array}$ & $\begin{array}{c}\text { Pr } \\
(\mathrm{W})\end{array}$ & Ptot (W) & Pout (W) & $\begin{array}{c}\text { free field focal } \\
\text { intensity (W/cm2) }\end{array}$ & $\begin{array}{c}\text { pressure } \\
\text { amplitude } \\
(\mathrm{Pa})\end{array}$ \\
\hline 25 & 0 & 0 & 0 & 0.2017 & 4.65 & 0.374 \\
\hline 50 & 1 & 0 & 1 & 0.7455 & 17.2 & 0.718 \\
\hline 100 & 4 & 0 & 4 & 2.939 & 67.8 & 1.43 \\
\hline 150 & 10 & 1 & 9 & 6.484 & 150 & 2.12 \\
\hline 200 & 16 & 2 & 14 & 11.396 & 263 & 2.81 \\
\hline 250 & 24 & 3 & 21 & 17.612 & 406 & 3.49 \\
\hline 300 & 34 & 5 & 29 & 25.118 & 579 & 4.17 \\
\hline 350 & 45 & 7 & 38 & 34.378 & 793 & 4.88 \\
\hline
\end{tabular}




\section{Chapter 6: Appendices}

\begin{tabular}{|c|c|c|c|c|c|c|}
400 & 58 & 8 & 50 & 43.848 & $1.01 \mathrm{E}+03$ & 5.51 \\
\hline 450 & 73 & 10 & 63 & 54.779 & $1.26 \mathrm{E}+03$ & 6.16 \\
\hline 500 & 89 & 13 & 76 & 66.933 & $1.54 \mathrm{E}+03$ & 6.80 \\
\hline 550 & 107 & 15 & 92 & 78.914 & $1.82 \mathrm{E}+03$ & 7.39 \\
\hline 600 & 126 & 18 & 108 & 93.185 & $2.15 \mathrm{E}+03$ & 8.03 \\
\hline
\end{tabular}

\section{A6: Sample Calculations for Locating Actual Focal Spot of pHIFU Transducer}

Calculation of the actual location of the focal spot along the axial centre of the pHIFU transducer:

$$
\begin{aligned}
d & =v t \\
& =1500 \frac{\mathrm{m}}{\mathrm{s}} \times 8.1 \times 10^{-6} \mathrm{sec} \\
& =0.01215 \mathrm{~m} \approx 122 \mathrm{~mm}
\end{aligned}
$$

\section{A7: Technical Specifications of the ThermoVision A40 Thermal Camera}

$\begin{array}{ll}\text { Imaging Performance } & \\ \text { Field of view/min focus distance } & 24^{\circ} \times 18^{\circ} / 0.3 \mathrm{~m} \\ \text { Spatial resolution (IFOV) } & 1.3 \mathrm{mrad} \\ \text { Thermal sensitivity @ } 50 / 60 \mathrm{~Hz} & 0.08^{\circ} \mathrm{C} \text { at } 30^{\circ} \mathrm{C} \\ \text { Focusing } & \text { Built-in focus motor } \\ \text { Detector type } & \text { Focal Plane Array (FPA), uncooled }\end{array}$




\section{Chapter 6: Appendices}

microbolometer

Spectral range

7.5 to $13 \mu \mathrm{m}$

\section{Measurement}

Range $1:-40^{\circ} \mathrm{C}$ to $+120^{\circ} \mathrm{C}\left(-40\right.$ to $\left.+248^{\circ} \mathrm{F}\right)$

Range 2: $0^{\circ} \mathrm{C}$ to $+500^{\circ} \mathrm{C}\left(+32\right.$ to $\left.+932^{\circ} \mathrm{F}\right)$

Temperature ranges

Optional: Up to $+1500^{\circ} \mathrm{C}\left(+2732^{\circ} \mathrm{F}\right)$

Optional: $\mathrm{Up}$ to $+2000^{\circ} \mathrm{C}\left(+3632^{\circ} \mathrm{F}\right)$

Accuracy $(\%$ of reading $) \pm 2{ }^{\circ} \mathrm{C}$ or $\pm 2 \%$

Measurement modes

Spot, Area, Isotherm,Difference

Automatic emissivity correction

Variable from 0.1 to 1.0

Individual emissivity settings

Individually settable

Reflected ambient, distance, relative

Measurement corrections humidity, external optics. Automatic, based on user input

\section{Environmental}

Operating temperature range

Storage temperature range

Humidity Operating and storage

Encapsulation

Shock

Vibration $-15^{\circ} \mathrm{C}$ to $+50^{\circ} \mathrm{C}\left(5^{\circ} \mathrm{F}\right.$ to $\left.122^{\circ} \mathrm{F}\right)$

$-40^{\circ} \mathrm{C}$ to $+70^{\circ} \mathrm{C}\left(-40^{\circ} \mathrm{F}\right.$ to $\left.158^{\circ} \mathrm{F}\right)$

$10 \%$ to $95 \%$, non-condensing

IP 40 (Determined by connector type)

Operational: 25G, IEC 68-2-29

Operational: 2G, IEC 68-2-6 


\section{Chapter 7 : Works Cited}

Barnard, John W., William J. Fry, Frank J. Fry, and Rolfs F. Krumins. (1955). "Effects of high intensity ultrasound on the central nervous system of the cat." Journal of Comparative Neurology 103, no. 3:459-484.

Bentley, Frederic H., and W. Schlapp. (1943). "The effects of pressure on conduction in peripheral nerve." The Journal of Physiology 102, no. 1 (1943): 72-82.

BIOPAC. (2005). Compound action potential - BSL pro lesson \#A03

Butt, Foaud. (2011a). "High performance computing for linear acoustic wave simulation.” M. Sc. Thesis (Paper 591), Ryerson University, http://digitalcommons.ryerson.ca/dissertations/591

Butt, Fouad, Abdolreza Abhari, and Jahan Tavakkoli. (2011b). "An application of high performance computing to improve linear acoustic simulation." In Proceedings of the 14th Communications and Networking Symposium, pp. 71-78. Society for Computer Simulation International,

Causey, G. (1948). "The effect of pressure on nerve fibres." Journal of anatomy 82, no. Pt 4 $: 262$.

Cobbold, Richard SC. (2007). Foundations of biomedical ultrasound. Oxford University Press on Demand.

Colucci, Vincent, Gary Strichartz, Ferenc Jolesz, Natalia Vykhodtseva, and Kullervo Hynynen. (2009). "Focused Ultrasound Effects on Nerve Action Potential In Vitro" Ultrasound in medicine \& biology 35, no. 10: 1737-1747.

Cooper, T. E., and G. J. Trezek. (1971). "Correlation of thermal properties of some human tissue with water content." Aerospace medicine 42, no. 1: 24-27.

De Col, Roberto, Karl Messlinger, and Richard W. Carr. (2008). "Conduction velocity is regulated by sodium channel inactivation in unmyelinated axons innervating the rat cranial meninges." The Journal of physiology 586, no. 4: 1089-1103.

Denny-Brown, D., and Charles Brenner. (1944). "Lesion in peripheral nerve resulting from compression by spring clip." Archives of Neurology \& Psychiatry 52, no. 1: 1-9.

Dinno, M. A., M. Dyson, S. R. Young, A. J. Mortimer, J. Hart, and L. A. Crum. (1989). "The significance of membrane changes in the safe and effective use of therapeutic and diagnostic ultrasound." Physics in medicine and biology 34, no. 11: 1543.

Dowling, John E. (2001). Neurons and Networks: An Introduction to Behavioral Neuroscience. Belknap Press. 


\section{Chapter 7: Works Cited}

Fahy, Frank. (1995). Sound intensity. CRC PressI Llc.

Foley, Jessica L., James W. Little, and Shahram Vaezy. (2008). "Effects of high-intensity focused ultrasound on nerve conduction." Muscle \& nerve 37, no. 2: 241-250.

Foley, Jessica L., Shahram Vaezy, and Lawrence A. Crum. (2007). "Applications of highintensity focused ultrasound in medicine: Spotlight on neurological applications." Applied Acoustics 68, no. 3: 245-259.

Foley, Jessica L., James W. Little, and Shahram Vaezy. (2007). "Image-guided high-intensity focused ultrasound for conduction block of peripheral nerves." Annals of biomedical engineering 35, no. 1: 109-119.

Holland, Christy K. (2000). "Mechanical bioeffects from diagnostic ultrasound: AIUM consensus statements." Journal of ultrasound in medicine: official journal of the American Institute of Ultrasound in Medicine 19, no. 2: 69.

Gavrilov, L. R., E. M. Tsirulnikov, and I. ab I. Davies. (1996). "Application of focused ultrasound for the stimulation of neural structures." Ultrasound in medicine \& biology 22, no. 2: 179-192.

Grundfest, Harry. (1936). "Effects of hydrostatic pressures upon the excitability, the recovery, and the potential sequence of frog nerve." In Cold Spring Harbor Symposia on Quantitative Biology, vol. 4, pp. 179-187. Cold Spring Harbor Laboratory Press.

Herrick, Francis Hobart.(1911). Natural history of the American lobster. No. 747. US Government Printing Office.

Hille, Bertil. (2001). Ionic channels of excitable membranes. Vol. 174. Sunderland, MA: Sinauer associates.

Hodgkin, Alan L., and Andrew F. Huxley. (1952). "A quantitative description of membrane current and its application to conduction and excitation in nerve."The Journal of physiology 117, no. 4: 500 .

Jabbary, Shahrad. (2011). "Effect of high intensity focused ultrasound on neural compound action potential: An in vitro study." M. Sc. Thesis (Paper 590), Ryerson University. [http://digitalcommons.ryerson.ca/dissertations/590/]

Kardong, Kenneth V. (2006). Vertebrates: comparative anatomy, function, evolution. Boston: McGraw-Hill.

Khraiche, Massoud L., William B. Phillips, Nathan Jackson, and Jitendran Muthuswamy. (2008). "Ultrasound induced increase in excitability of single neurons." In Engineering in Medicine and 


\section{Chapter 7: Works Cited}

Biology Society, 2008. EMBS 2008. 30th Annual International Conference of the IEEE, pp. 4246-4249. IEEE.

Klumpp, D., and M. Zimmermann. (1980). "Irreverisble differential block of A-and C-fibres following local nerve heating in the cat." The Journal of physiology 298, no. 1: 471-482.

Kremkau, Frederick W. (1979). "Cancer therapy with ultrasound: a historical review."Journal of clinical ultrasound 7, no. 4: 287-300.

Lawrence, John P. "Physics and instrumentation of ultrasound. (2007). " Critical care medicine 35, no. 8: S314-S322.

Letcher, Frank S., and Sidney Goldring. (1968). "The effect of radiofrequency current and heat on peripheral nerve action potential in the cat." Journal of neurosurgery 29, no. 1: 42.

Long, Marshall. (2005). Architectural acoustics. Academic press.

Marieb, Elaine. Essentials of Human Anatomy and Physiology. Benjamin Cummings. 2006

Marwan, Norbert, Niels Wessel, Udo Meyerfeldt, Alexander Schirdewan, and Jürgen Kurths. (2002). "Recurrence-plot-based measures of complexity and their application to heart-ratevariability data." Physical Review E 66, no. 2: 026702

Mihran, R. T., F. S. Barnes, and H. Wachtel. (1990). "Transient modification of membrane potential and conductance by single ultrasound bursts modulates neuronal excitability." In Engineering in Medicine and Biology Society, 1990., Proceedings of the Twelfth Annual International Conference of the IEEE, pp. 447-448. IEEE.

Mihran, Richard T., Frank S. Barnes, and Howard Wachtel. (1990). "Temporally-specific modification of myelinated axon excitability in vitro following a single ultrasound pulse." Ultrasound in medicine \& biology 16, no. 3: 297-309.

Mihran, Richard T., Sean K. Lineaweaver, Frank S. Barnes, and Howard Wachtel. (1996). "Effects of pulsed acoustic and mechanical stimuli on the excitability of isolated neuronal and cardiac cells." Applied occupational and environmental hygiene 11, no. 4: 271-274.

Mitragotri, Samir, David A. Edwards, Daniel Blankschtein, and Robert Langer. (1995). "A mechanistic study of ultrasonically-enhanced transdermal drug delivery."Journal of pharmaceutical sciences 84, no. 6: 697-706.

Ocheltree, Kenneth B., and L. A. Frizzel. (1989). "Sound field calculation for rectangular sources." Ultrasonics, Ferroelectrics and Frequency Control, IEEE Transactions on 36, no. 2: 242-248. 


\section{Chapter 7: Works Cited}

Ochoa, J., T. J. Fowler, and R. W. Gilliatt. (1972). "Anatomical changes in peripheral nerves compressed by a pneumatic tourniquet." Journal of Anatomy 113, no. Pt 3: 433.

Ochs, Sidney, Rahman Pourmand, Kenan Si, and Richard N. Friedman. (2000). "Stretch of mammalian nerve in vitro: effect on compound action potentials."Journal of the Peripheral Nervous System 5, no. 4: 227-235.

Ohmic Instruments Company. (2006). Ultrasound power meter operator's manual.

Pennes, Harry H. (1948). "Analysis of tissue and arterial blood temperatures in the resting human forearm." Journal of applied physiology 1, no. 2: 93-122.

Phillips, William B., Patrick J. Larson, and Bruce C. Towe. (2004). "Ultrasonically-assisted intracortical microstimulation of the rat." In Engineering in Medicine and Biology Society, 2004. IEMBS'04. 26th Annual International Conference of the IEEE, vol. 2, pp. 4217-4220. IEEE.

Poul-Erik Paulev. (2004). New human physiology. Copenhagen Medical Publishers.

Reynolds, William W., and Martha E. Casterlin. (1979). "Behavioral thermoregulation and activity in Homarus americanus." Comparative Biochemistry and Physiology Part A: Physiology 64, no. 1: 25-28.

Rydevik, B., and C. Nordborg. (1980). "Changes in nerve function and nerve fibre structure induced by acute, graded compression." Journal of Neurology, Neurosurgery \& Psychiatry 43, no. 12: 1070-1082.

Schwartz, Jean-Louis. (1978). "Influence of a constant magnetic field on nervous tissues: I. Nerve conduction velocity studies." Biomedical Engineering, IEEE Transactions on 5: 467-473.

Stecker, Mark M., Kelly Baylor, Jacob Wolfe, and Matthew Stevenson. (2011). "Acute nerve stretch and the compound motor action potential." J Brachial Plex Peripher Nerve Inj 6, no. 4..

Sundaram, Jagannathan, Berlyn R. Mellein, and Samir Mitragotri. (2003). "An experimental and theoretical analysis of ultrasound-induced permeabilization of cell membranes." Biophysical journal 84, no. 5: 3087-3101.

ter Haar, Gail. (2007). "Therapeutic applications of ultrasound." Progress in biophysics and molecular biology 93, no. 1: 111-129.

ter Haar, Gail. (2000). "Therapeutic ultrasound." European Journal of Ultrasound 9, no. 1: 3-9.

Tsui, Po-Hsiang, Shyh-Hau Wang, and Chih-Chung Huang. (2005). "In vitro effects of ultrasound with different energies on the conduction properties of neural tissue." Ultrasonics 43, no. 7: 560-565. 


\section{Chapter 7: Works Cited}

Tyler, William J. (2011). "Noninvasive neuromodulation with ultrasound? A continuum mechanics hypothesis." The Neuroscientist 17, no. 1: 25-36.

Unger, Evan C., Thomas Porter, William Culp, Rachel Labell, Terry Matsunaga, and Reena Zutshi. (2004). "Therapeutic applications of lipid-coated microbubbles."Advanced drug delivery reviews 56, no. 9: 1291-1314.

Wahab, Radia Abdul, Mina Choi, Yunbo Liu, Victor Krauthamer, Vesna Zderic, and Matthew R. Myers. (2012). "Mechanical bioeffects of pulsed high intensity focused ultrasound on a simple neural model." Medical Physics 39: 4274.

Widmaier, Eric P., Hershel Raff, and Kevin T. Strang. (2006). Vander's human physiology. McGraw-Hill Higher Education.

Wright, Ernest B., and John P. Reuben. (1958). "A comparative study of some excitability properties of the giant axons of the ventral nerve cord of the lobster, including the recovery of excitability following an impulse." Journal of Cellular and Comparative Physiology 51, no. 1: 13-28.

Wu, Junru, and Wesley Le Mars Nyborg. (2006). Emerging therapeutic ultrasound. World Scientific.

Yu, Wen-li, Su-pin Wang, Nan Zhao, and Min-xi Wan. (2008). "Focused-ultrasound modifications on the conduction properties of toad's sciatic nerve." Ultrasonics Symposium, 2008. IUS 2008. IEEE, pp. 1710-1713. IEEE. 